Issued by Sandia National Laboratories, operated for the United States Department of Energy by Sandia Corporation.

NOTICE: This report was prepared as an account of work sponsored by an agency of the United States Government. Neither the United States Government, nor any agency thereof, nor any of their employees, nor any of their contractors, subcontractors, or their employees, make any warranty, express or implied, or assume any legal liability or responsibility for the accuracy, completeness, or usefulness of any information, apparatus, product, or process disclosed, or represent that its use would not infringe privately owned rights. Reference herein to any specific commercial product, process, or service by trade name, trademark, manufacturer, or otherwise, does not necessarily constitute or imply its endorsement, recommendation, or favoring by the United States Government, any agency thereof, or any of their contractors or subcontractors. The views and opinions expressed herein do not necessarily state or reflect those of the United States Government, any agency thereof, or any of their contractors.

Printed in the United States of America. This report has been reproduced directly from the best available copy.

Available to DOE and DOE contractors from

Office of Scientific and Technical Information

P.O. Box 62

Oak Ridge, TN 37831

Prices available from (703) 605-6000

Web site: http://www.ntis.gov/ordering.htm

Available to the public from

National Technical Information Service

U.S. Department of Commerce

5285 Port Royal Rd

Springfield, VA 22161

NTIS price codes

Printed copy: A06

Microfiche copy: A01

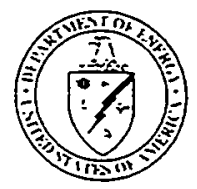




\section{DISCLAIMER}

Portions of this document may be illegible in electronic image products. Images are produced from the best available original document. 
SAND99-1781

Unlimited Release

Printed July 1999

\title{
Aluminum Honeycomb Characteristics in Dynamic Crush Environments
}

\author{
Vesta I. Bateman \\ Lloyd $\mathrm{H}$. Swanson \\ Engineering Sciences Center \\ Sandia National Laboratories \\ P. O. Box 5800 \\ Albuquerque, NM 87185-0555
}

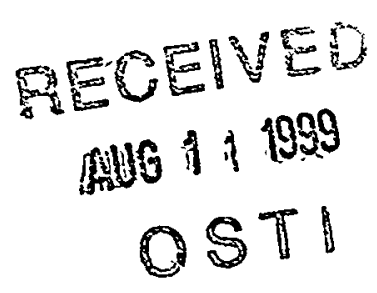

\section{Abstract}

Fifteen aluminum honeycomb cubes ( 3 in.) have been crushed in the Mechanical Shock Laboratory's drop table testing machines. This report summarizes shock experiments with honeycomb densities of 22.1 pcf and 38.0 pcf and with crush weights of $45 \mathrm{lb}, 168 \mathrm{lb}$, and $268 \mathrm{lb}$. The honeycomb samples were crushed in all three orientations, W, L, and T. Most of the experiments were conducted at an impact velocity of $\approx 40 \mathrm{fps}$, but higher velocities of up to $90 \mathrm{fps}$ were used for selected experiments. Where possible, multiple experiments were conducted for a specific orientation and density of the honeycomb samples. All results are for Hexcel honeycomb except for one experiment with Alcore honeycomb and have been evaluated for validity. This report contains the raw acceleration data measured on the top of the drop table carriage, pictures of the crushed samples, and normalized force-displacement curves for all fifteen experiments. These data are not strictly valid for material characteristics in $\mathrm{L}$ and $\mathrm{T}$ orientations because the cross-sectional area of the honeycomb changed (split) during the crush. However, these are the best data available at this time. These dynamic crush data do suggest a significant increase in crush strength to 8000 psi ( 25-30\% increase) over quasi-static values of $\sim 6000$ psi for the 38.0 pcf Hexcel Honeycomb in the Torientation. An uncertainty analysis is included and estimates the error in these data. 


\section{Contents}

Abstract 3

Introduction $\quad 7$

Experimental Configuration $\quad 7$

Experimental Results 12

Uncertainty Analysis $\quad 14$

Conclusions and Future Work 14

References 22

\section{Appendix}

A Normalized Honeycomb Crush Characteristics (1997-98) 23

Experiment 2: Hexcel Honeycomb, 38.0 pcf, W orientation, and 40 fps. 24 Experiment 3: Hexcel Honeycomb, $38.0 \mathrm{pcf}$, L orientation, and $40 \mathrm{fps} . \quad 25$

Experiment 4: Hexcel Honeycomb, 22.1 pcf, L orientation, and $40 \mathrm{fps} . \quad 26$

Experiment 5: Hexcel Honeycomb, $22.1 \mathrm{pcf}, \mathrm{W}$ orientation, and $40 \mathrm{fps} .27$ Experiment 25: Hexcel Honeycomb, $38.0 \mathrm{pcf}$, T orientation, and $58 \mathrm{fps} .28$

Experiment 26: Hexcel Honeycomb, 22.1 pcf, T orientation, and $90 \mathrm{fps} . \quad 29$

Experiment 27: Hexcel Honeycomb, $22.1 \mathrm{pcf}$, T orientation, and $50 \mathrm{fps} . \quad 30$

Experiment 28: Hexcel Honeycomb, $38.0 \mathrm{pcf}$, T orientation, and $53 \mathrm{fps} . \quad 31$

Experiment 29: Hexcel Honeycomb, $38.0 \mathrm{pcf}$, T orientation, and $50 \mathrm{fps} . \quad 32$

Experiment 31: Hexcel Honeycomb, $22.1 \mathrm{pcf}$, $\mathrm{T}$ orientation, and $42 \mathrm{fps} . \quad 33$

Experiment 37: Alcor Honeycomb, $38.0 \mathrm{pcf}$, T orientation, and $51 \mathrm{fps} . \quad 34$

B Normalized Honeycomb Crush Characteristics (1999) 35

Experiment 3: Hexcel Honeycomb, $38.0 \mathrm{pcf}, \mathrm{W}$ orientation, and $40 \mathrm{fps} . \quad 36$

Experiment 5: Hexcel Honeycomb, $38.0 \mathrm{pcf}$, L orientation, and $40 \mathrm{fps} . \quad 37$

Experiment 6: Hexcel Honeycomb, $38.0 \mathrm{pcf}, \mathrm{W}$ orientation, and $40 \mathrm{fps} . \quad 38$

Experiment 8: Hexcel Honeycomb, 38.0 pcf, L orientation, and 40 fps. $\quad 39$

C Pictures of Crushed Honeycomb for Experiments 1997-98 40

Two Pictures for Experiment No. 2. 41

Two Pictures for Experiment No. 3 . 43

Two Pictures for Experiment No. 4.

Two Pictures for Experiment No. 5

Two Pictures for Experiment No. 25 . 49

One Picture for Experiment No. 26.

Two Pictures for Experiment No. 27. 52

Two Pictures for Experiment No. 28. 54

Two Pictures for Experiment No. 29.

Two Pictures for Experiment No. 31. 58

Two Pictures for Experiment No. 37. 


\section{Appendix (cont.)}

D Pictures of Crushed Honeycomb for Experiments 1999

Two Pictures for Experiment No. 3. 63

Two Pictures for Experiment No. 5 . 65

Two Pictures for Experiment No. 6. 67

Two Pictures for Experiment No. 8. 69

E Raw Accelerometer Data Measured on the Drop Table Carriage and 71 the Reaction Mass (1997-98)

Raw Accelerometer Data for Experiment No. 2. 72

Raw Accelerometer Data for Experiment No. 3. 74

Raw Accelerometer Data for Experiment No. 4. 76

Raw Accelerometer Data for Experiment No. 5. 78

Raw Accelerometer Data for Experiment No. 25. 80

Raw Accelerometer Data for Experiment No. 26. 82

Raw Accelerometer Data for Experiment No. 27. 84

Raw Accelerometer Data for Experiment No. 28. 86

Raw Accelerometer Data for Experiment No. 29.

Raw Accelerometer Data for Experiment No. 31. 90

Raw Accelerometer Data for Experiment No. 37. 90

F Raw Accelerometer Data Measured on the Drop Table Carriage and 94 the Reaction Mass (1999)

Raw Accelerometer Data for Experiment No. 3. 95

Raw Accelerometer Data for Experiment No. 5. 99

Raw Accelerometer Data for Experiment No. 6. 103

Raw Accelerometer Data for Experiment No. 8. 107 


\section{Figures}

1 Unconfined Honeycomb Experimental Configuration with a Drop Table Shock Machine.

2 Definition of $\mathrm{T}, \mathrm{L}$, and $\mathrm{w}$ Orientations for Aluminum Honeycomb. 9

3 Semiconfined Honeycomb Experimental Configuration With a Punch and a Drop Table Shock Machine.

4 Experiment 5 (98): Hexcel, 22.1 pcf, W Orientation and 40 fps.

5 Experiment 4 (98): Hexcel, 22.1 pcf, L Orientation and 40 fps.

6 Experiments 26,27\&31 (98): Hexcel Honeycornb, 22.1 pcf, $T$ Orientation, $168 \mathrm{lb}$ Crush Weight.

7 Experiments 2 (98) 3\&6 (99): Hexcel, 38.0 pcf, W Orientation and 40 fps. 18

8 Experiments 3 (98) 5\&8 (99): Hexcel, 38.0 pcf, L Orientation and 40 fps. 19

9 Experiments 25,28,29\&37: Honeycomb, 38.0 pcf, T Orientation, $268 \mathrm{lb} \quad 20$ Crush Weight.

10 Quasi-Static Characteristics for Hexcel 38.0 pcf Aluminum Honeycomb 21 in T Orientation Quasi-Static Characteristics [9].

\section{Tables}

I Aluminum Honeycomb Crush Experiment Parameters 10

II Aluminum Honeycomb Crush Experiment Dimensional 12 Measurements

III Experimental Matrix for 38 pcf Hexcel Honeycomb Cubes (3 in.) 


\section{Aluminum Honeycomb Characteristics in Dynamic Crush Environments}

\section{Introduction}

Sandia National Laboratories (SNL) designs and builds energy absorbing components that are capable of cushioning the impact of a structure in $150 \mathrm{fps}$ head-on impact or a $73 \mathrm{fps}$ (B61 Mod 3,4,10) and $90 \mathrm{fps}$ (B61 Mod 7) slapdown environment. The certification of these energy absorbing components involves both impact experiments and finite element models. The models must be validated and verified so that they can be used to predict component performance and thereby reduce the number of expensive full-scale experiments that are performed. Additionally, the models are used to optimize the experiments by identifying the impact environments.

The honeycomb experiments presented in this report were conducted to aid in the modeling of an energy absorbing component that uses aluminum honeycomb. Fifteen aluminum honeycomb cubes ( 3 in.) have been crushed in the Mechanical Shock Laboratory using drop table shock machine carriages as the crush weight. This report summarizes shock experiments with honeycomb densities of $22.1 \mathrm{pcf}$ and $38.0 \mathrm{pcf}$ and with crush weights of $45 \mathrm{lb}, 168 \mathrm{lb}$, and $268 \mathrm{lb}$. The honeycomb samples were crushed in all three orientations, W, L, and T. Most of the experiments were conducted at an impact velocity of $\approx 40 \mathrm{fps}$, but higher velocities of up to $90 \mathrm{fps}$ were used for selected experiments. Where possible, multiple experiments were conducted for a specific orientation and density of the honeycomb samples. All results are for Hexcel ${ }^{*}$ honeycomb except for one experiment with Alcore* honeycomb and have been examined for validity. This report contains the raw acceleration data measured on the top of the drop table carriage, pictures of the crushed samples, and normalized forcedisplacement curves for all fifteen experiments. Although these data are not valid for material characteristics for $\mathrm{L}$ and $\mathrm{T}$ orientations because the cross-sectional area of the honeycomb changed during the crush, these are the best dynamic data available for honeycomb undergoing crush in a shock environment. An uncertainty analysis is included and estimates the error in these data.

\section{Experimental Configuration}

The general experimental configuration for eleven unconfined aluminum honeycomb crush experiments in 1997-98 and four experiments in 1999 is shown in Figure 1, and the experimental parameters are shown in Table $I$. The three orientations of $W, L$, and $T$ for the honeycomb are shown in Figure 2. The honeycomb sample was placed on the reaction mass in the specified orientation. For the experiments in 1997-98, one each of

*Reference to a commercial product implies no endorsement by SNL or the Department of Energy or lack of suitable substitute. 


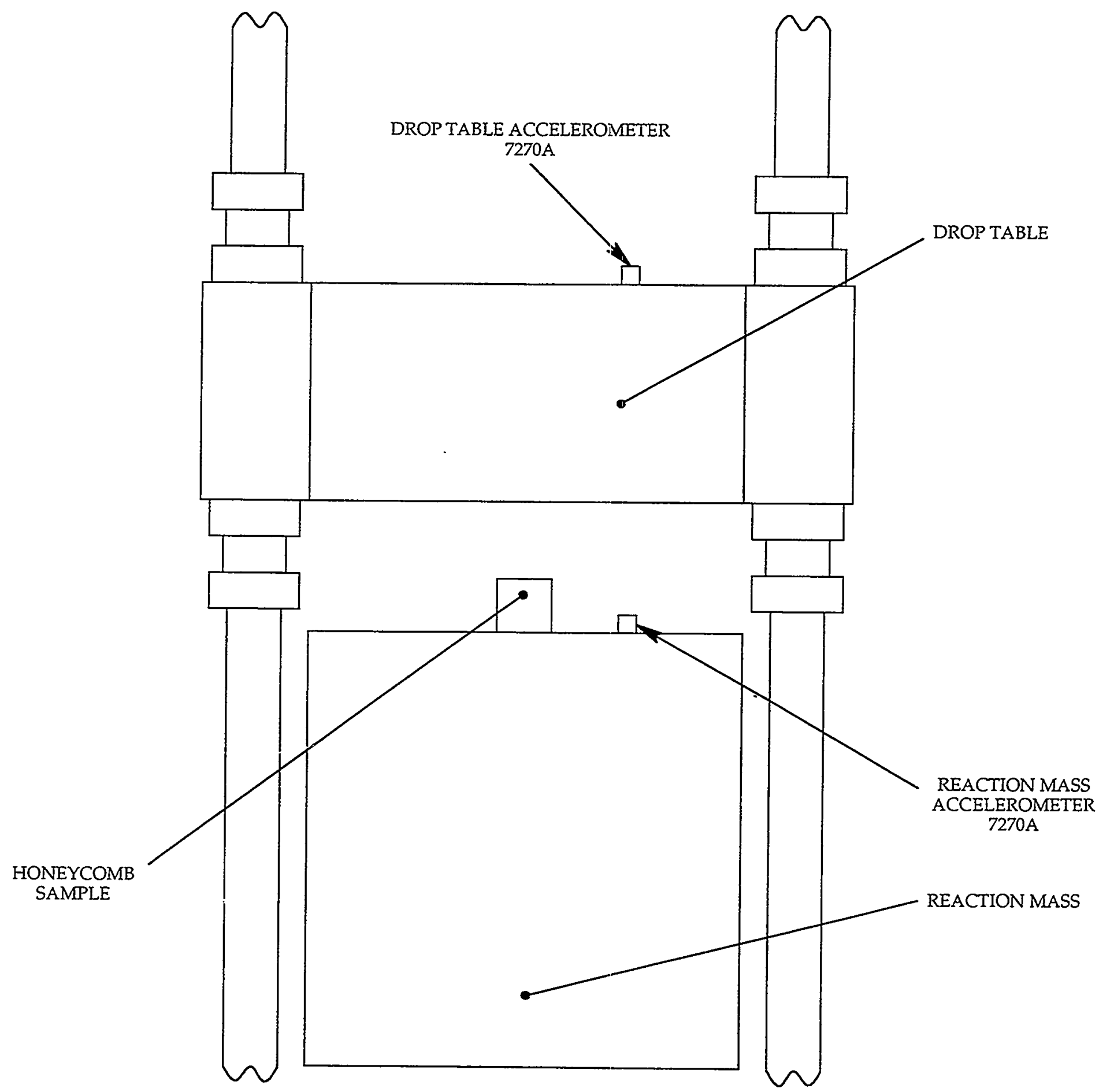

Figure 1: Experimental Configuration for Unconfined Honeycomb Experiments with a Drop Table Shock Machine. 

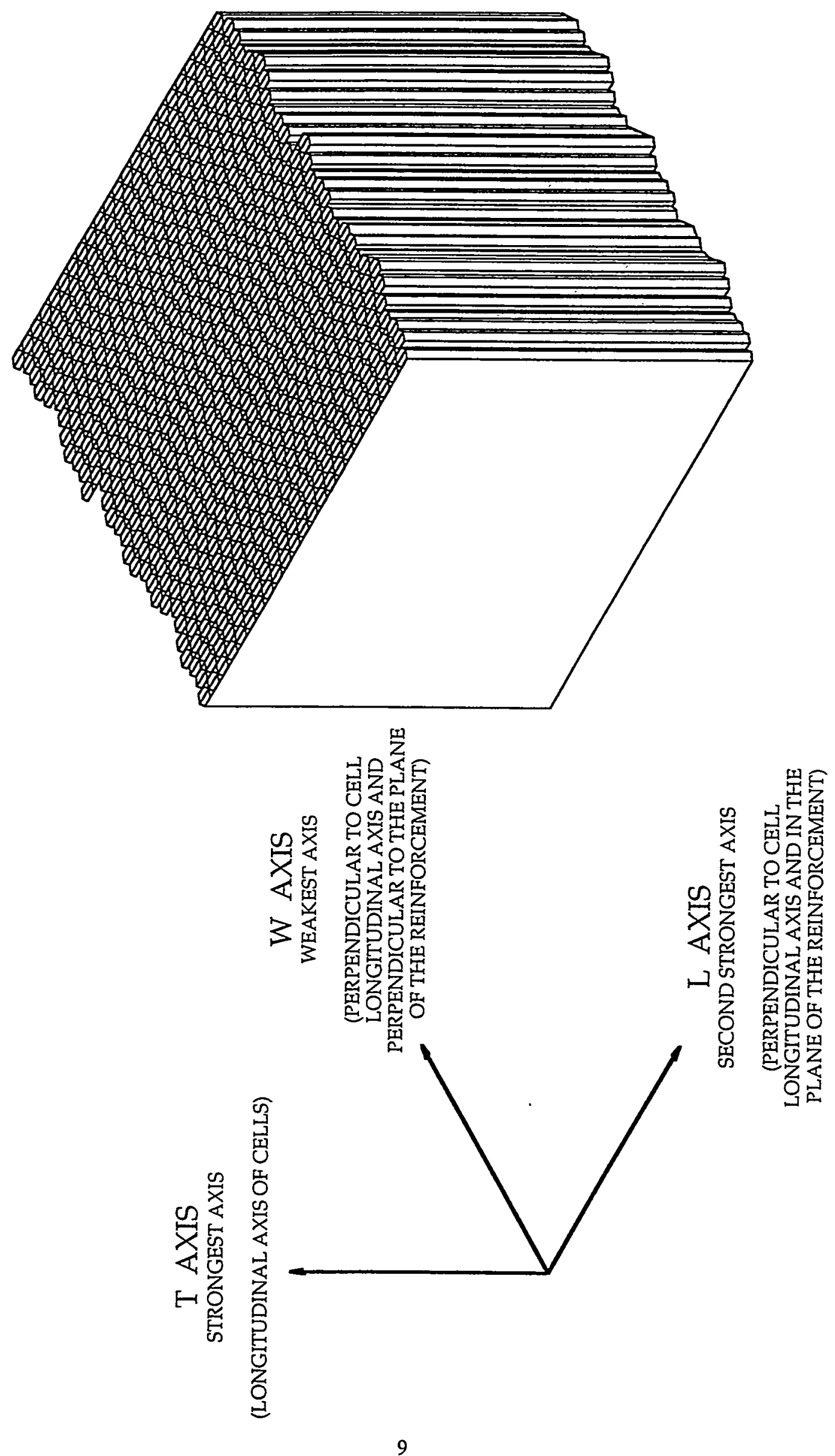

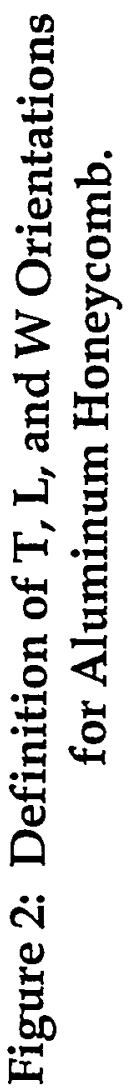


Table I: Aluminum Honeycomb Crush Experiment Parameters.

\begin{tabular}{|c|c|c|c|c|c|}
\hline $\begin{array}{c}\text { Experiment } \\
\text { Number }\end{array}$ & $\begin{array}{c}\text { Experiment } \\
\text { Date }\end{array}$ & $\begin{array}{c}\text { Crush } \\
\text { Weight (lbs) }\end{array}$ & $\begin{array}{c}\text { Density } \\
\text { (pcf) }\end{array}$ & $\begin{array}{c}\text { Honeycomb } \\
\text { Orientation }\end{array}$ & $\begin{array}{c}\text { GHI Velocity } \\
\text { (fps) }\end{array}$ \\
\hline 002 & $1997-8$ & 45 & 38.0 & W & 40.23 \\
\hline 003 & $1997-8$ & 45 & 38.0 & $\mathrm{~L}$ & 39.85 \\
\hline 004 & $1997-8$ & 45 & 22.1 & $\mathrm{~L}$ & 39.68 \\
\hline 005 & $1997-8$ & 45 & 22.1 & $\mathrm{~W}$ & 39.63 \\
\hline 025 & $1997-8$ & 268 & 38.0 & $\mathrm{~T}$ & 57.70 \\
\hline 026 & $1997-8$ & 168 & 22.1 & $\mathrm{~T}$ & 90.00 \\
\hline 027 & $1997-8$ & 168 & 22.1 & $\mathrm{~T}$ & 50.00 \\
\hline 028 & $1997-8$ & 268 & 38.0 & $\mathrm{~T}$ & 53.12 \\
\hline 029 & $1997-8$ & 268 & 38.0 & $\mathrm{~T}$ & 50.00 \\
\hline 031 & $1997-8$ & 168 & 22.1 & $\mathrm{~T}$ & 50.00 \\
\hline 037 & $1997-8$ & 268 & $38.0 *$ & $\mathrm{~T}$ & 51.13 \\
\hline 003 & 1999 & 45 & 38.0 & $\mathrm{~W}$ & 39.66 \\
\hline 005 & 1999 & 45 & 38.0 & $\mathrm{~L}$ & 39.72 \\
\hline 006 & 1999 & 168 & 38.0 & $\mathrm{~W}$ & 40.18 \\
\hline 008 & 1999 & 168 & 38.0 & $\mathrm{~L}$ & 40.11 \\
\hline
\end{tabular}

* Test \#37 is an Alcore sample.

the ENDEVCO 7270AM6-20K* Accelerometers were mounted on the drop table and the reaction mass. The honeycomb is crushed by the drop table carriage at a specified impact velocity. The impact velocity is calculated from the time it takes a precise length of steel to pass by two optical sensors as measured by the $\mathrm{GHI}^{*}$ device. The integration of the carriage accelerometer provides a redundant velocity measurement and validation of the GHI measurement. These experiments are not a constant velocity crush of the honeycomb samples. The carriage slows down continuously during the crush.

In 1999, four experiments as shown in Table I were conducted with accelerometers that have a lower range than the ENDEVCO 7270AM6-20K* used in the 1997-98 experiments. One undamped, piezoresistive accelerometer, ENDEVCO 7270AM6-6K*, and one oil-damped, piezoelectric accelerometer, ENDEVCO 2262-1K*, were placed in the two locations of the drop table carriage and on the reaction mass. The redundant instrumentation for these four experiments allowed validation of the previous data taken in 1997-98. The two accelerometers used in 1999 are equally suited to this work.

A second experimental configuration for semiconfined honeycomb experiments with a punch and a drop table shock machine shown in Figure 3 was proposed and constructed. The honeycomb experimental matrix in Table II for the existing $38 \mathrm{pcf}$ (6500 psi) Hexcel samples was chosen with the concurrence of those constructing a

*Reference to a commercial product implies no endorsement by SNL or the Department of Energy or lack of suitable substitute. 


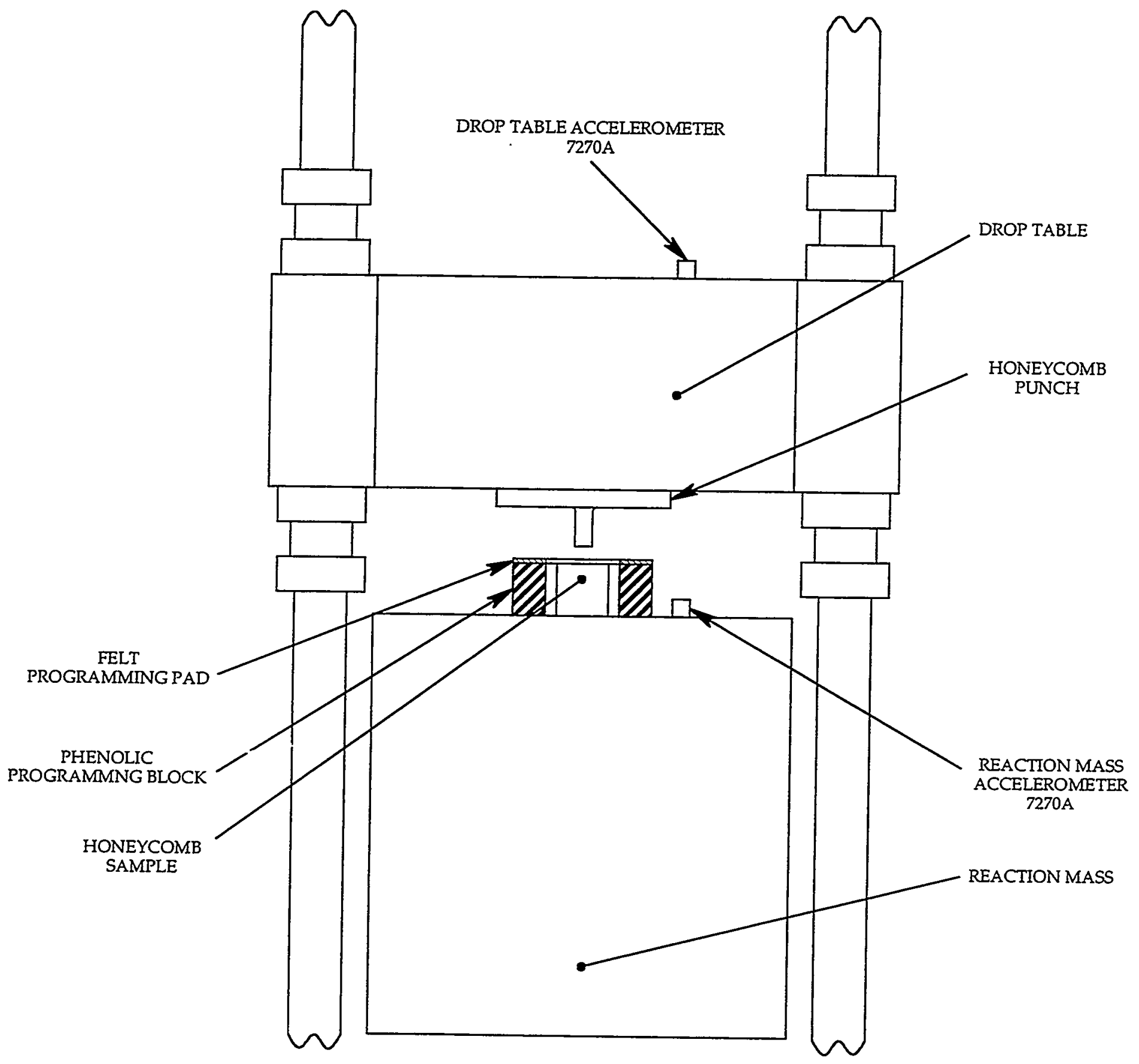

Figure 3: Semiconfined Honeycomb Experimental Configuration with Punch and Drop Table Shock Machine. 


\section{Table II: Experimental Matrix for 38 pcf Hexcel Honeycomb ( 3 by 3 by 3 in. Samples)}

No. of Samples Orientation

$\begin{array}{lcl}3 & \text { T and L } & \text { Experimental Configuration Confirmation } \\ 8 & \text { T } & \text { Compare results with Lu's Static Experiments } \\ 4 & \text { L } & \text { Requested by Terry Hinnerich for lateral model }\end{array}$

constitutive model for the honeycomb. One experiment with the punch bolted to the bottom of the drop table shock machine was conducted at the maximum available impact velocity in the Area I Mechanical Shock Laboratory of $90 \mathrm{fps}$ with an impact weight of $168 \mathrm{lb}$. The minimum crush weight available is $168 \mathrm{lb}$ at this velocity. Since the honeycomb characteristics prior to lockup are needed, a two-in penetration depth was desired. Accelerometers were mounted on the carriage and the reaction mass to obtain data for calculation of force-displacement characteristics, and the GHI optical device measured impact velocity. The honeycomb sample was placed in the middle of the phenolic programmer in the $T$ orientation. No valid data were obtained from this experimental configuration because the sample split upon impact. The data were examined visually but were not stored on the data acquisition system. It was concluded that this configuration is not useful to crush the honeycomb samples. Consequently, this experimental configuration was abandoned and the experiments proposed in Table II will be conducted with another experimental configuration.

\section{Experimental Results}

The pre-test and post-test dimensional measurements for the fifteen honeycomb crush experiments are shown in Table III. Excellent agreement between the redundant accelerometer measurements made in 1999 was obtained even though honeycomb crushes were performed with two substantially different crush weights for the $W$ and $L$ orientations. To obtain the correct honeycomb crush characteristics in the form of normalized force-displacement curves, the acceleration measurements on the reaction mass during honeycomb crush were used to remove reaction mass motion from the carriage acceleration response. Both acceleration time-histories were integrated over the entire time window recorded for each experiment. Most of the data were low-pass filtered with a cutoff frequency at $10 \mathrm{kHz}$ prior to the integration, although some data were low-pass filtered with a lower cutoff frequency as noted on the raw acceleration plots in the appendices. The carriage velocity was corrected by subtracting out the reaction mass velocity. A correct crush distance was then obtained by integrating the corrected carriage velocity. The crush distance obtained from double integration of the acceleration data agreed with the physical measurements shown in Table III within 5\% or less.

The reaction mass is made of steel and is substantially heavier that the aluminum carriage. The reaction mass starts to move during the honeycomb crush. By the time 


\section{Table III: Aluminum Honeycomb Crush Experiment Dimensional Measurements.}

\begin{tabular}{|c|c|c|c|c|c|c|c|}
\hline \multirow{2}{*}{$\begin{array}{l}\text { Experiment } \\
\text { Number }\end{array}$} & \multirow{2}{*}{$\begin{array}{l}\text { Honeycomb } \\
\text { Orientation }\end{array}$} & \multicolumn{3}{|c|}{ Pre-Experiment Dimensions (in) } & \multicolumn{3}{|c|}{ Post-Experiment Dimensions (in) } \\
\hline & & $\mathrm{W}$ & $\mathrm{L}$ & $\mathrm{T}$ & $\bar{W}$ & $\bar{L}$ & $\mathrm{~T}$ \\
\hline 002 & W & \multirow{4}{*}{\multicolumn{3}{|c|}{$\begin{array}{l}\text { No pre-experiment dimensions } \\
\text { Taken for these experiments }\end{array}$}} & 1.304 & 3.053 & 3.037 \\
\hline 003 & $\mathrm{~L}$ & & & & 3.78 & 1.468 & 3.003 \\
\hline 004 & $\mathrm{~L}$ & & & & 5.55 & 0.433 & 3.028 \\
\hline 005 & $\bar{W}$ & & & & 0.670 & 3.494 & 2.990 \\
\hline 025 & $\mathrm{~T}$ & 2.998 & 3.006 & 3.002 & 6.0 & 3.194 & 0.667 \\
\hline 026 & $\bar{T}$ & \multicolumn{6}{|c|}{ Maximum velocity demonstration for 22.1 pcf sample*. } \\
\hline 027 & $\mathrm{~T}$ & 3.011 & 3.025 & 3.014 & 3.70 & 3.700 & 0.615 \\
\hline 028 & $\bar{T}$ & 3.028 & 2.977 & 2.991 & * & 3.160 & 0.710 \\
\hline 029 & $T$ & 3.001 & 3.024 & 3.026 & 3.241 & * & 0.660 \\
\hline 031 & $\mathrm{~T}$ & 3.006 & 3.025 & 3.013 & 3.600 & 3.600 & 0.651 \\
\hline 037 & $\mathrm{~T}$ & 3.022 & 3.010 & 3.002 & 6.750 & 3.290 & 0.625 \\
\hline 003 & $\mathrm{~W}$ & 3.004 & 3.019 & 3.014 & 1.341 & 3.038 & 3.036 \\
\hline 005 & $\bar{L}$ & 3.023 & 2.959 & 2.991 & 3.537 & 1.435 & 3.014 \\
\hline 006 & $\bar{W}$ & 2.983 & 2.948 & 3.004 & 0.779 & 3.267 & 3.082 \\
\hline 008 & $\mathrm{~L}$ & 2.996 & 3.012 & 2.994 & 4.730 & 0.713 & 3.066 \\
\hline
\end{tabular}

* Dimensional readings were not obtained due to either sample distortion or sample fragmentation.

lockup of the honeycomb has occurred, the carriage and the reaction mass are moving together. When the drop table and the reaction mass move together, the relative motion must be used to calculate the honeycomb crush characteristics, and the accelerometer measurement on the reaction mass is used to do this. The ratio of carriage mass to reaction mass is 10 for DT-66 drop table shock machine that has a $45 \mathrm{lb}$ carriage. The ratio of carriage mass to reaction mass is 18 for DT- 45 drop table shock machine that has a $168 \mathrm{lb}$ carriage. The movement of the reaction mass was much later in the honeycomb crush for DT-45 than for DT-66 whose reaction mass started to move shortly after the crush was initiated. Consequently, better data are obtained with the higher mass ratio between the carriage or crush weight and the reaction mass because the reaction mass acts more like the desired rigid mass.

The honeycomb crush characteristics in the form of normalized force-displacement curves for individual experiments are shown in Appendices A and B for the 1997-98 experiments and the 1999 experiments, respectively. Post-test pictures of the honeycomb samples taken with a digital camera are shown in Appendices $C$ and $D$ for the 1997-98 experiments and the 1999 experiments, respectively. Finally, the wideband accelerometer data for each experiment are shown in Appendices E and F for the 199798 experiments and the 1999 experiments, respectively. 
Composite plots of multiple experiments for a specific density and orientation have been made in Figures 4-9. Figures 4-6 are for the $22.1 \mathrm{pcf}$ honeycomb in the three orientations, and Figures 7-9 are for the $38.0 \mathrm{pcf}$ honeycomb in the three orientations. These data have been digitally filtered with a low-pass filter [1] whose cutoff frequency of $2000 \mathrm{~Hz}$ has been chosen to minimize the structural response in the data without compromising the dynamic response in the form of the rise-time of the stress timehistory. The structural response is the first bending mode of the carriage at $7200 \mathrm{~Hz}$. The cutoff frequency at $2000 \mathrm{~Hz}$ restricts the influence of the structural response to $10 \%$. These data plots show the initiation of honeycomb lockup when the crush event is over and the reaction mass and carriage move together with no carriage rebound.

\section{Uncertainty Analysis}

The uncertainty in these measurements and results are attributed to two sources: the uncertainty in the accelerometer calibrations and the influence of the carriage structural response. The uncertainty in the GHI velocity measurement is $0.1 \%$ and is negligible in this analysis. The accelerometer and data acquisition uncertainty is monitored on a continual basis in the SNL Mechanical Shock Laboratory as required by the SNL Specification 9958003 [2]. These requirements include the performance of both the hardware (accelerometers, amplifiers, digitizers etc.) [2,3] and the software IMPAX that controls the data acquisition system through a computer $[2,4,5]$. The current data acquisition system and software meet these requirements within $\pm 0.5 \%$, and documentation of these results is maintained in the Mechanical Shock Laboratory. Consequently, the only uncertainty in these measurements is the uncertainty in the accelerometer calibration, $\pm 5 \%$ [6] and the influence of the carriage structural response of $10 \%$ [6]. These two uncertainties are considered random, so they may be combined in an uncertainty analysis with a $95 \%$ confidence level as [7,8]:

$$
w_{T}=\sqrt{w_{s}^{2}+w_{c s r}^{2}}
$$

where: $\quad \mathrm{w}_{\mathrm{T}}=$ total uncertainty,

$\mathrm{w}_{\mathrm{s}}=$ accelerometer calibration uncertainty $5 \%$, and

$\mathrm{w}_{\mathrm{csr}}=$ carriage structural response uncertainty $10 \%$.

The value of the total uncertainty, $\mathrm{w}_{\mathrm{T}}$, is $\pm 11 \%$ and is typical for the measurements made in the SNL Mechanical Shock Laboratory.

\section{Conclusions and Future Work}

Of the fifteen honeycomb crush experiments documented in this report, seven experiments were in the $T$ orientation. Since this orientation is the most important for the model of the honeycomb, future experiments should concentrate on the $T$ orientation. The 22.1 pcf density honeycomb has approximately the same performance 
in the $\mathrm{W}$ and $\mathrm{L}$ orientations. However, the $38.0 \mathrm{pcf}$ density honeycomb has better performance in the $L$ orientation compared to the $W$ orientation because of the additional stiffener through the middle of each $\mathrm{L}$ cell. The differences in the honeycomb performance (lockup) in Figure 6 are attributed to the two different impact velocities.

These data show dynamic enhancement in the performance of the honeycomb in a dynamic crush environment or impact shock environment and are consistent with current MAVEN results. The dynamic enhancement is the increase in the T orientation strength over the nominal value of 6500 psi for 38.0 pcf and 3800 psi for the 22.1 pcf. These data are not strictly valid for material characteristics in $\mathrm{L}$ and $\mathrm{T}$ orientations because the cross-sectional area of the honeycomb changed (split) during the crush. However, these are the best data available at this time. These dynamic crush data do suggest a significant increase in crush strength to $8000 \mathrm{psi}$ ( $25-30 \%$ increase) over quasi-static values [9] of $\sim 6000$ psi shown in Figure 10 for the 38.0 pcf Hexcel Honeycomb in the T-orientation.

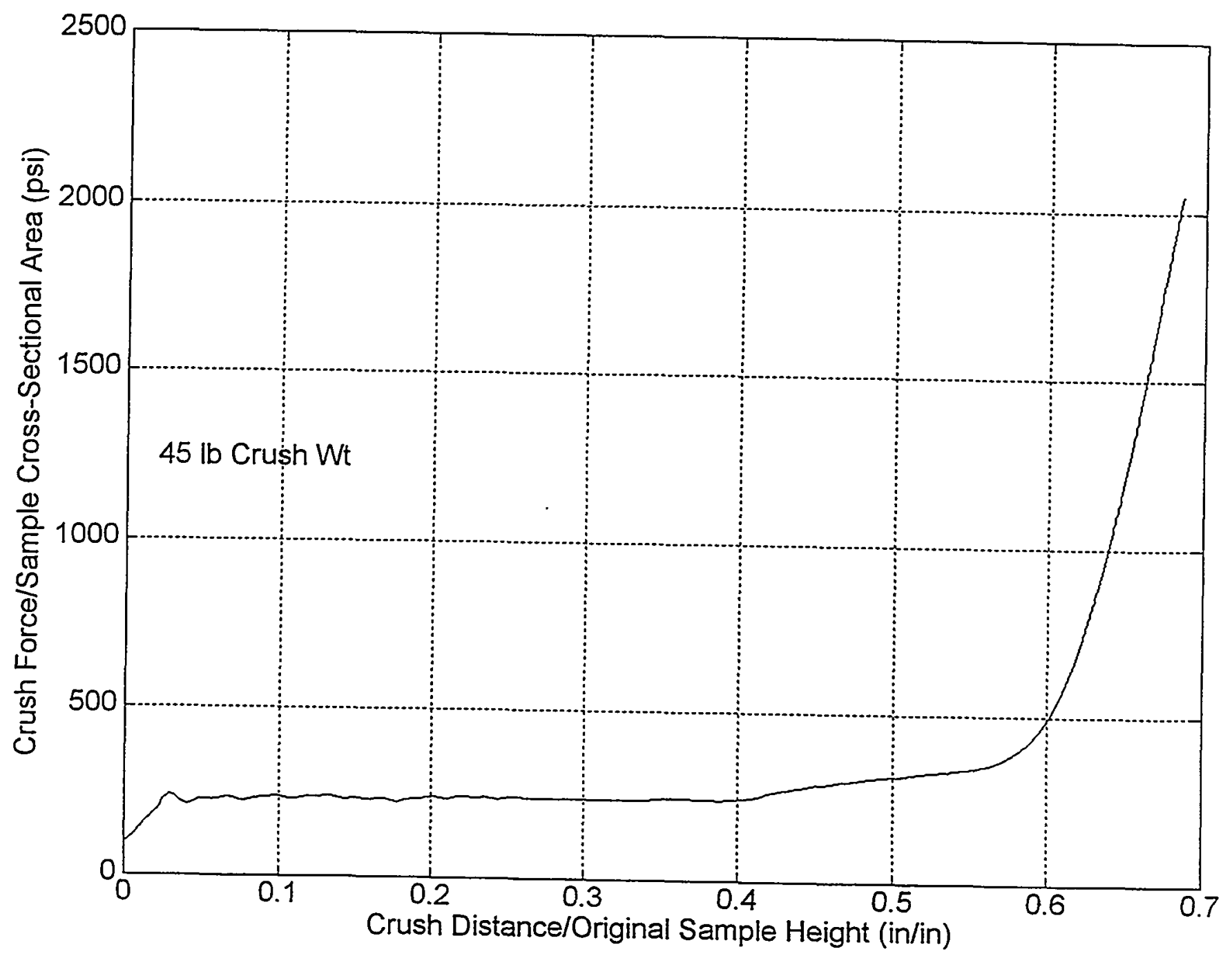

Figure 4: Experiment 5 (98): Hexcel, 22.1 pcf, W Orientation and $40 \mathrm{fps}$. 


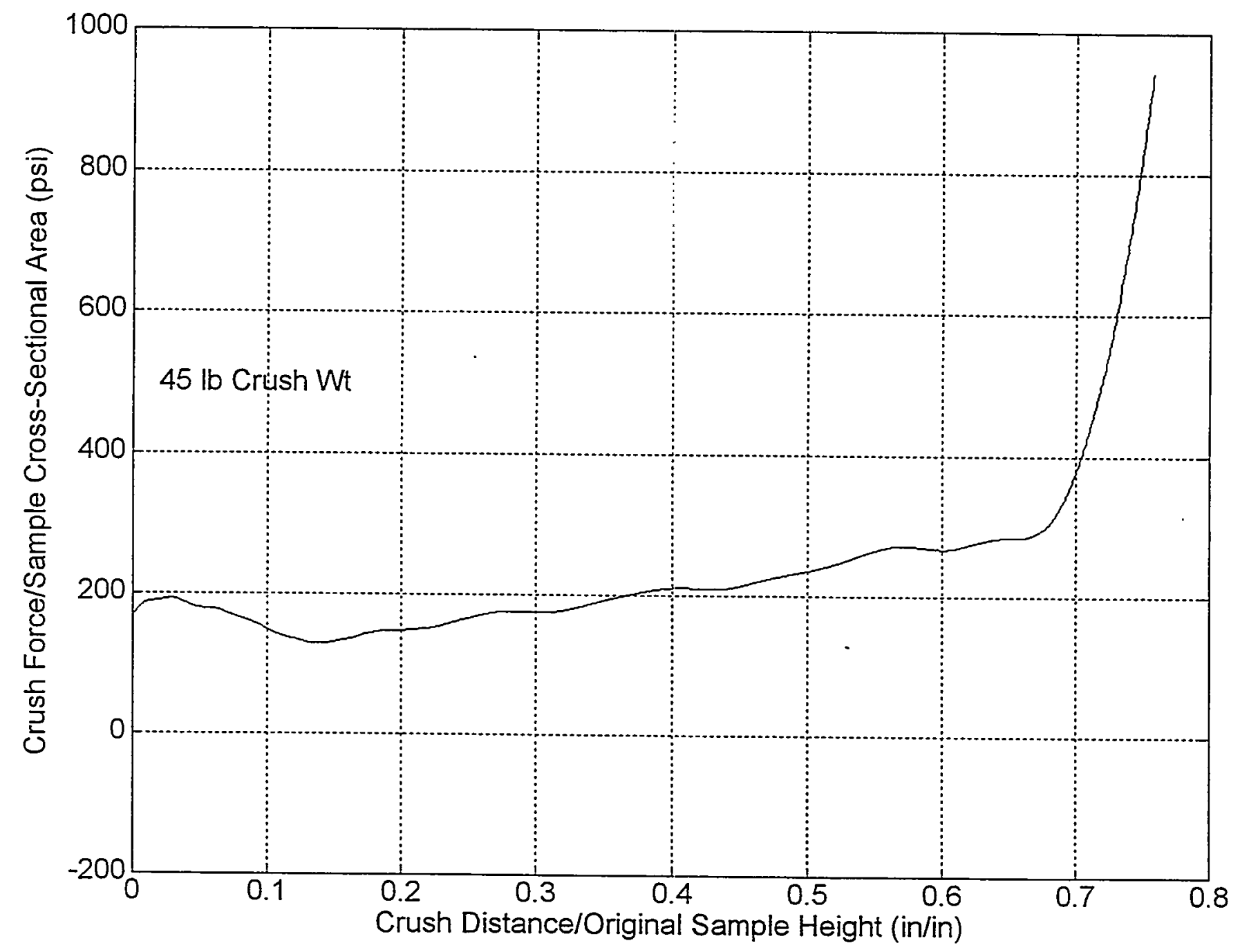

Figure 5: Experiment 4 (98): Hexcel, 22.1 pcf, L Orientation and 40 fps. 


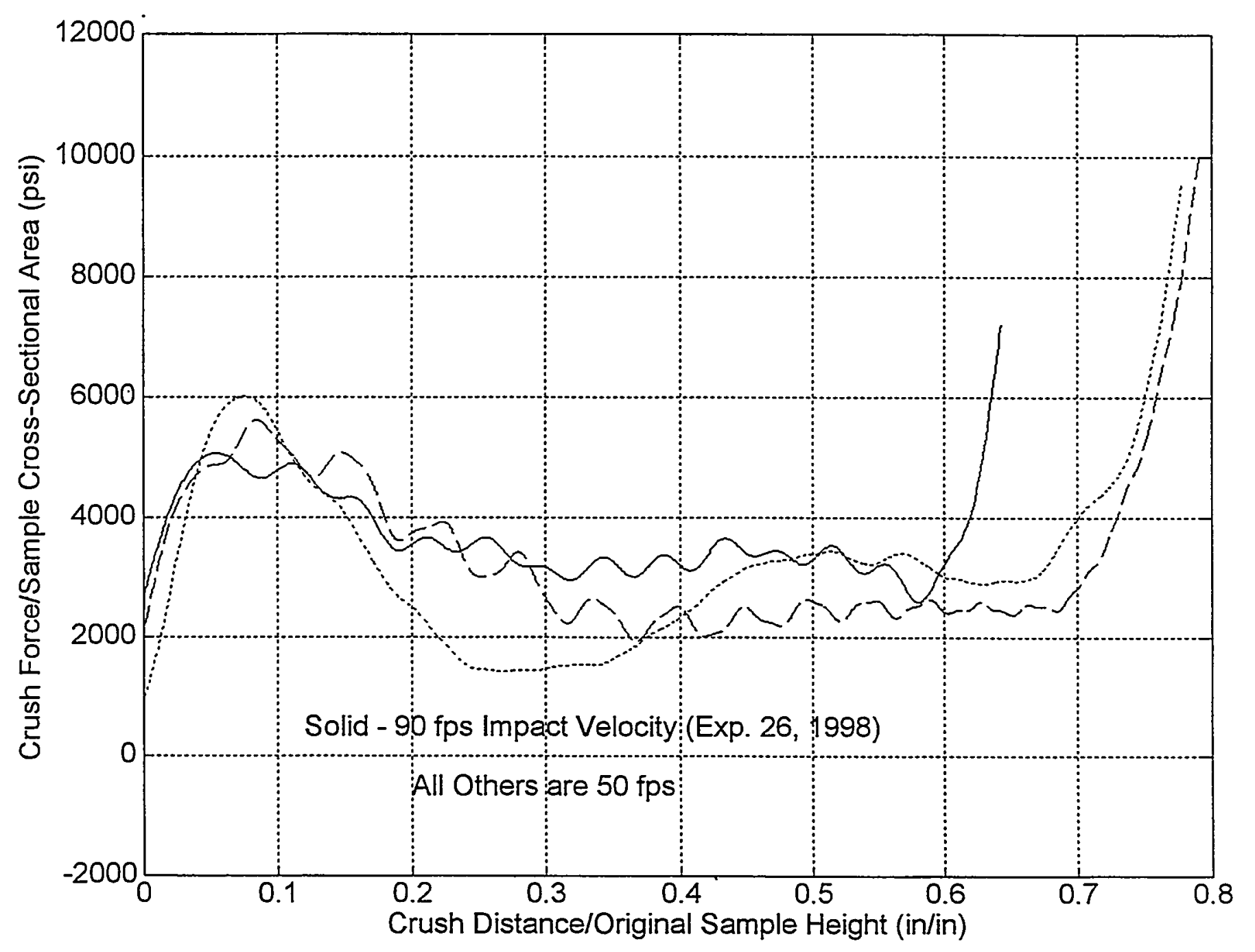

Figure 6: Experiments 26,27\&31 (98): Hexcel Honeycomb, 22.1 pcf, T Orientation, $168 \mathrm{lb}$ Crush Weight. 


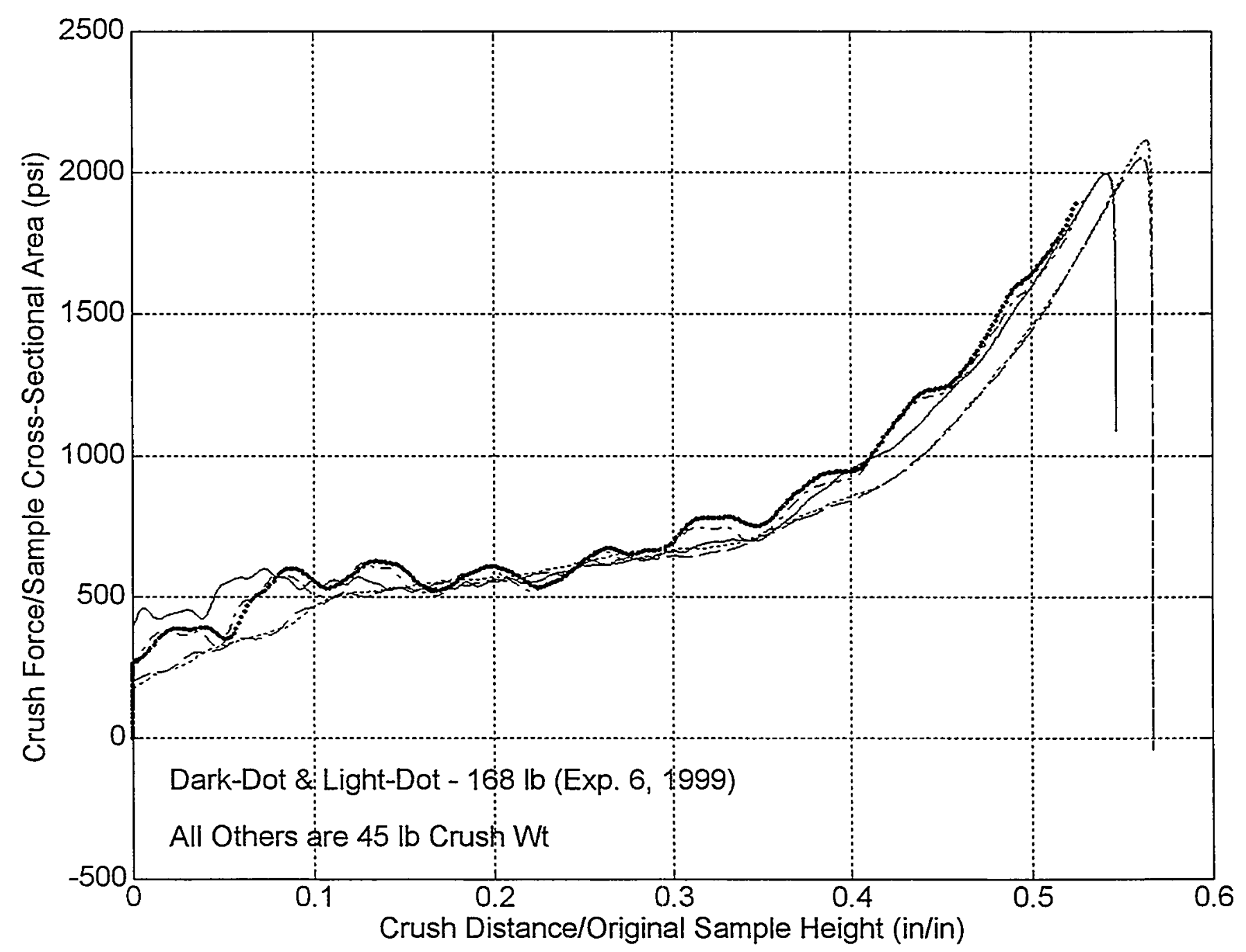

Figure 7: Experiments 2 (98) 3\&6 (99): Hexcel, 38.0 pcf, W Orientation and $40 \mathrm{fps}$. 


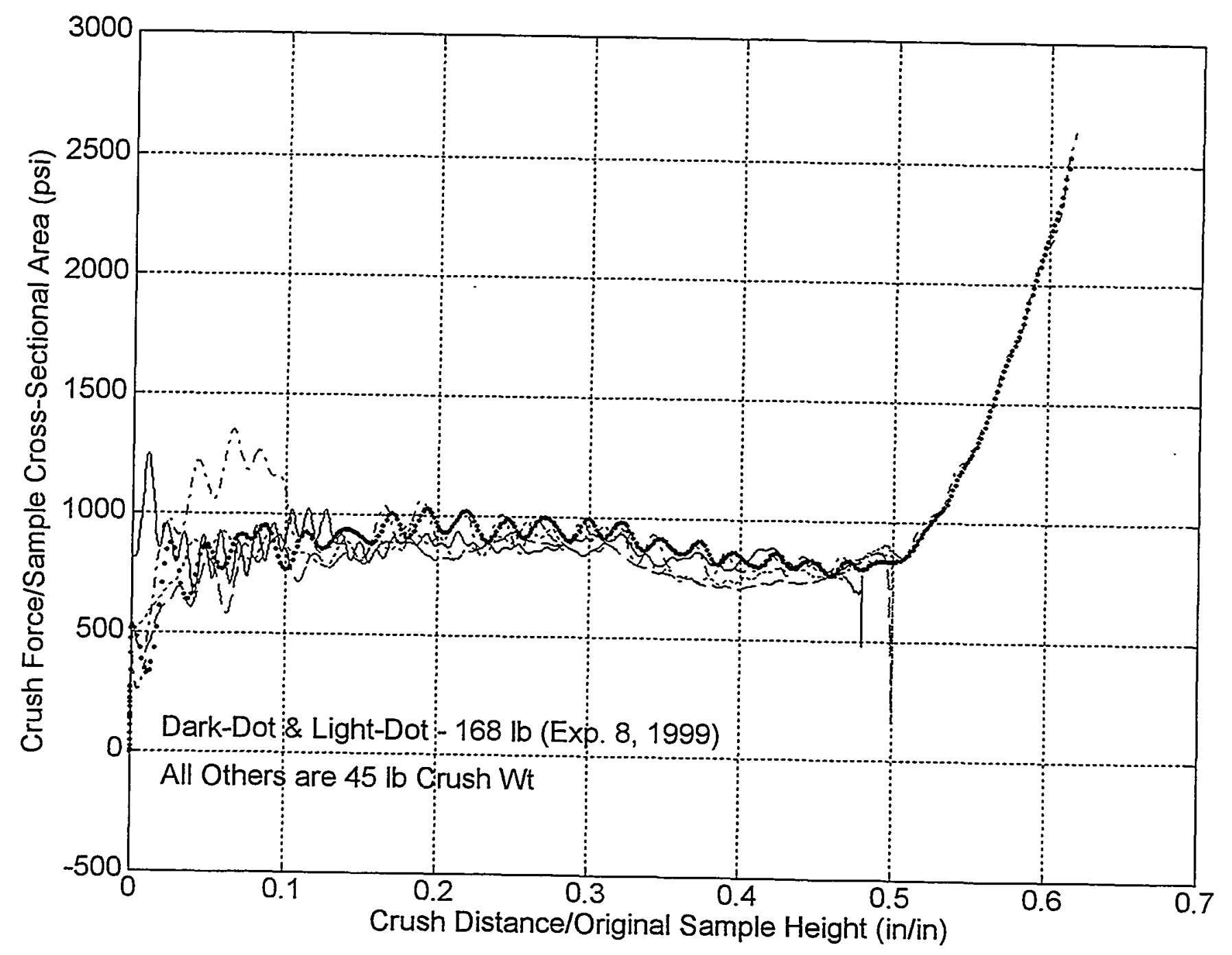

Figure 8: Experiments 3 (98) 5\&8 (99): Hexcel, 38.0 pcf, L Orientation and $40 \mathrm{fps}$. 


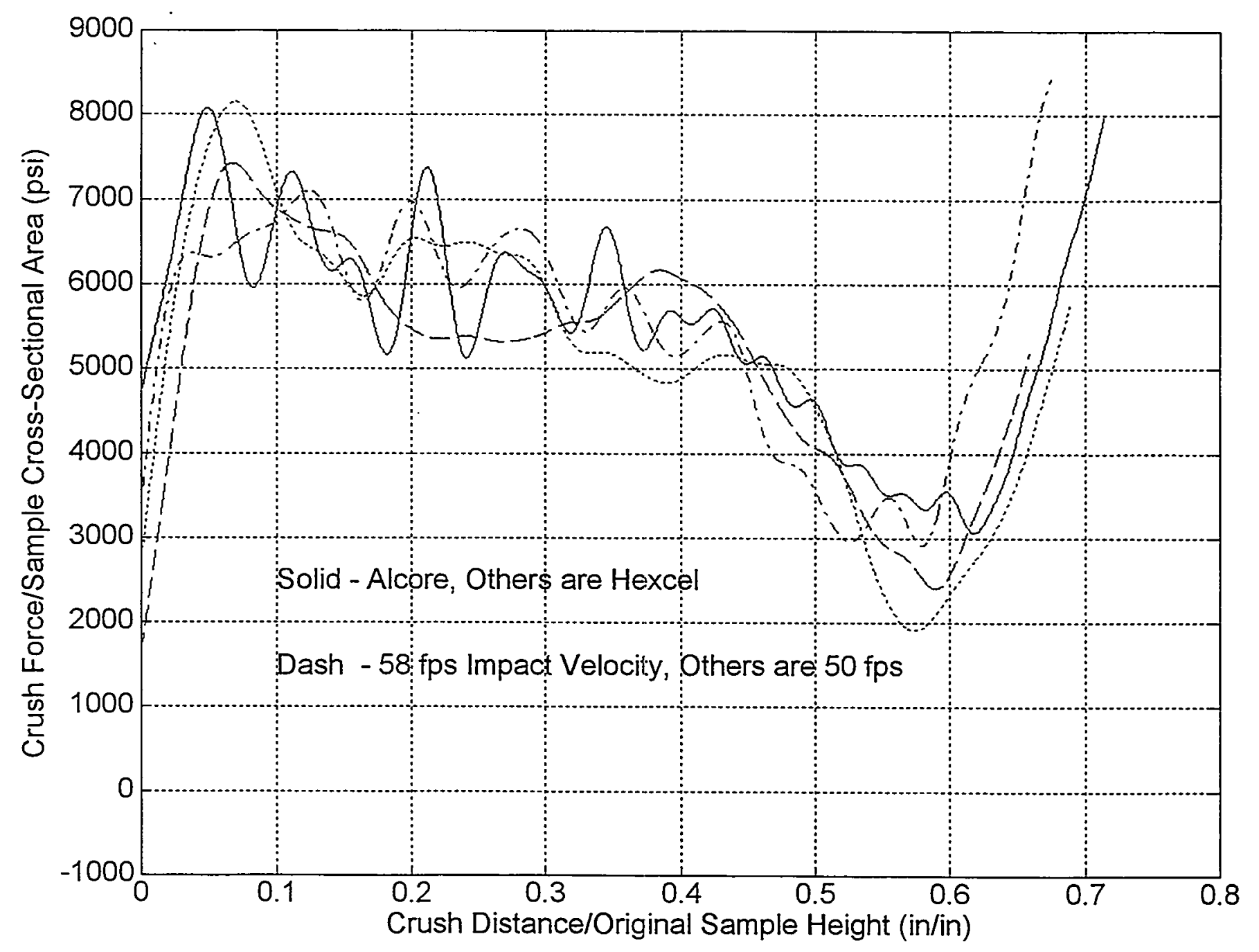

Figure 9: Experiments 25,28,29\&37: Honeycomb, 38.0 pcf, T Orientation, $268 \mathrm{lb}$ Crush Weight. 


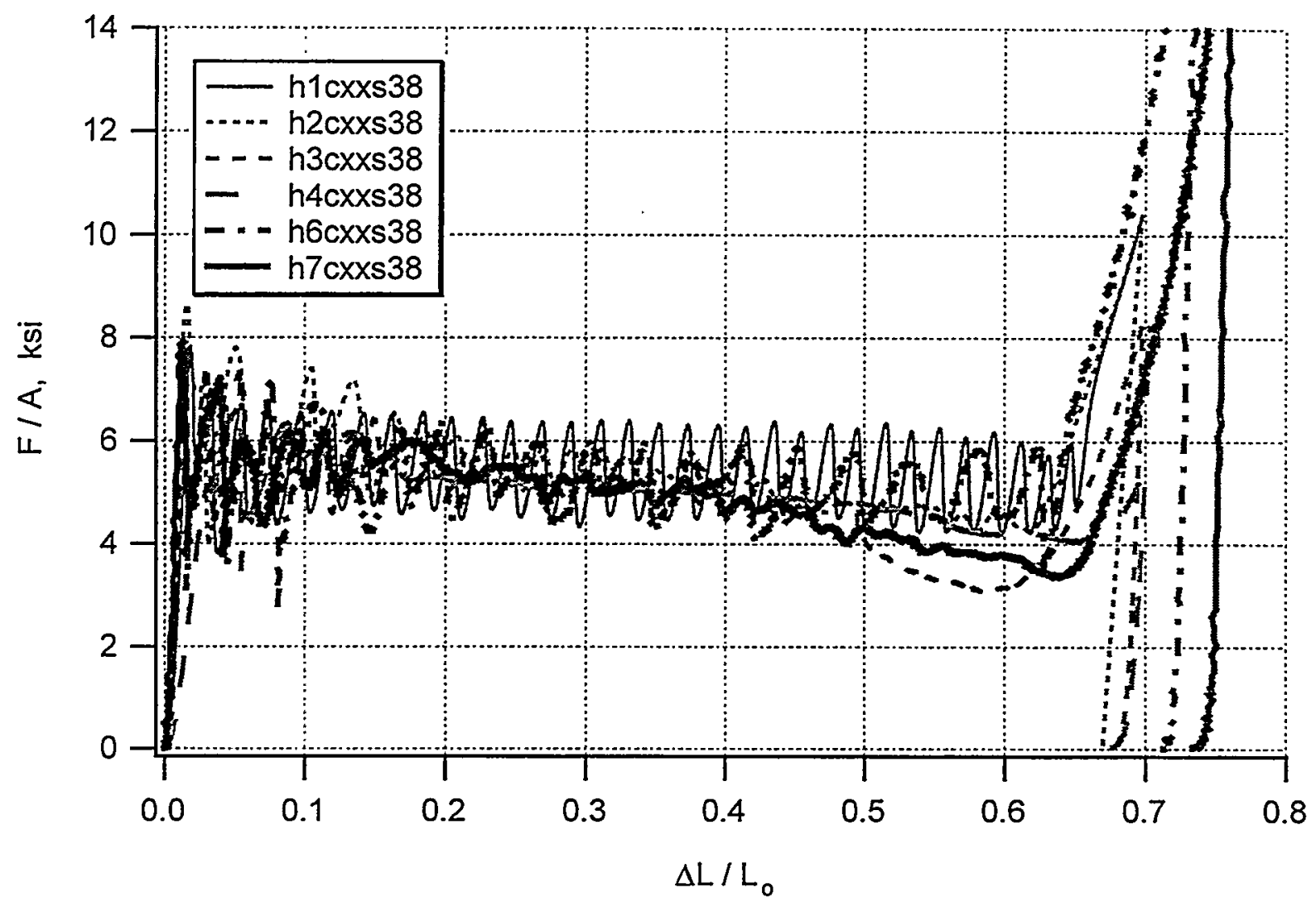

Figure 10: Quasi-Static Characteristics for Hexcel 38.0 pcf Aluminum Honeycomb in T Orientation Quasi-Static Characteristics [9]. 


\section{References}

1. Dunn, William N., "GRAFLAB 2.3 for UNIX: A MATLAB Database, Plotting. and Analysis Tool," SAND98-0628, National Technical Information Services, U.S. Department of Commerce, 5285 Port Royal Rd., Springfield, VA 22161, March 1998, p. 32.

2. Ulibarri, Davie, and Kuehnle, "Mechanical Shock Test Instrumentation," Sandia National Laboratories Specification 9958003-4, 1992, pp. 1-19.

3. Bateman, V. I., "Data Acquisition System Hardware Fidelity Check Procedures," February 14, 1997, pp. 1-21.

4. Bateman, V. I., "Software Management Plan for Software Supporting Production Lot Acceptance Testing," January 11, 1996, pp. 1-5.

5. Bateman, V. I., "Software Quality Requirements for Area I Mechanical Shock Laboratory," Issue A, January 11, 1996, pp. 1-10.

6. Bateman, V. I. And O. M. Solomon, Jr., "Characterization of Accelerometer Mountings in Shock Environments," Proceedings of the 14th Transducer Workshop, Colorado Springs, CO, June 1987.

7. Doebelin, E. O., "Measurement Systems Application and Design," McGraw Hill Book Company, New York, N. Y., 1983, pp.57-60.

8. Abernathy, R. B. "Measurement Uncertainty Handbook," Instrument Society of America. Research Triangle Park, N.C., 1980.

9. Lu, Wy, "Static Crush Experiments with Aluminum Honeycomb," SAND99XXXX, National Technical Information Services, U.S. Department of Commerce, 5285 Port Royal Rd., Springfield, VA 22161, July 1999 (to be published). 


\section{Appendix A \\ Normalized Honeycomb Crush Characteristics (1997-98)}




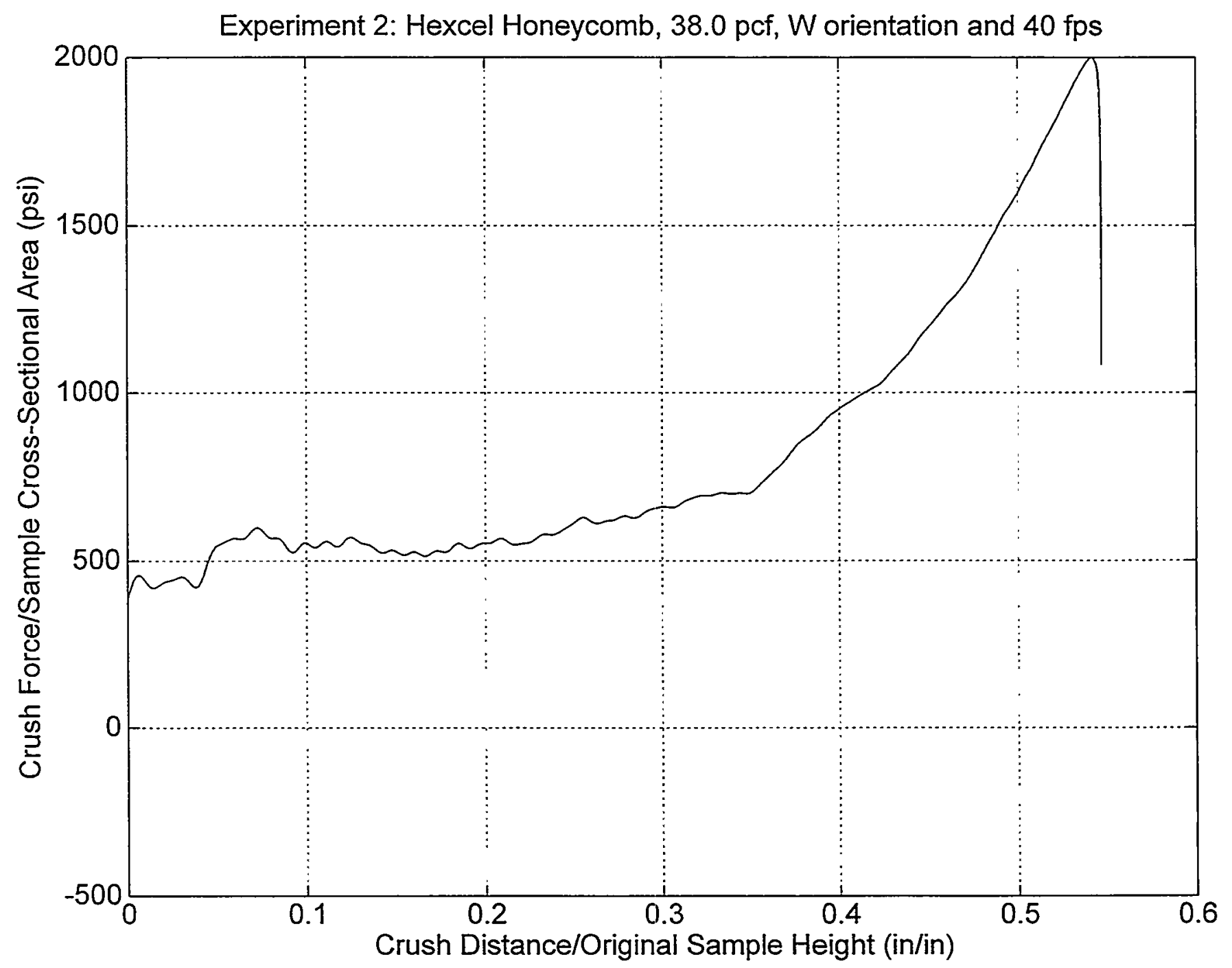




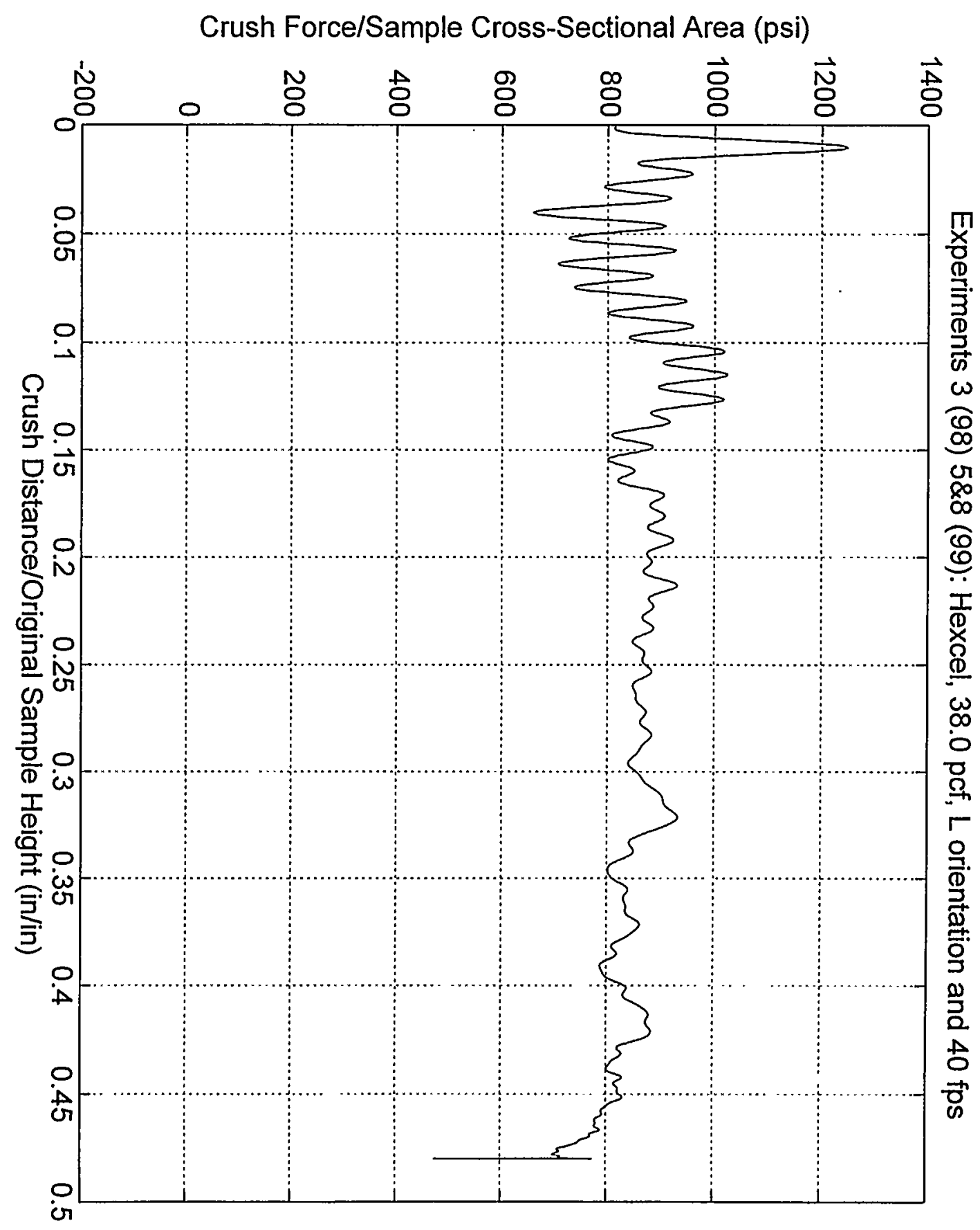




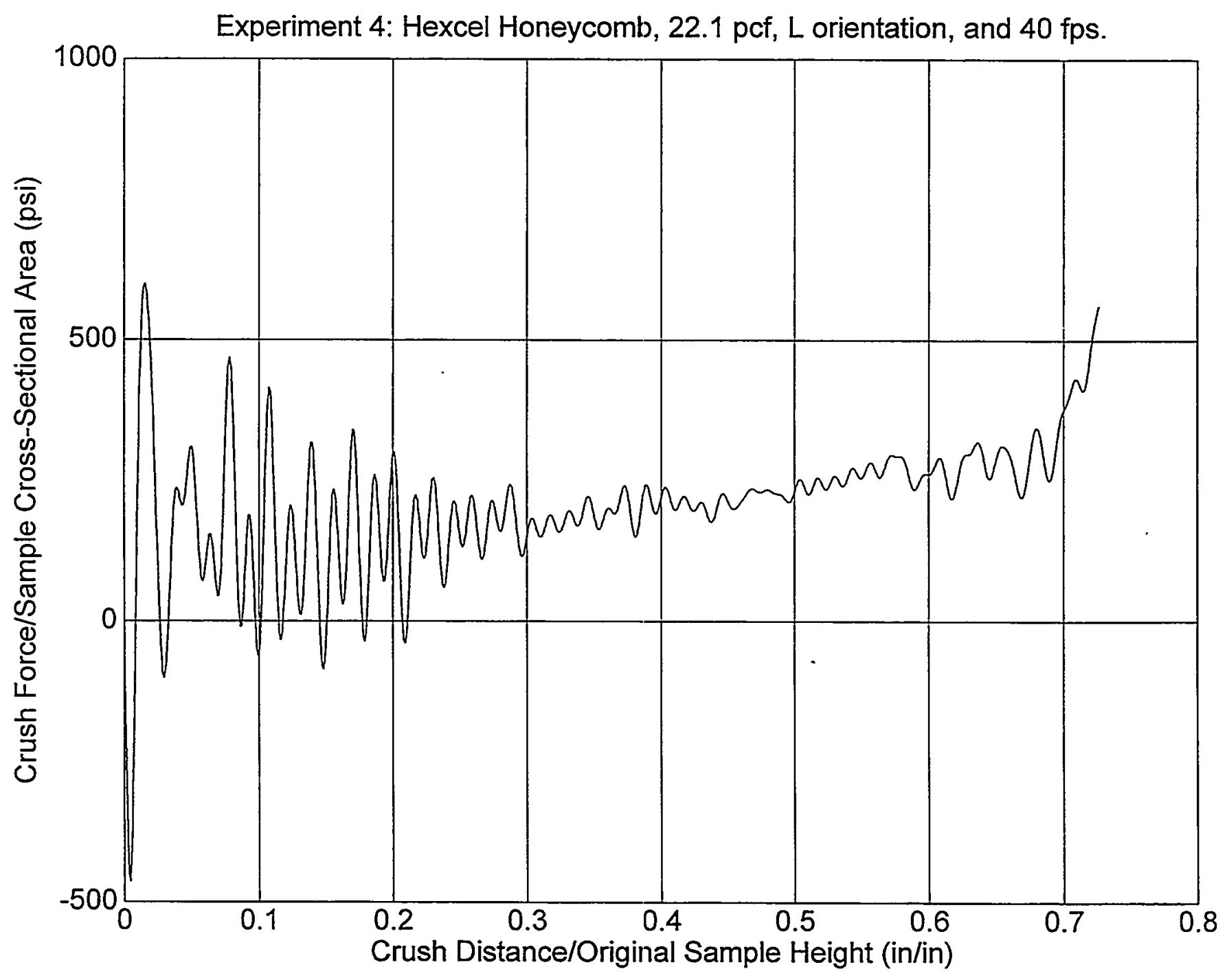




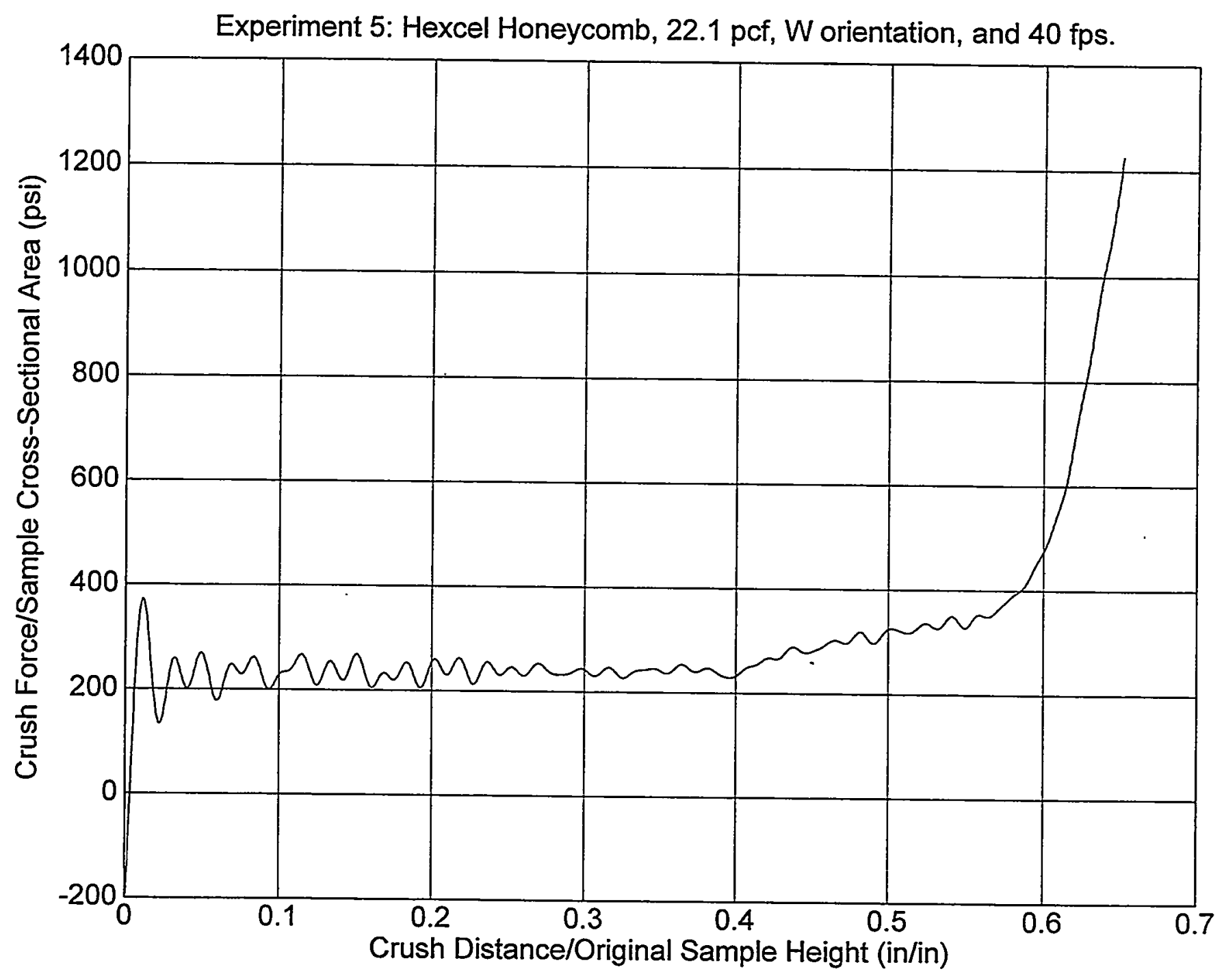




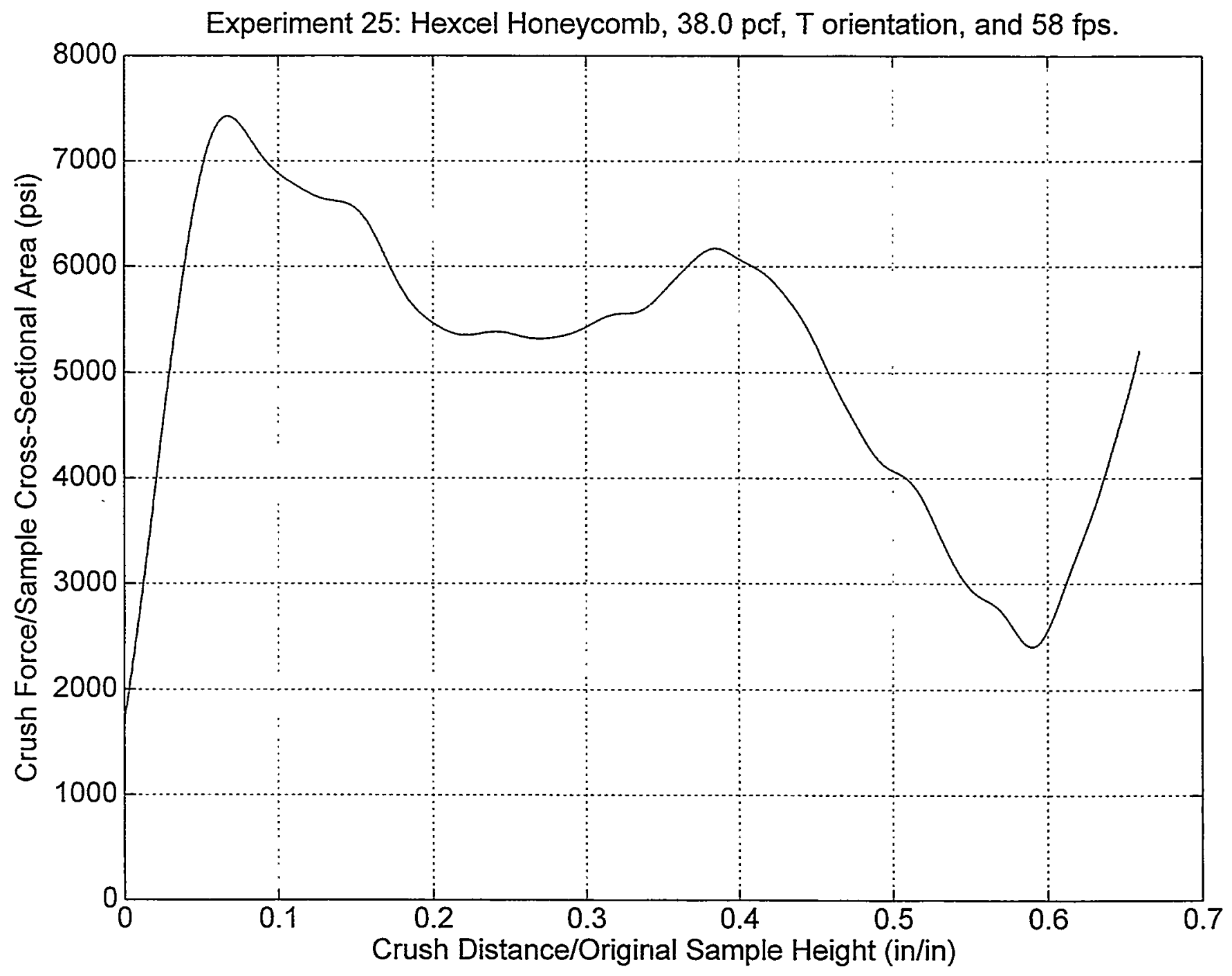




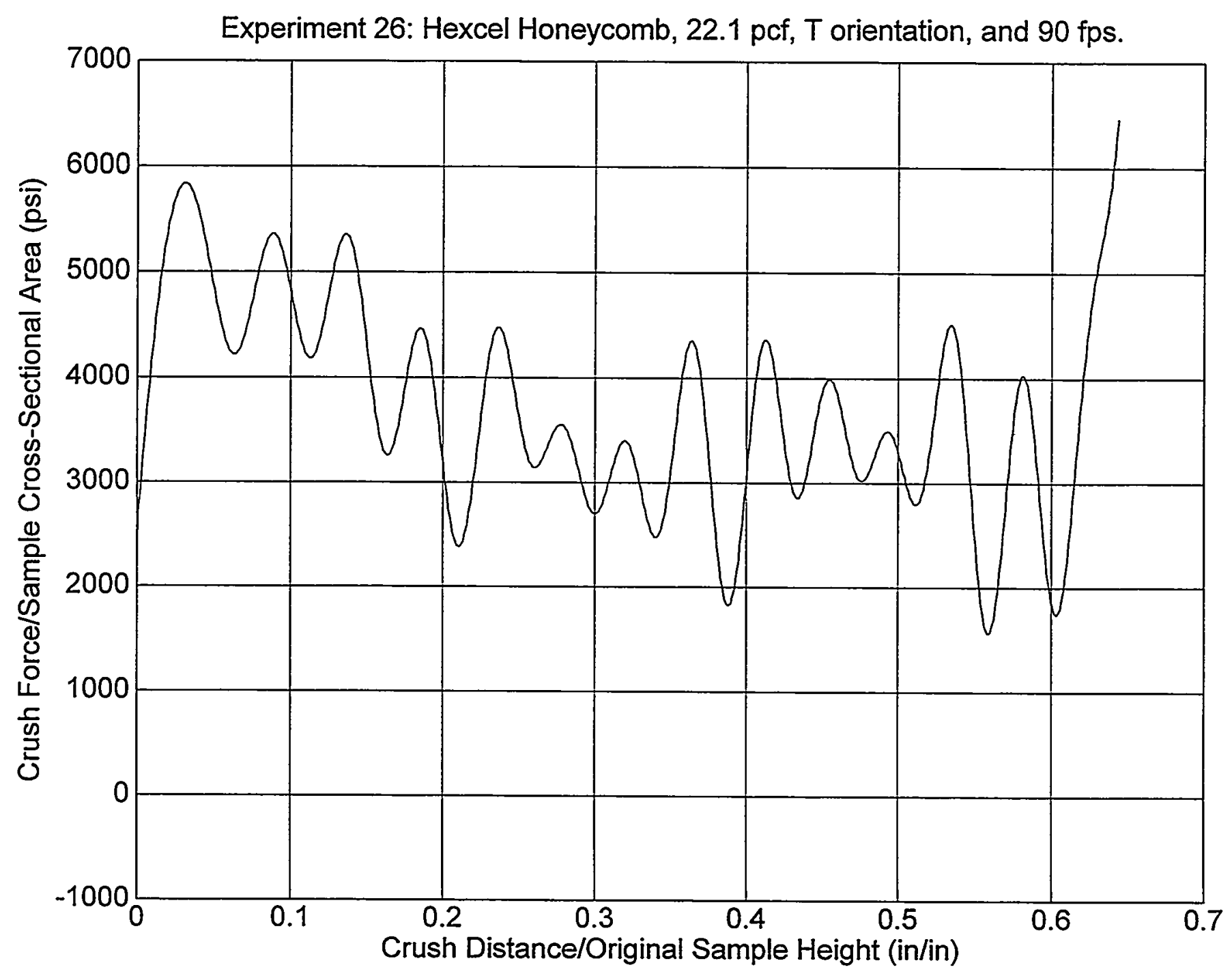




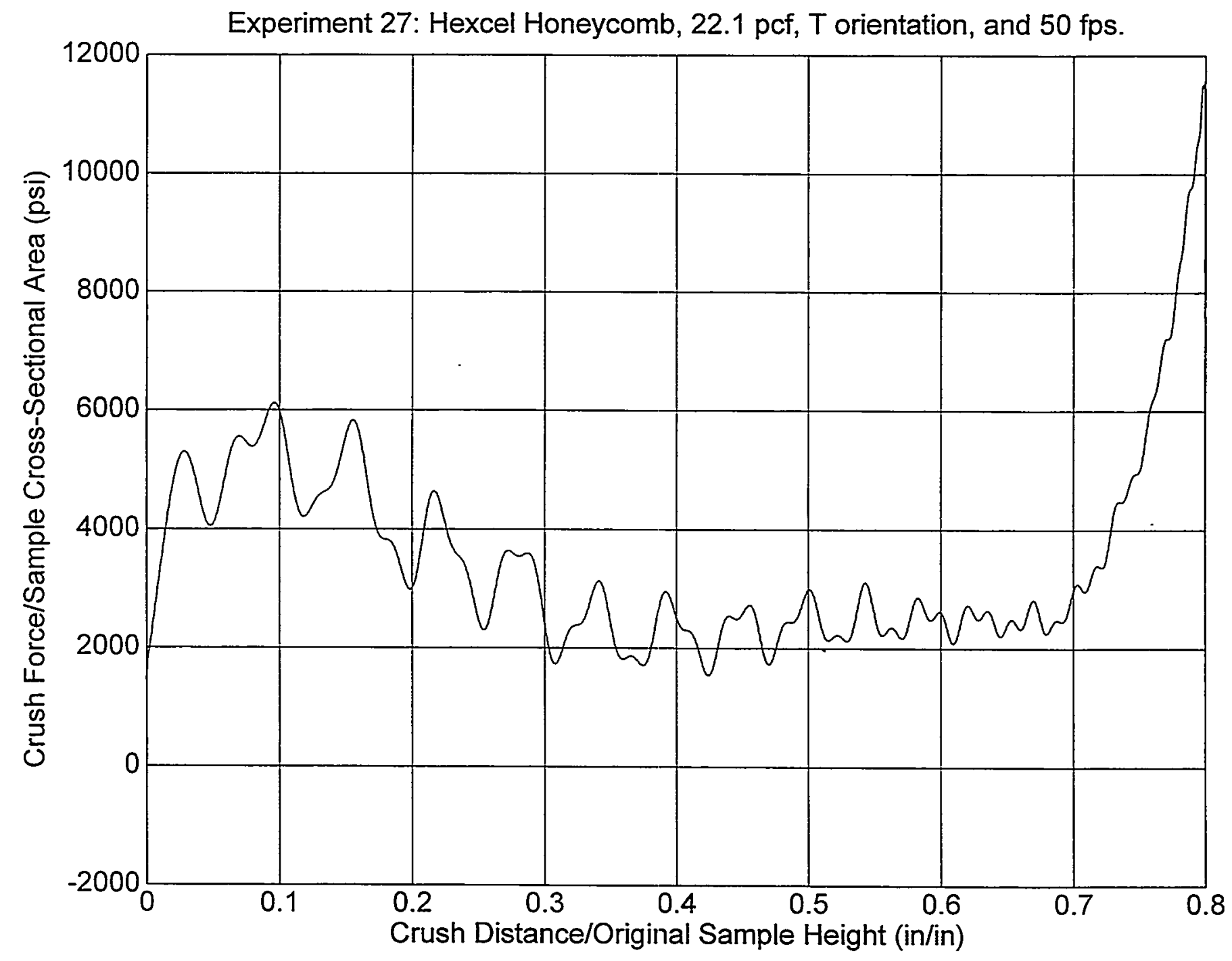




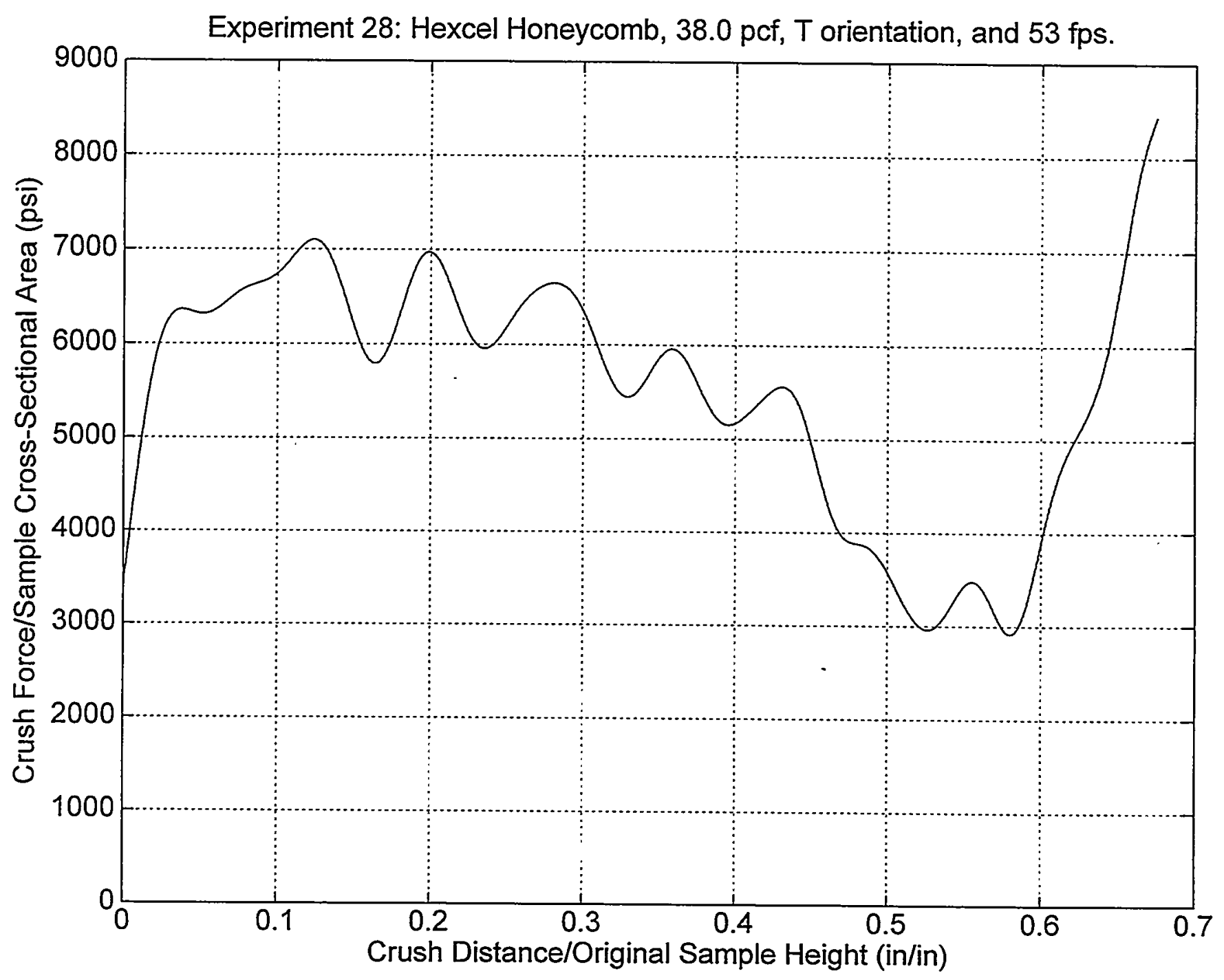




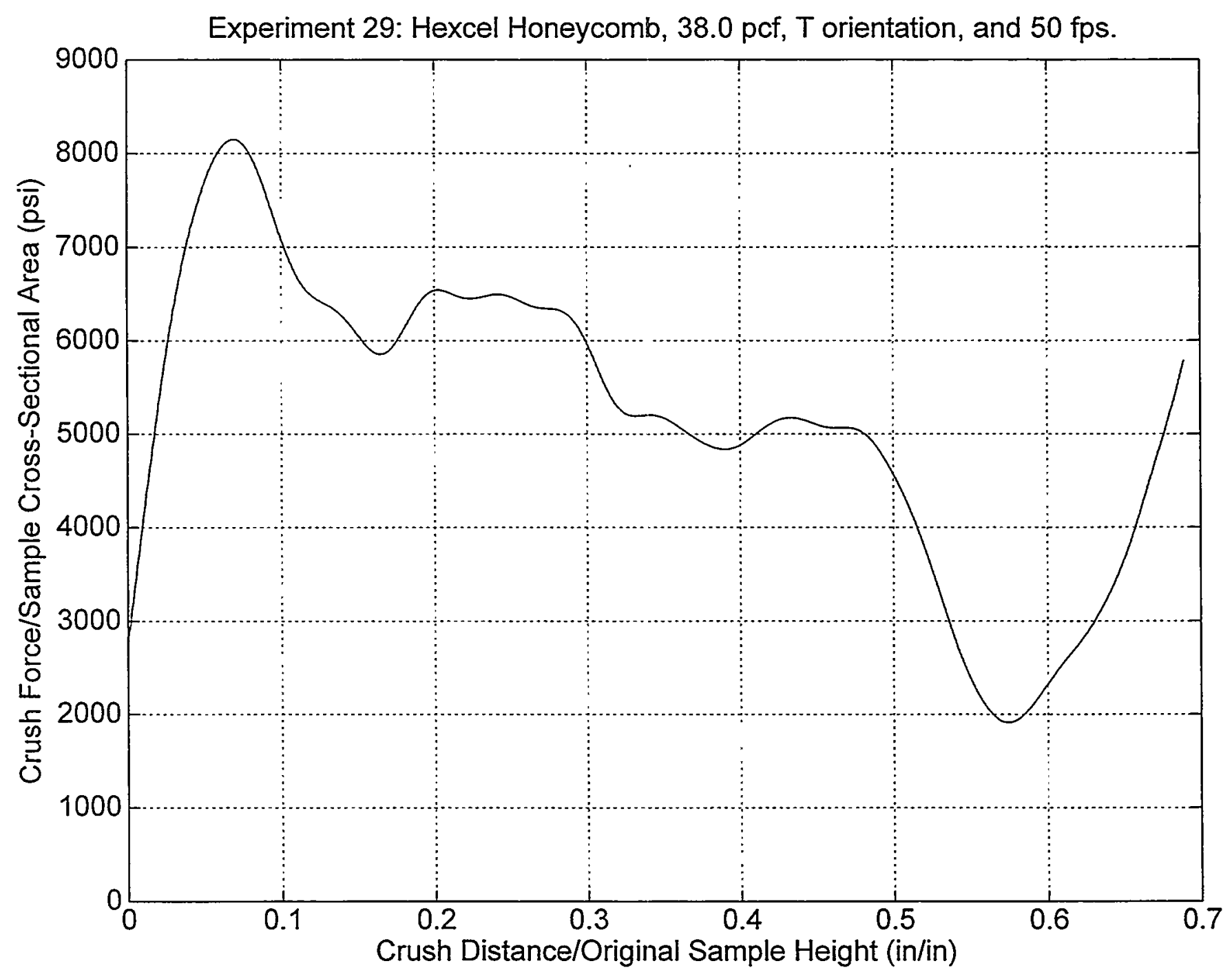




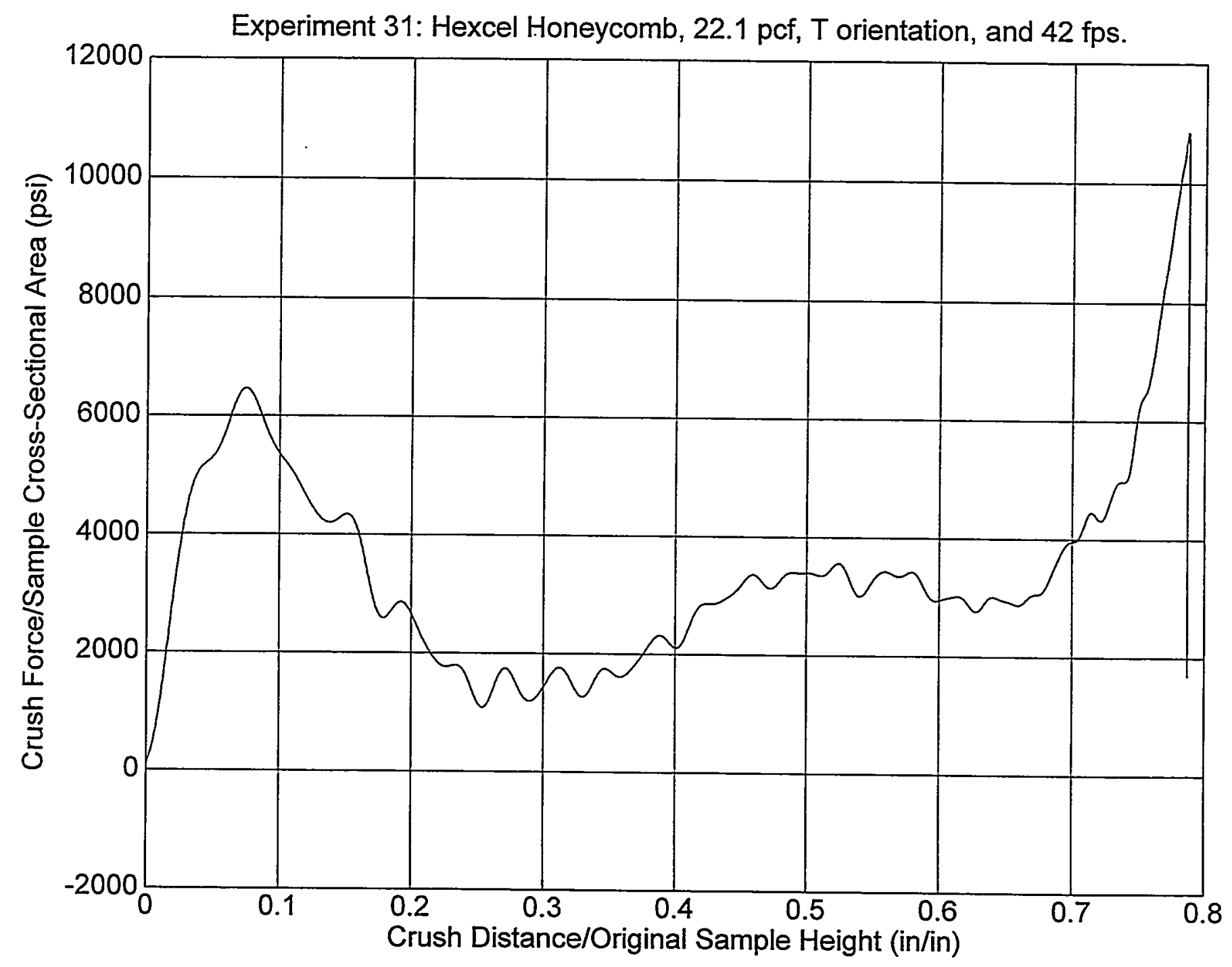




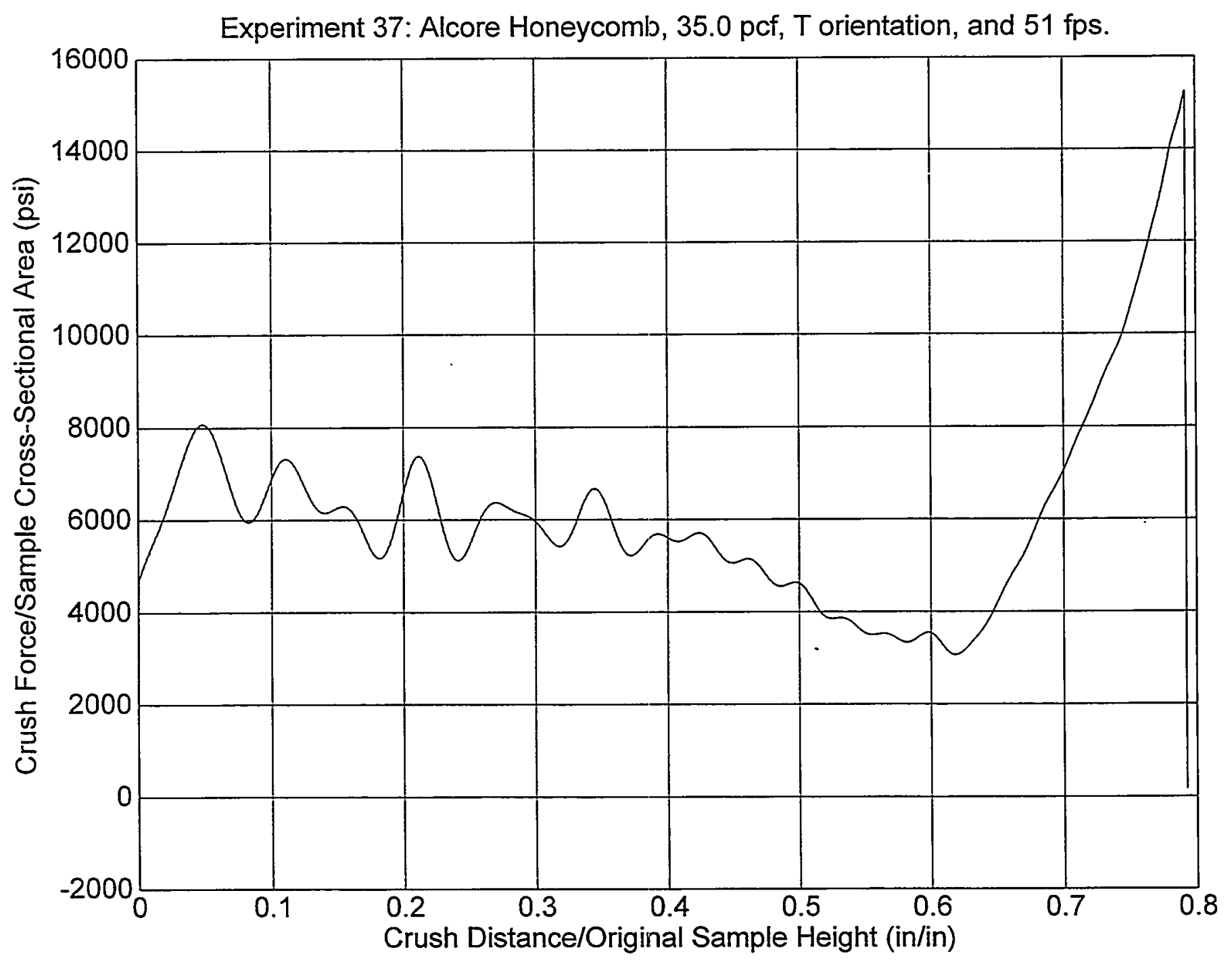




\section{Appendix B}

\section{Normalized Honeycomb Crush Characteristics (1999)}




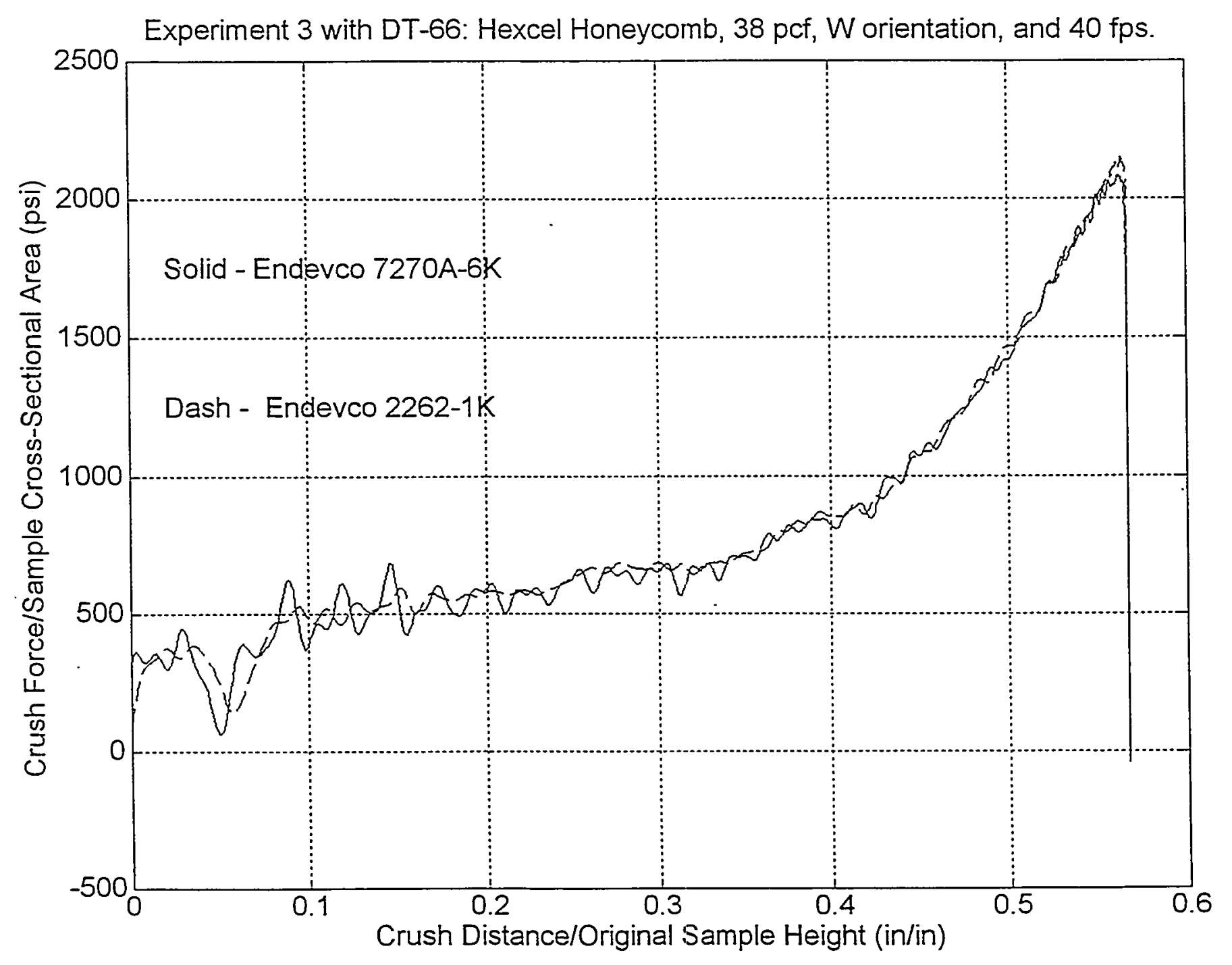




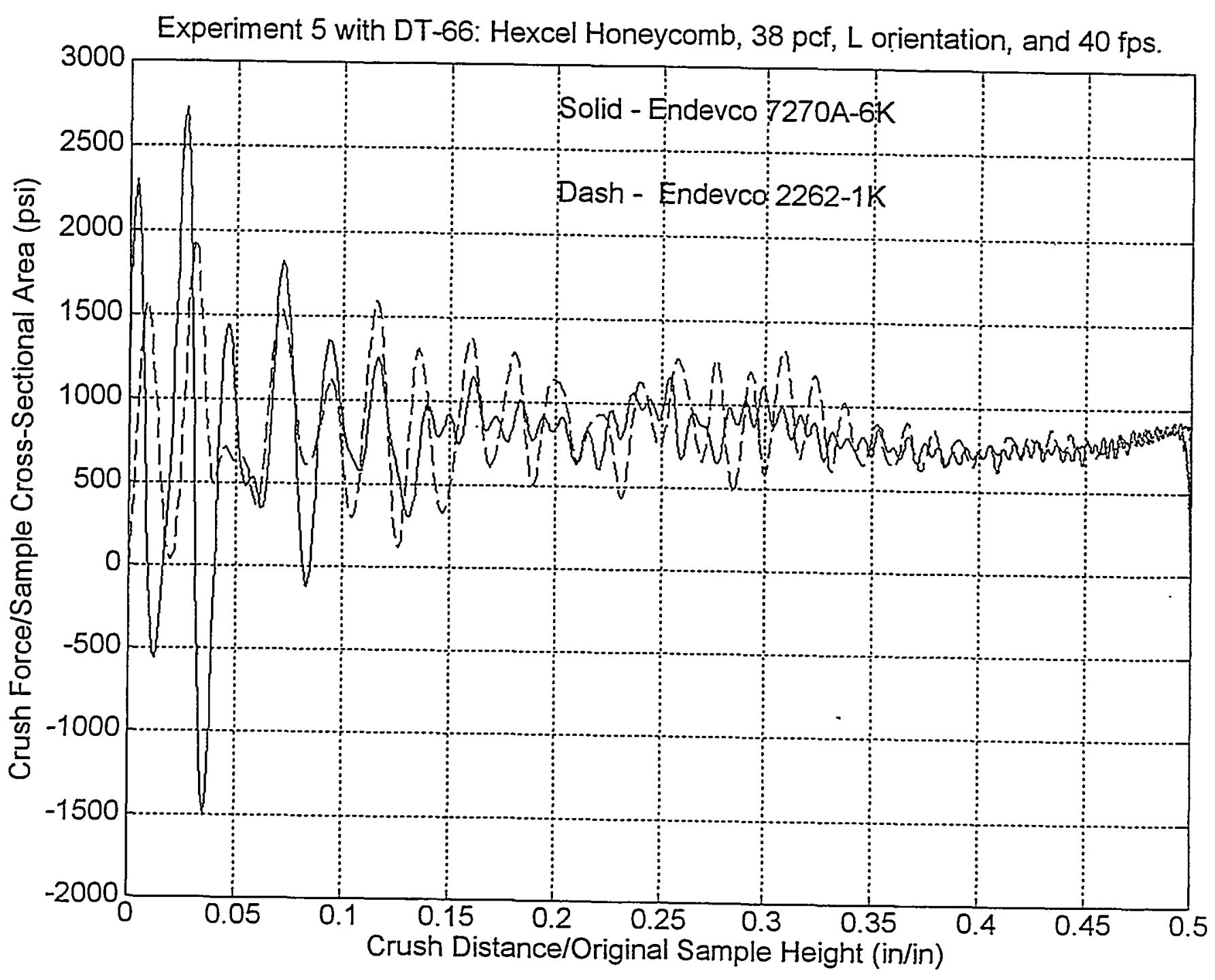




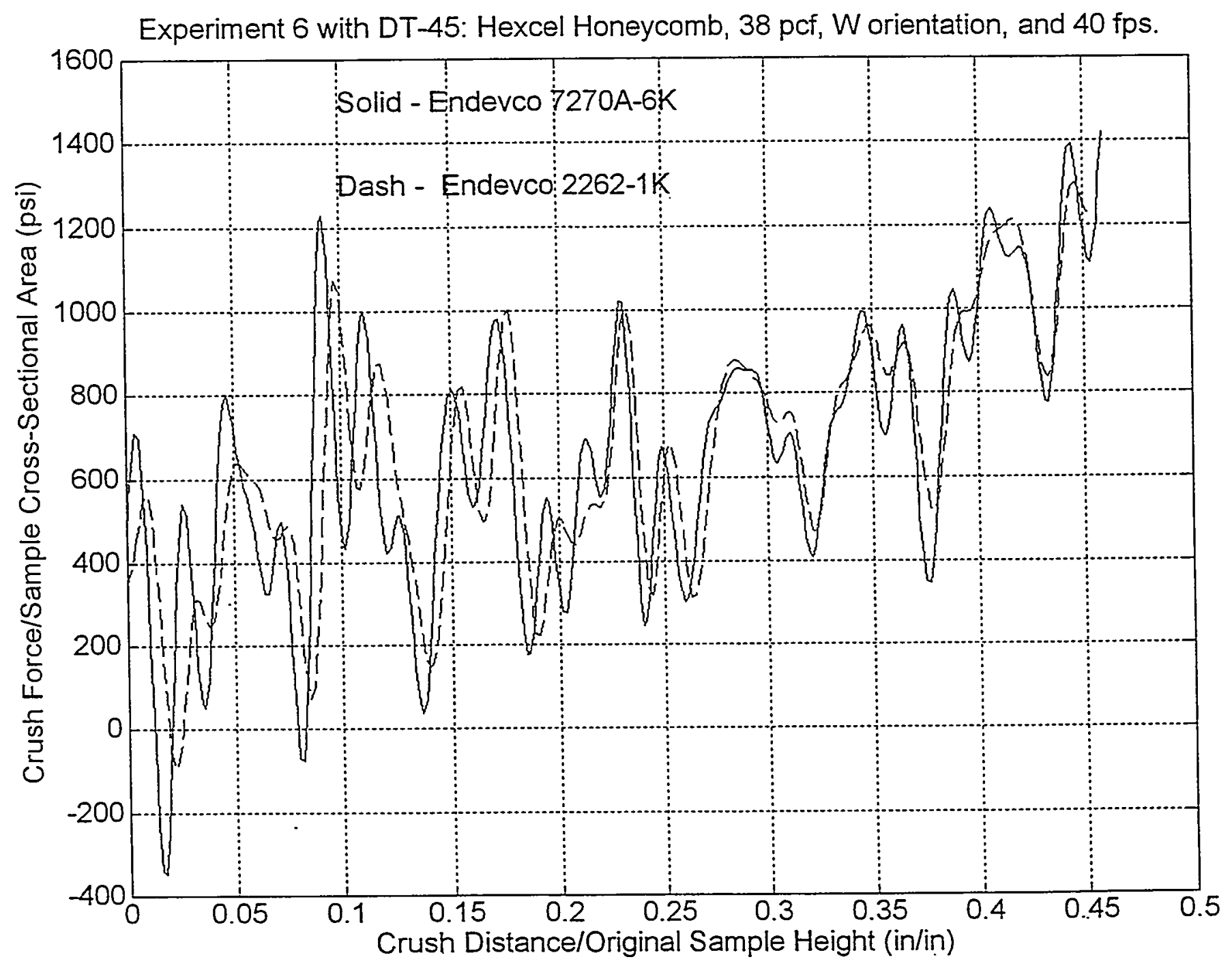




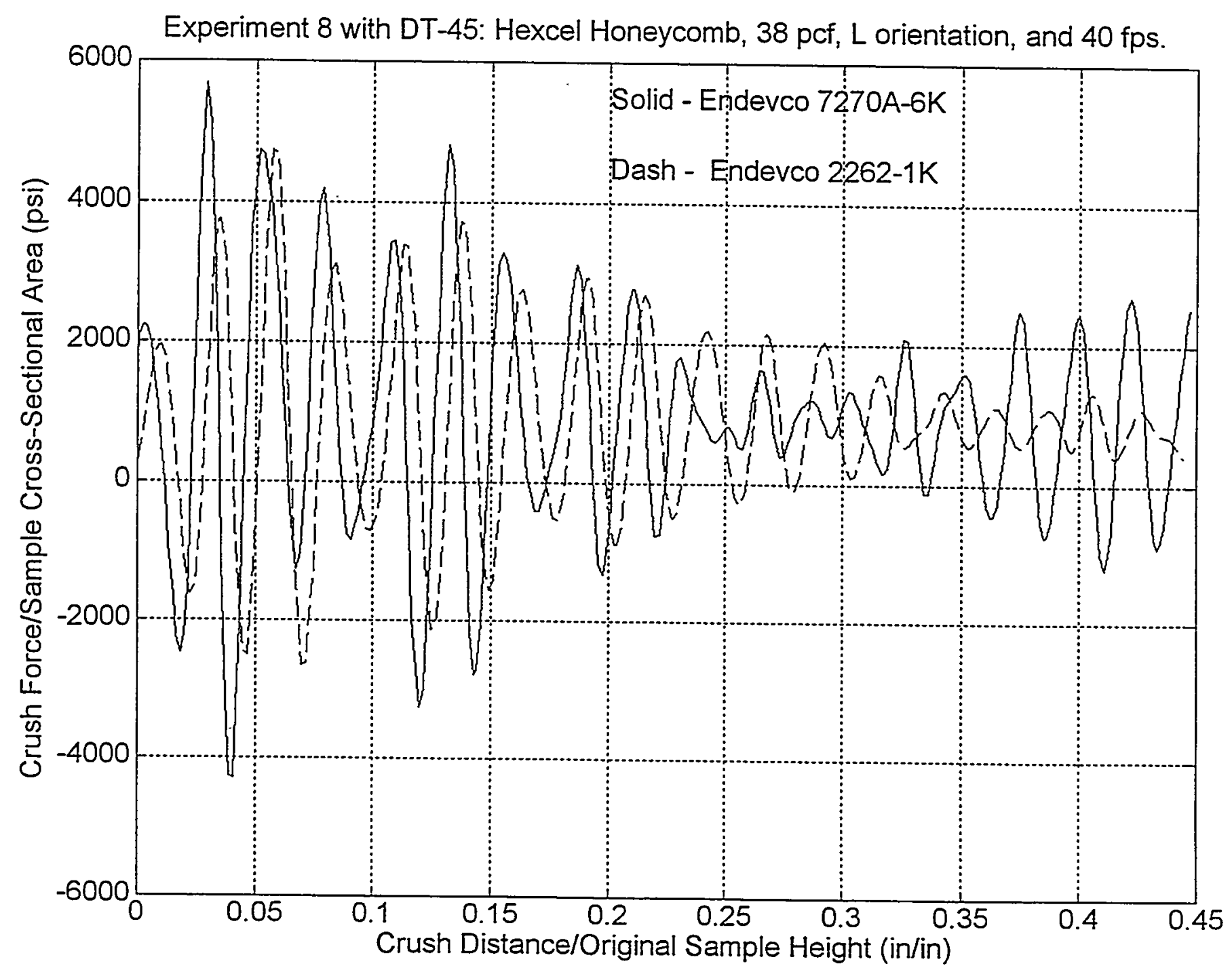




\section{Appendix C}

\section{Pictures of Crushed Honeycomb for Experiments 1997-98}




\section{f2 - 38.0 PCF Materisl}

W axis test

45 pound carriage

40.23 FPS impact velocity

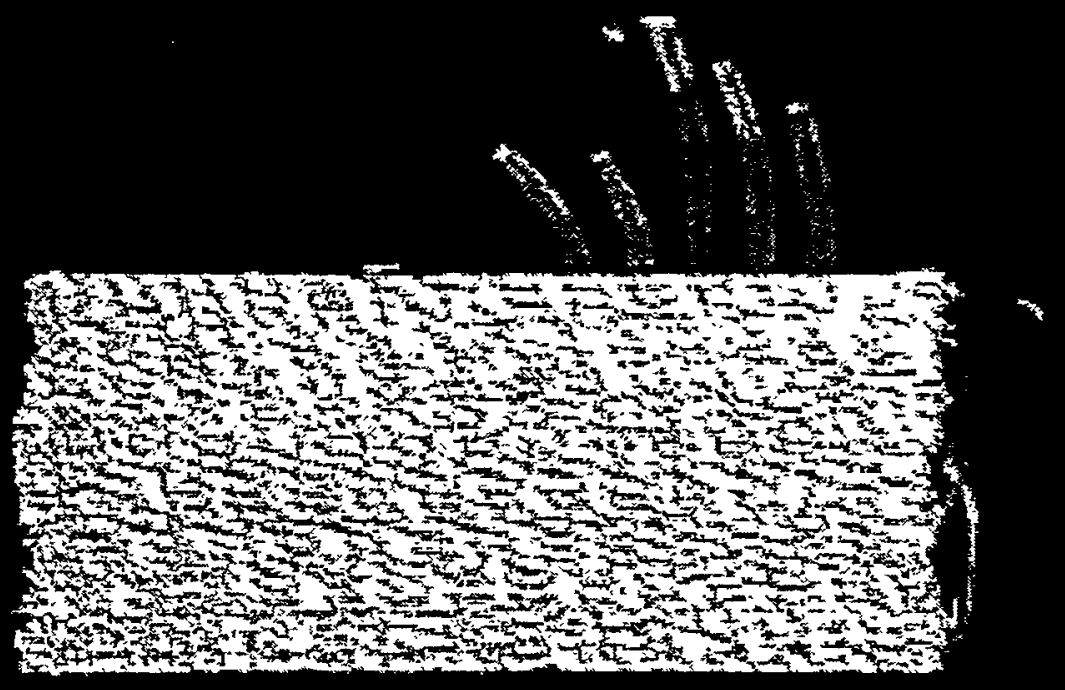

4 


\section{H2 - 38.0 PCF Matorial}

Waxis tegt

45 pound carriage

40.23 FPS impact velocily

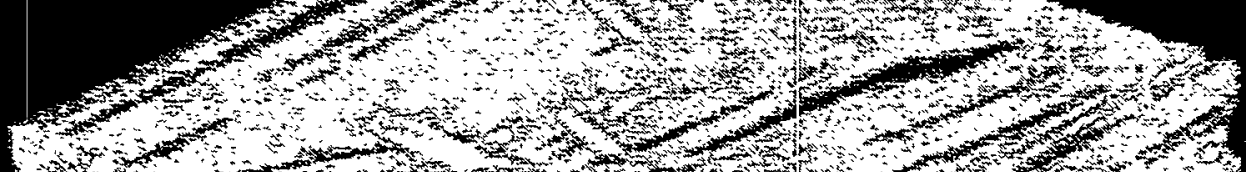

$x=\frac{1}{20}$

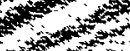

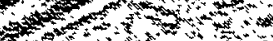
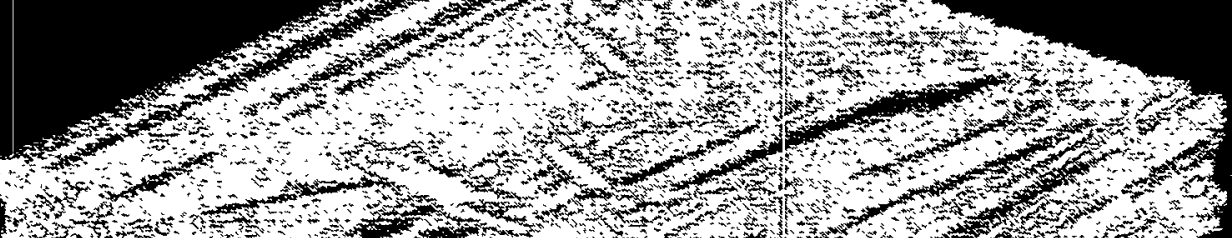

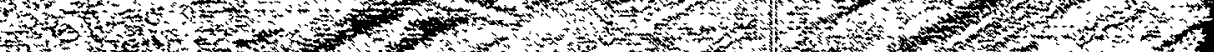
F. -

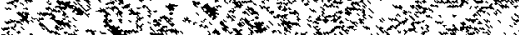

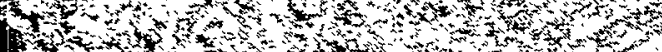
ats.

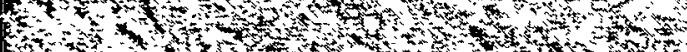

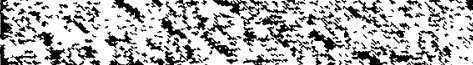

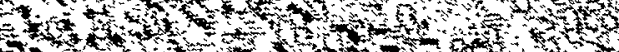

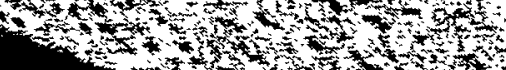

5 -

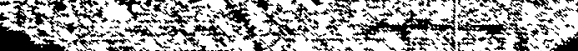

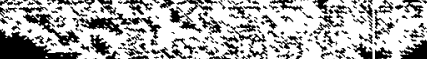

$-4=0+2,4$

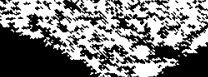




\section{\#3 -38.0 PCF Material}

L axis test

45 pound carriage

39.85 FPS impact velocity

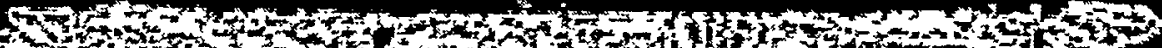

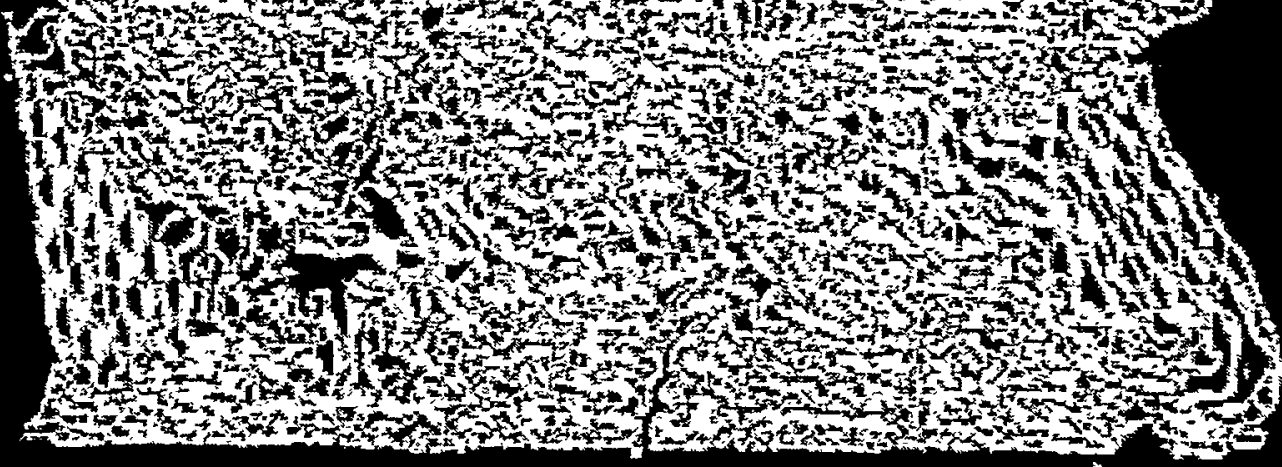

$-\infty$ 


\section{f $3-38.0 \mathrm{PCF}$ Material}

\section{L axis test}

\section{5 pound carriage \\ 39.85 FPS impact velocity}

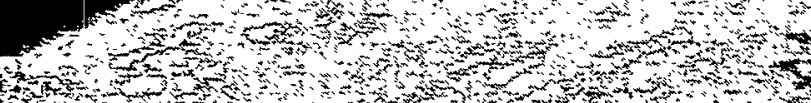
ats

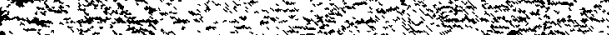

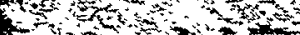

$-3 x^{2}+x^{2}+5$

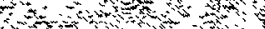

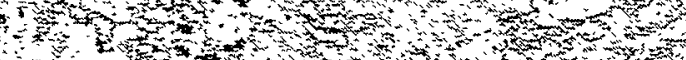

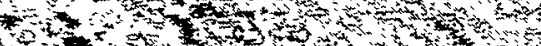

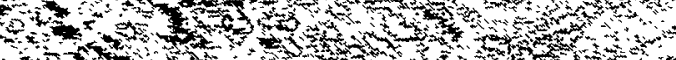

(1)

$\rightarrow+3$

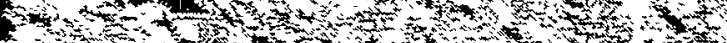

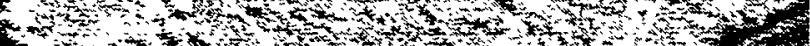

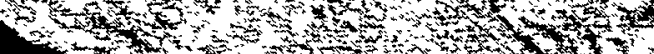

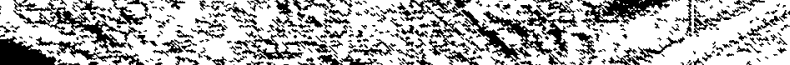

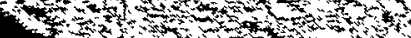

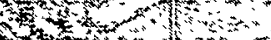

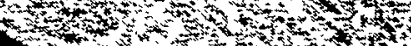

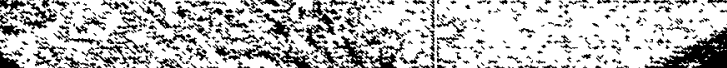

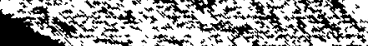

$-$

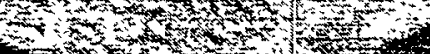

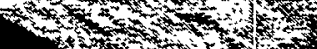

$+3+1+20^{3}$

$+2$ 


\section{ff4 -22.1 PCF Material}

\section{L axis test}

45 pound carriage

39.68 FPS impact velocity

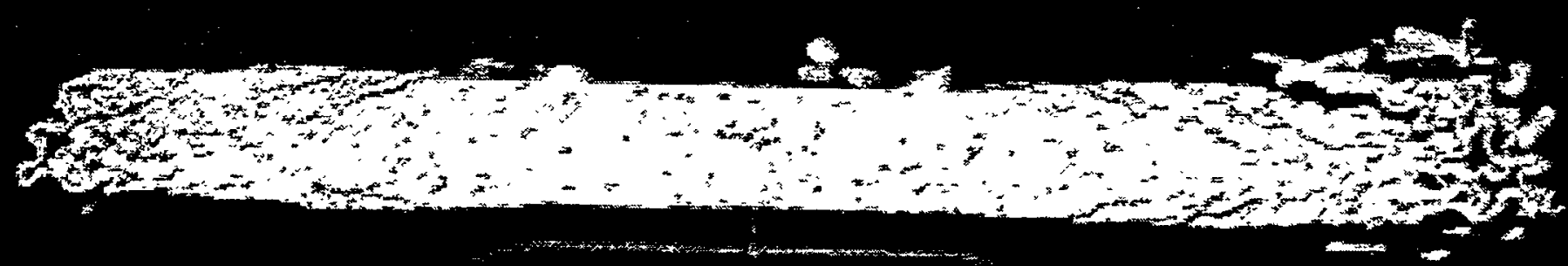




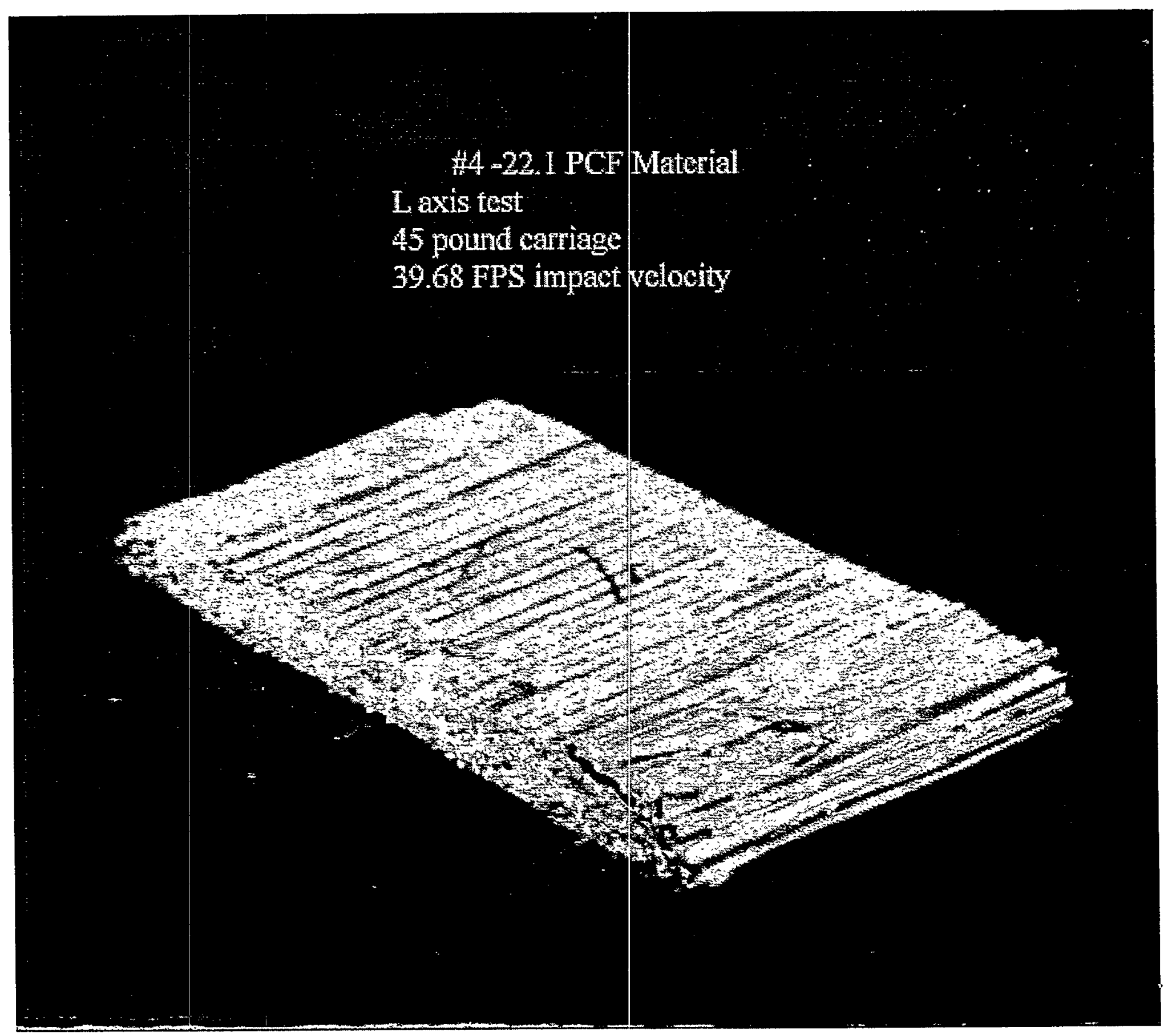




\section{\#5 -22.1 PCF Material \\ W axis test \\ 45 pound carriage \\ 39.63 FPS impact velocity}

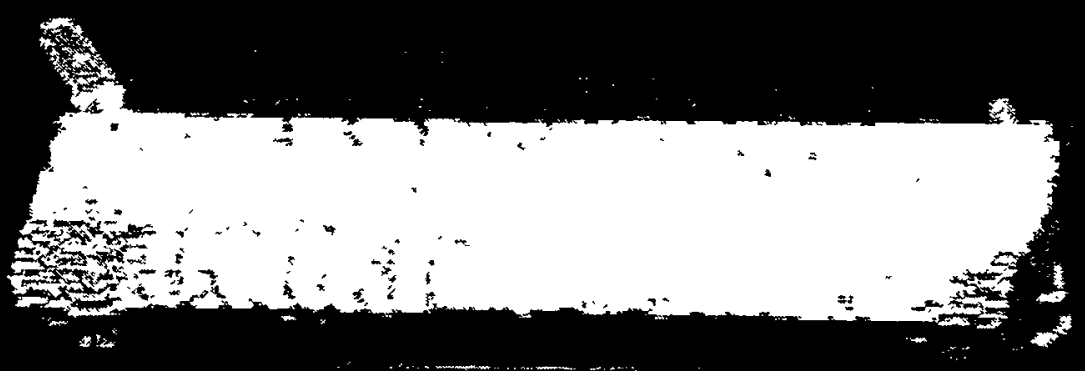




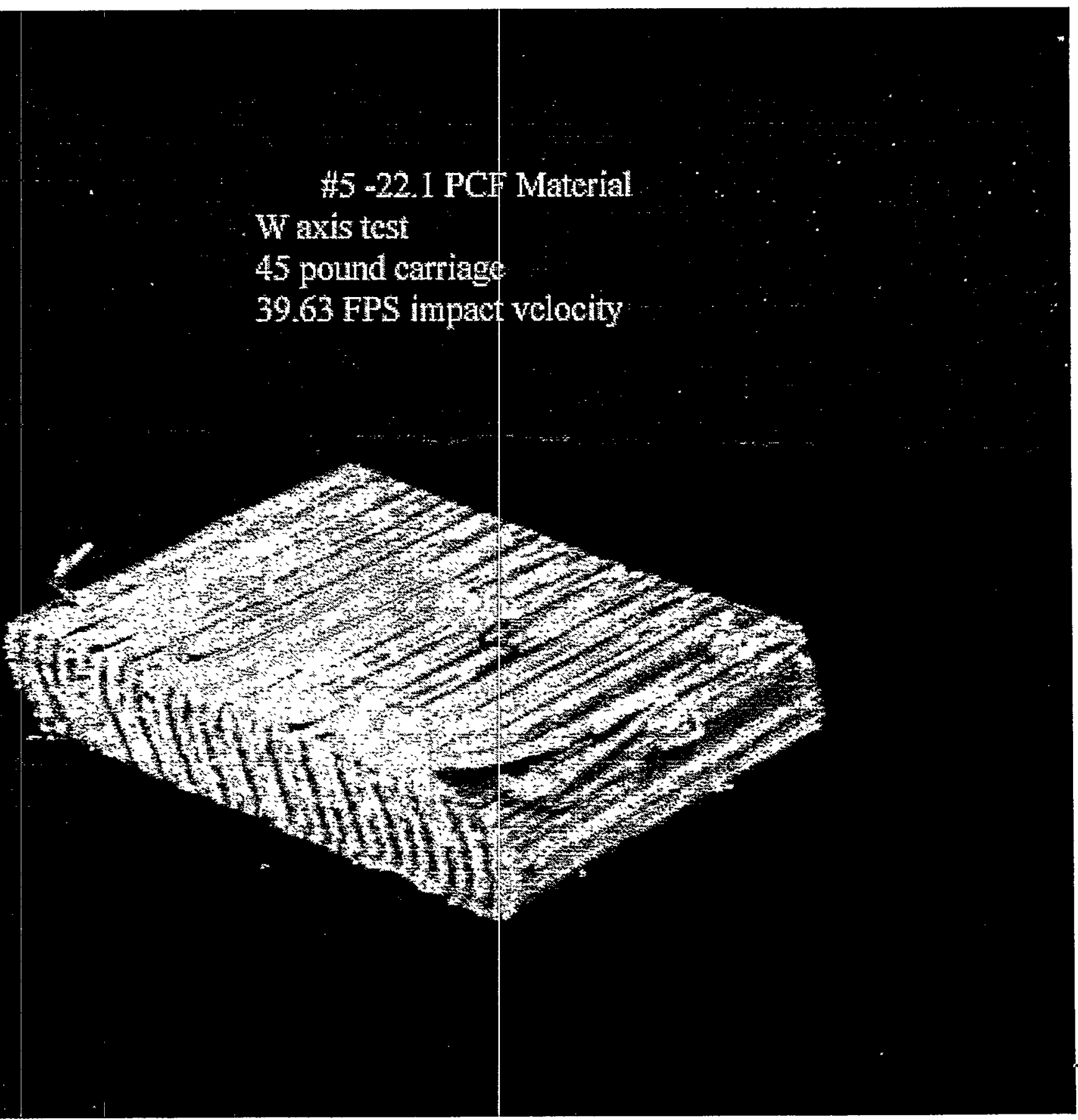




\section{\#25 - 38.0 PCF Material \\ $\mathrm{T}$ axis test \\ 268 pound carriage \\ 57.70 FPS impact velocity}

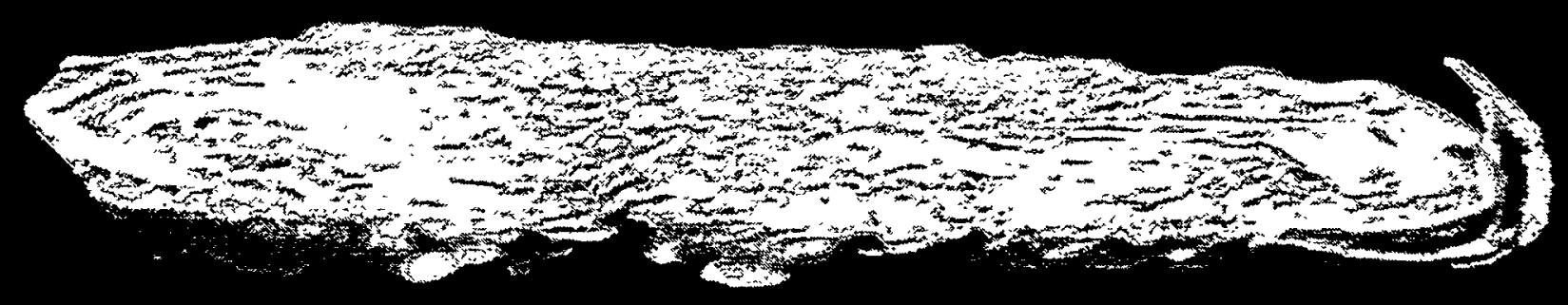




\title{
\#25 - 38.0 PCF Material
}

\author{
T axis test \\ 268 pound carriage \\ 57.70 FPS impact velocity
}

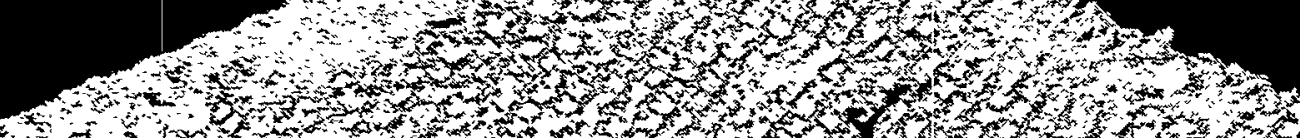

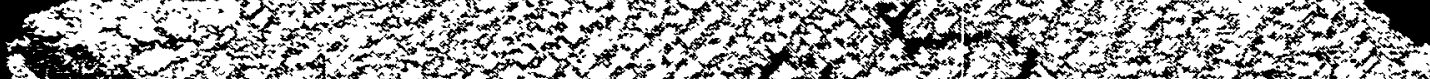

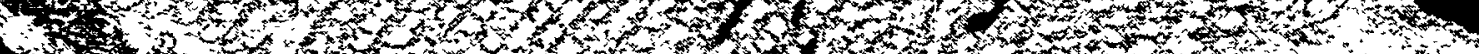

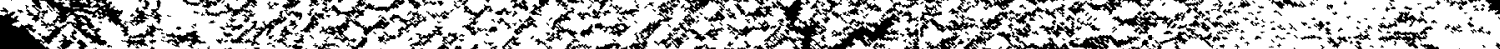

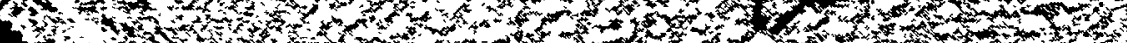

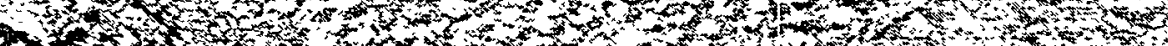

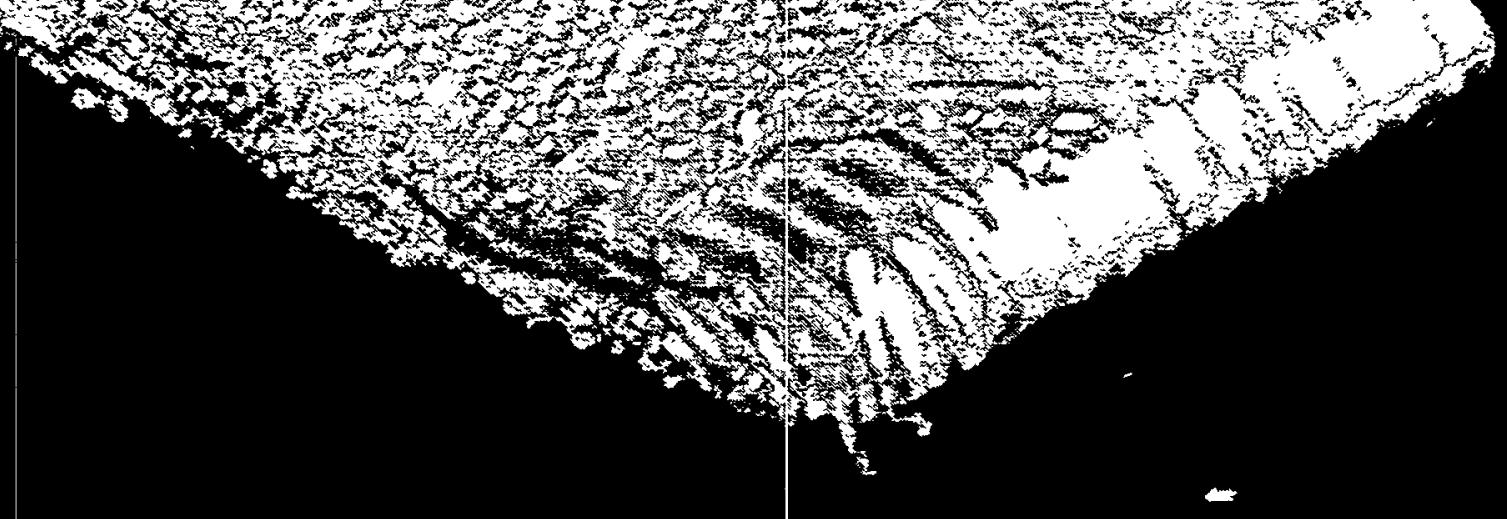




\section{\#26 - 22.1 PCF Material \\ $T$ axis test \\ 168 pound carriage about 90 FPS impact velocity}

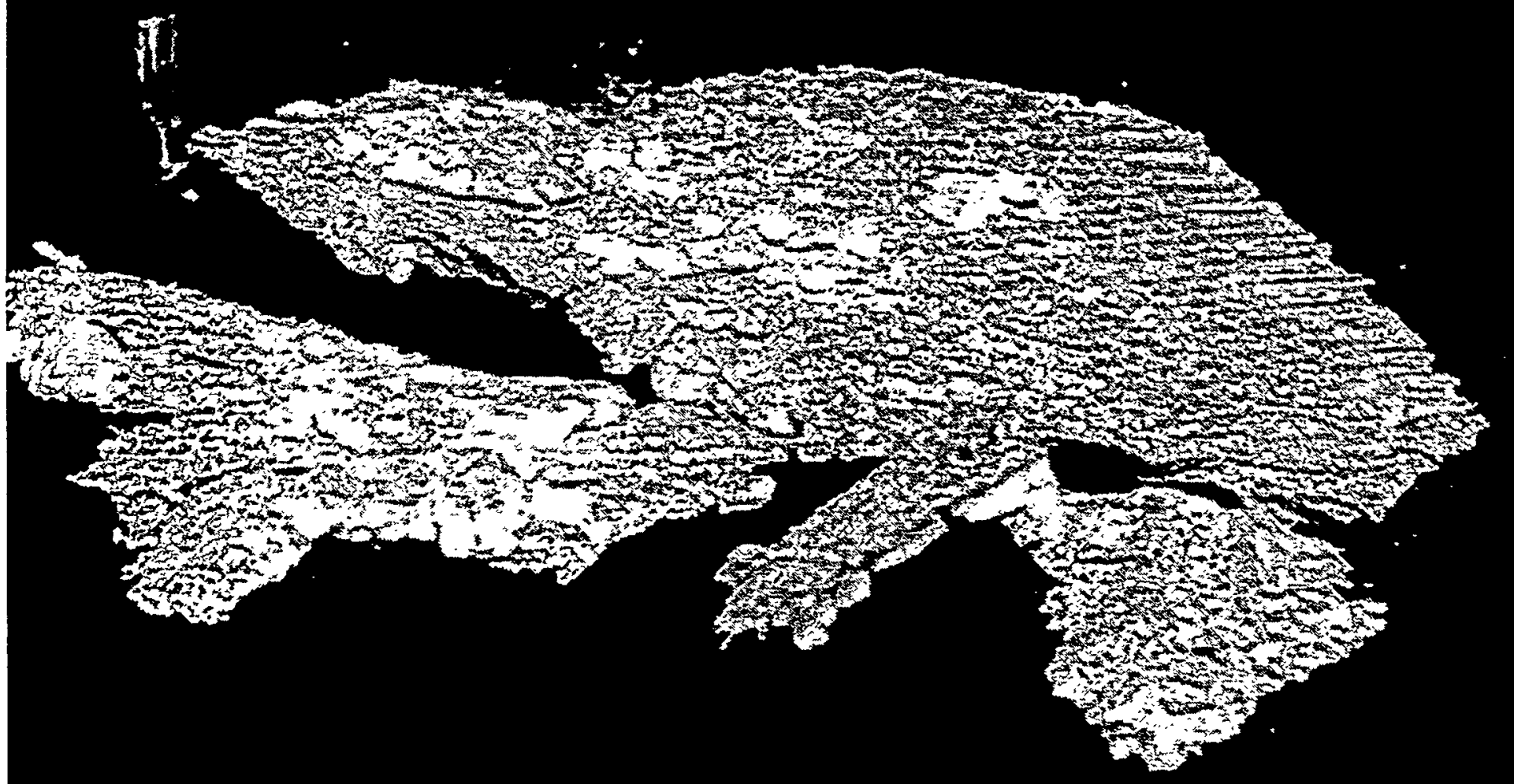




\section{\#27 - 22.1 PCF Material}

$\mathrm{T}$ axis test

168 pound carriage 50.00 FPS impact velocity

(1)

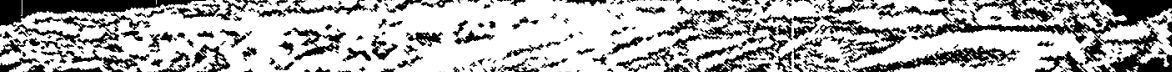

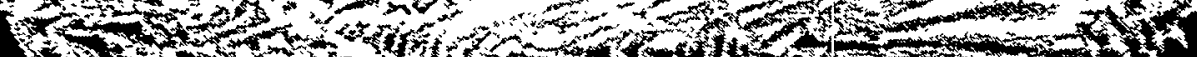

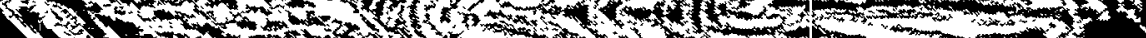

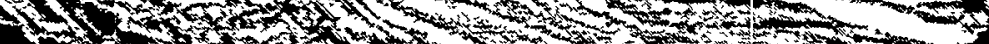

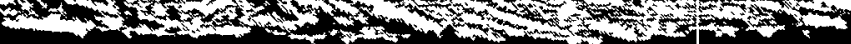




\section{\#27 - 22.1 PCF Material \\ $T$ axis test \\ 168 pound carriage \\ 50.00 FPS impact velocity}

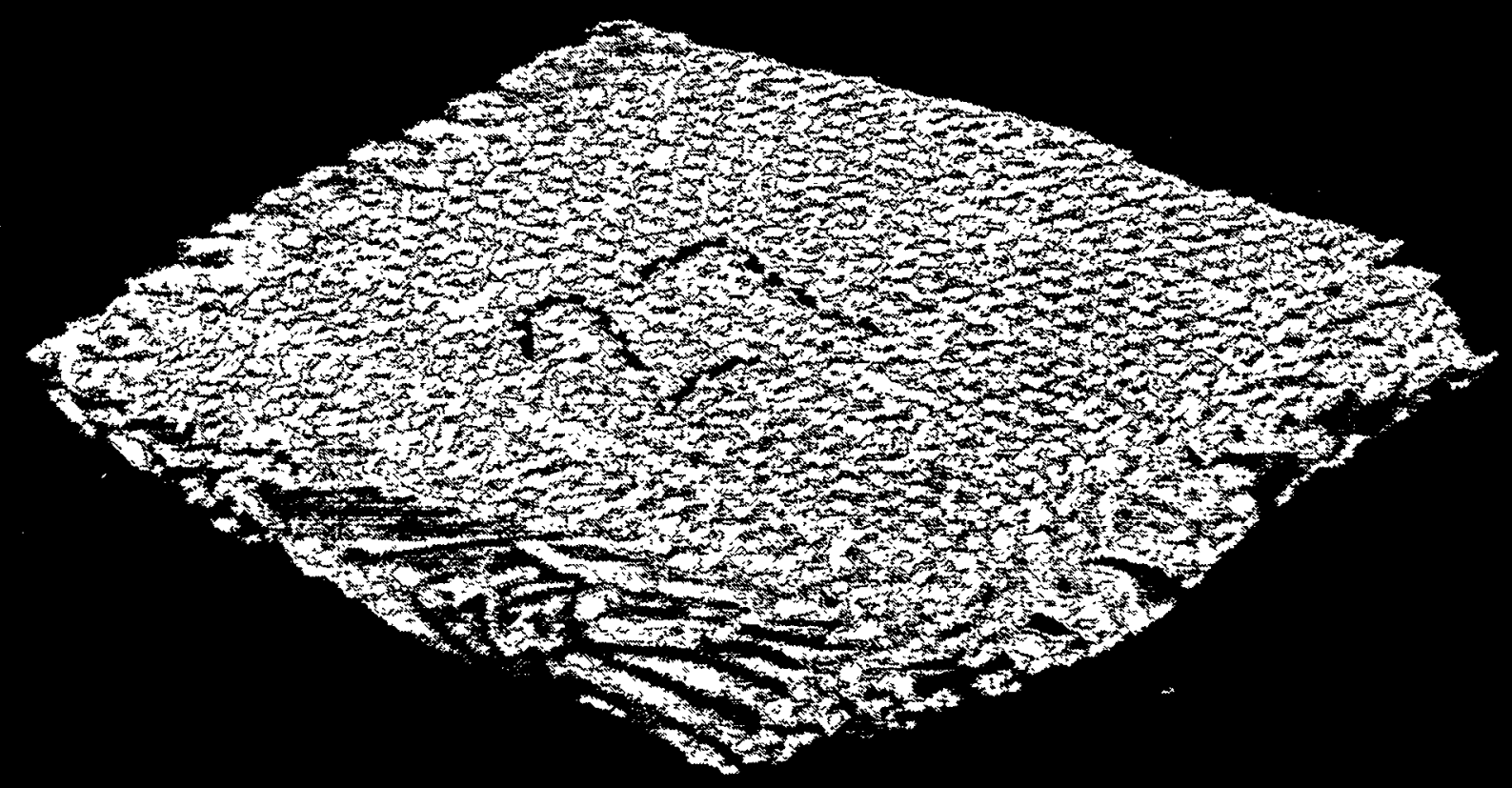




\section{\#28 - 38.0 PCF Material}

T axis test

168 pound carriage

53.12 FPS impact velocity

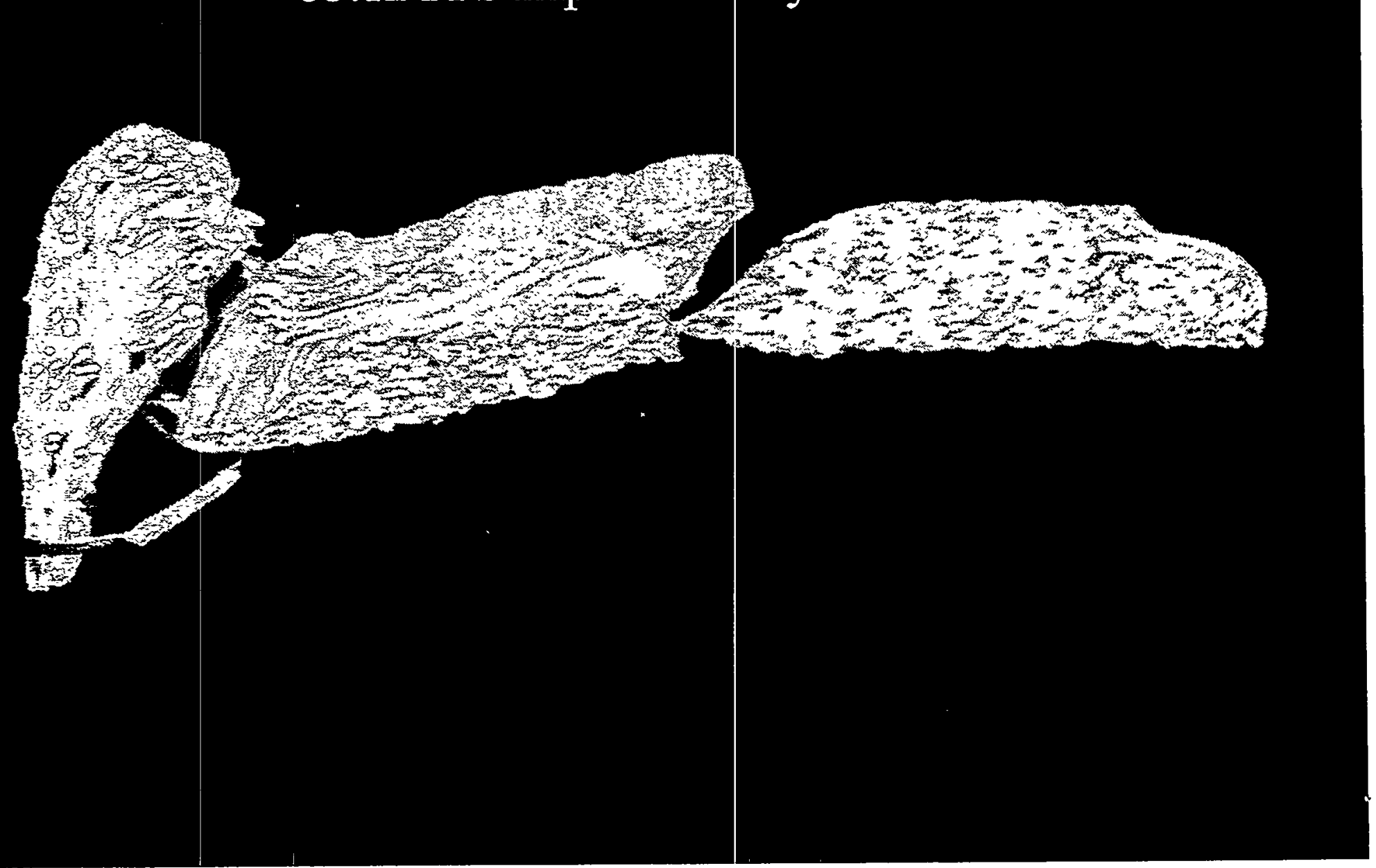




\title{
\#28 - 38.0 PCF Material
}

\author{
$\mathrm{T}$ axis test \\ 168 pound carriage \\ 53.12 FPS impact velocity
}

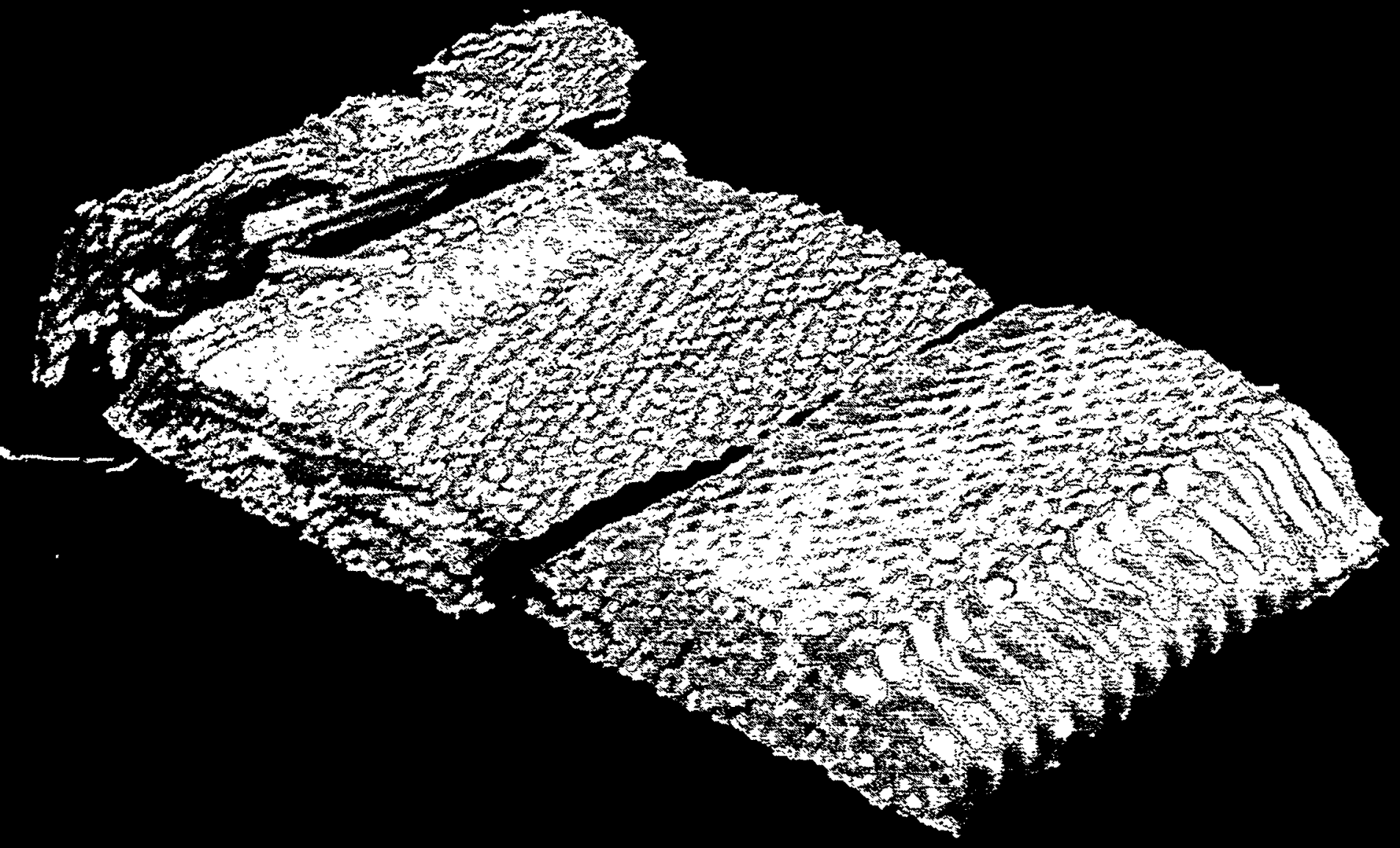



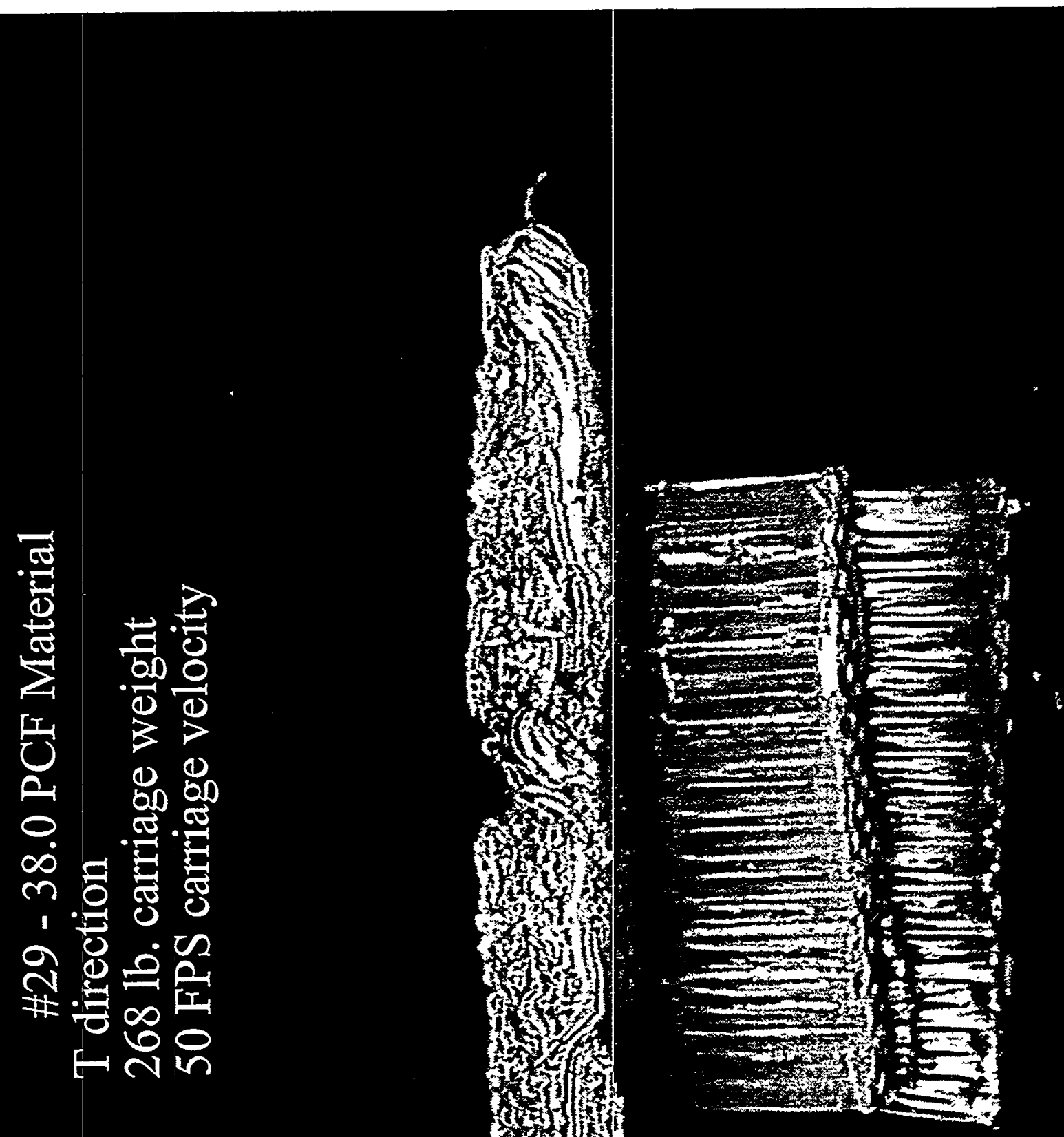

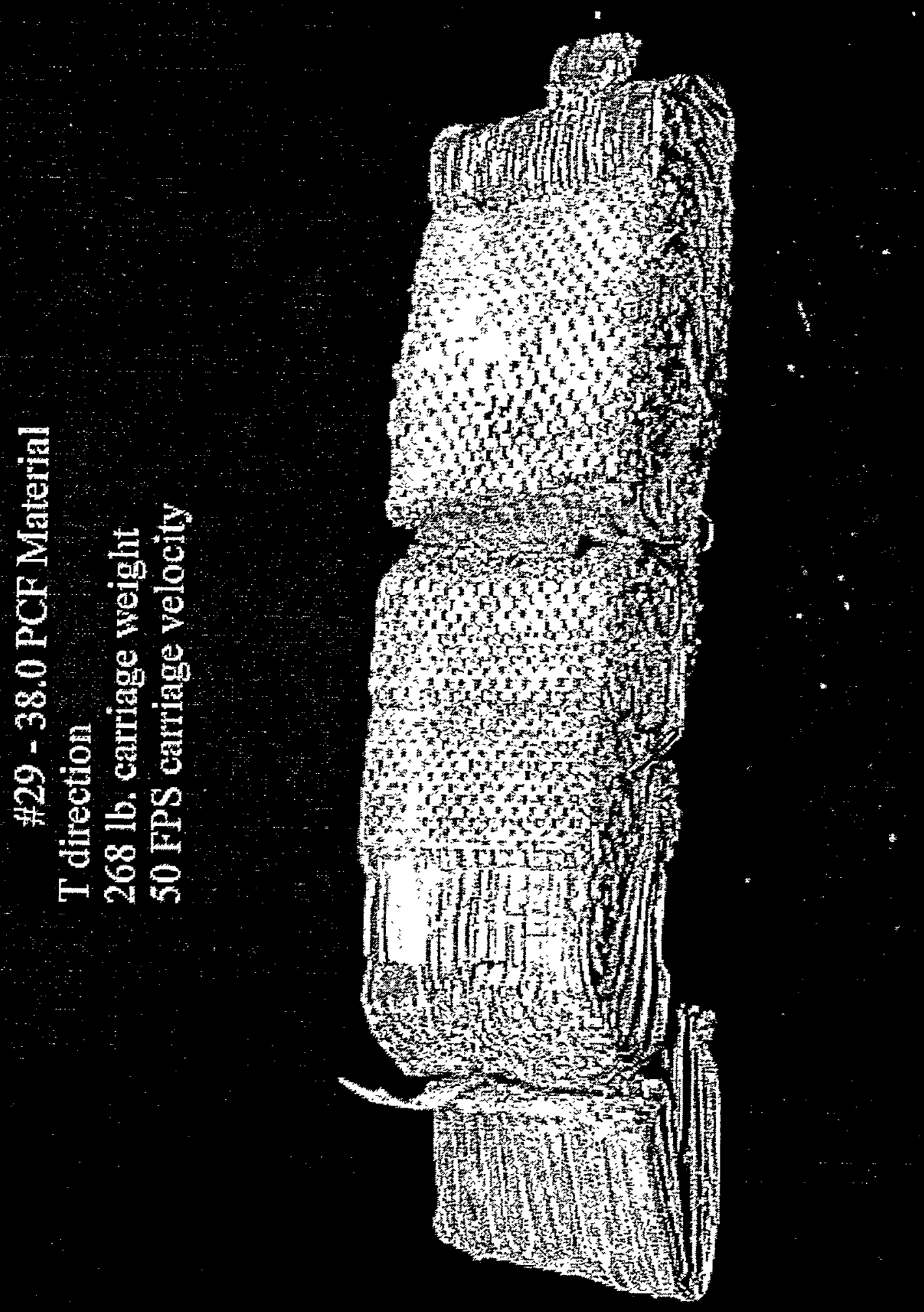


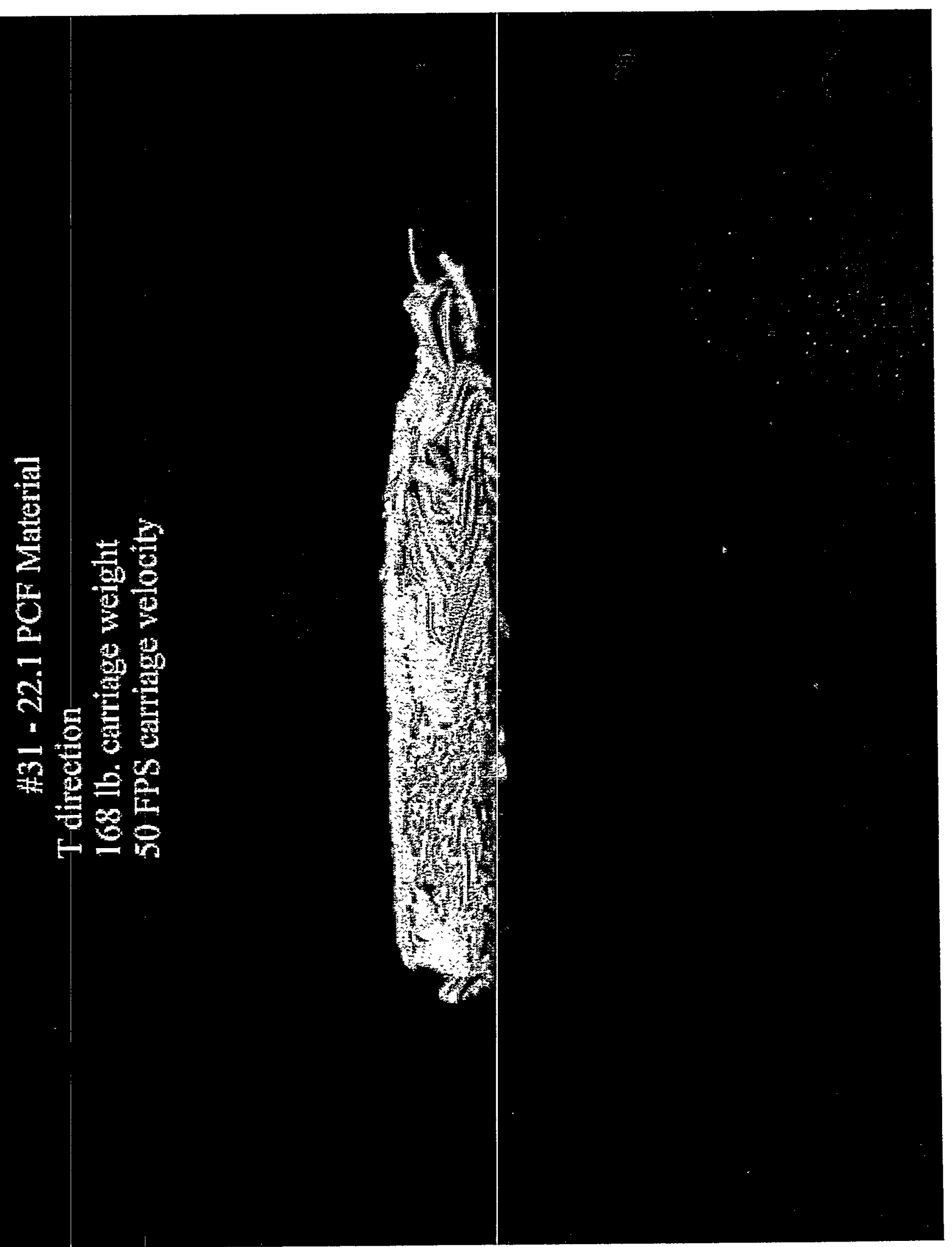



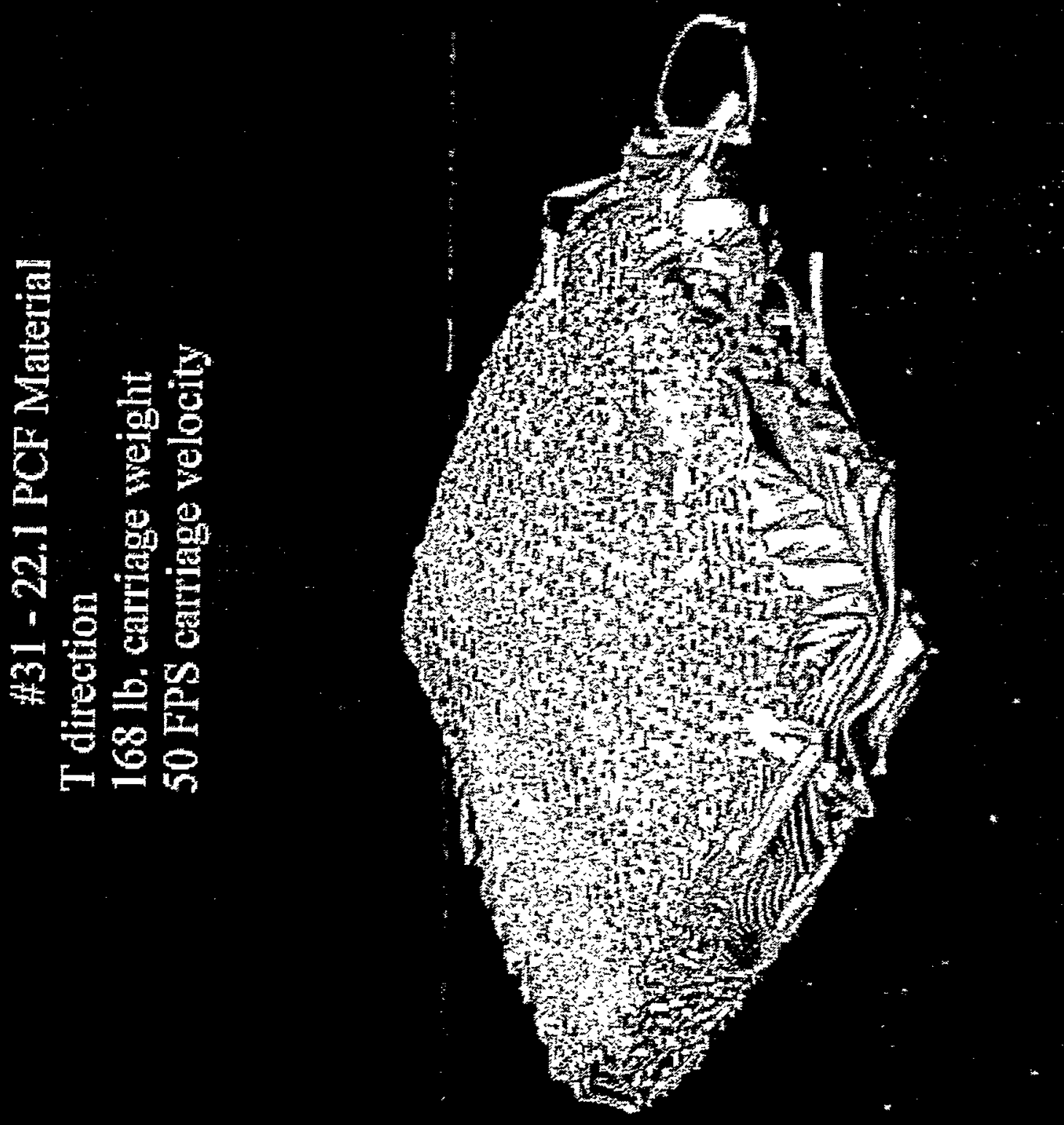


\section{$\mathrm{T}$ axis test}

\section{8 pound carriage}

51.13 FPS impact velocity

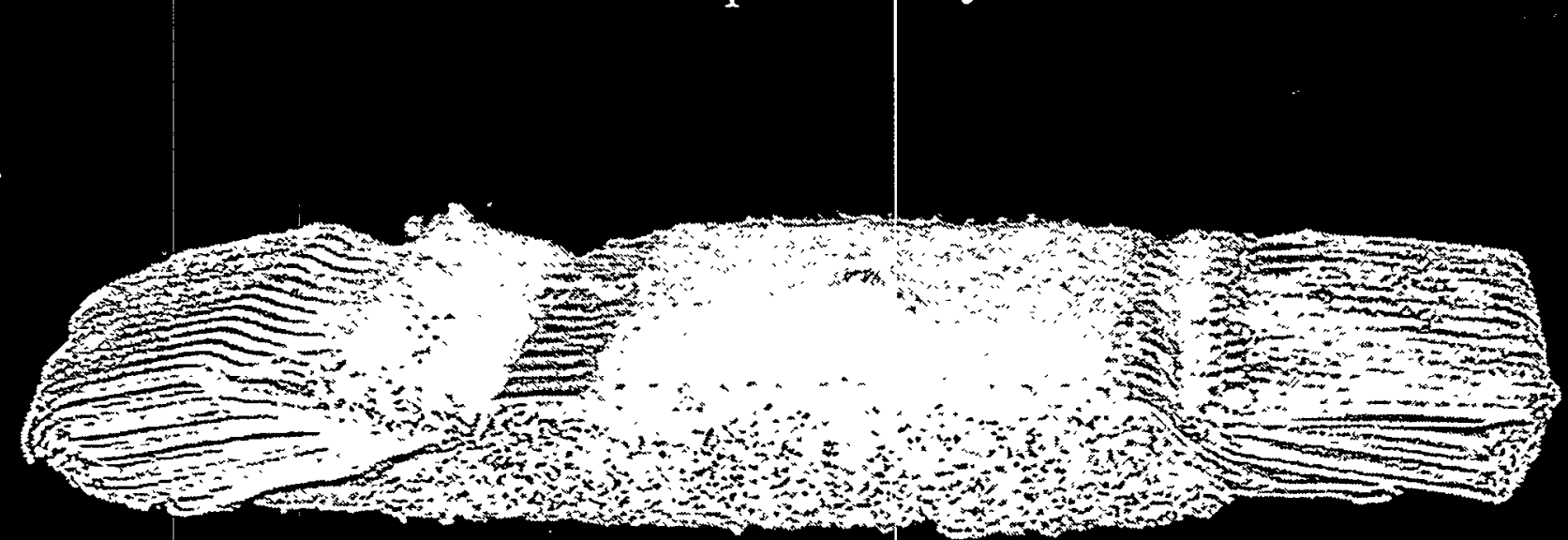




\section{\#37 - 38.0 PCF Material - Alcore \\ T axis test \\ 268 pound carriage \\ 51.13 FPS impact velocity}

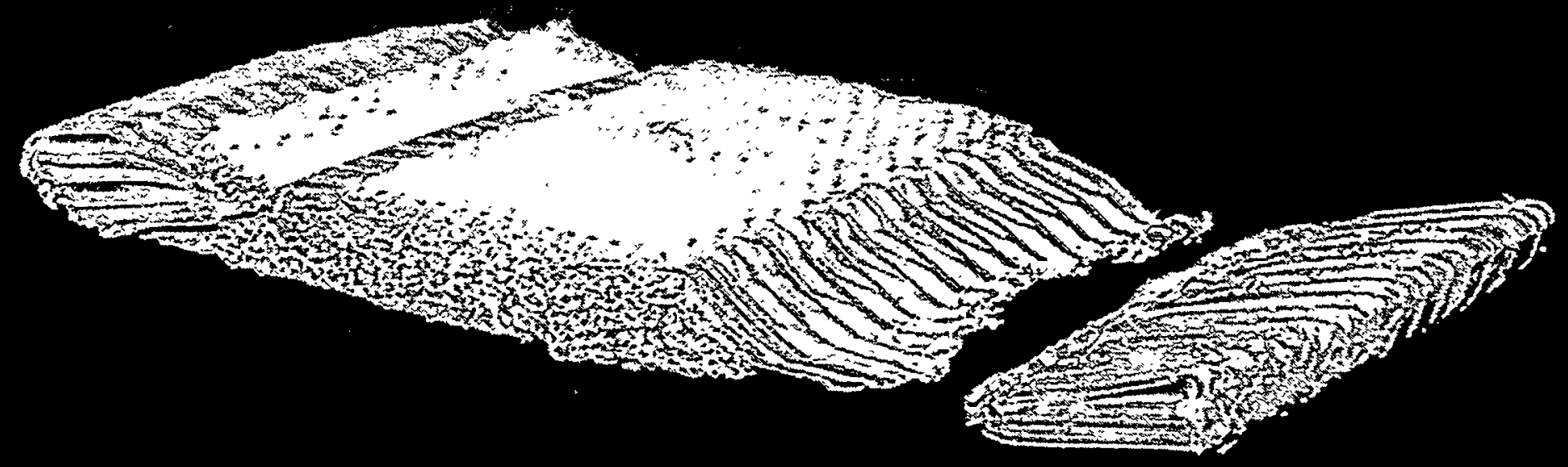




\section{Appendix $1 \mathrm{D}$}

\section{Pictures of Crushed Honeycomb for Experiments 1999}




\section{$4 / 6 / 99$ - $\# 3$ - 38.0 PCF Material W Axis Test 45 pound carriage 39.66 FPS impact velocity}

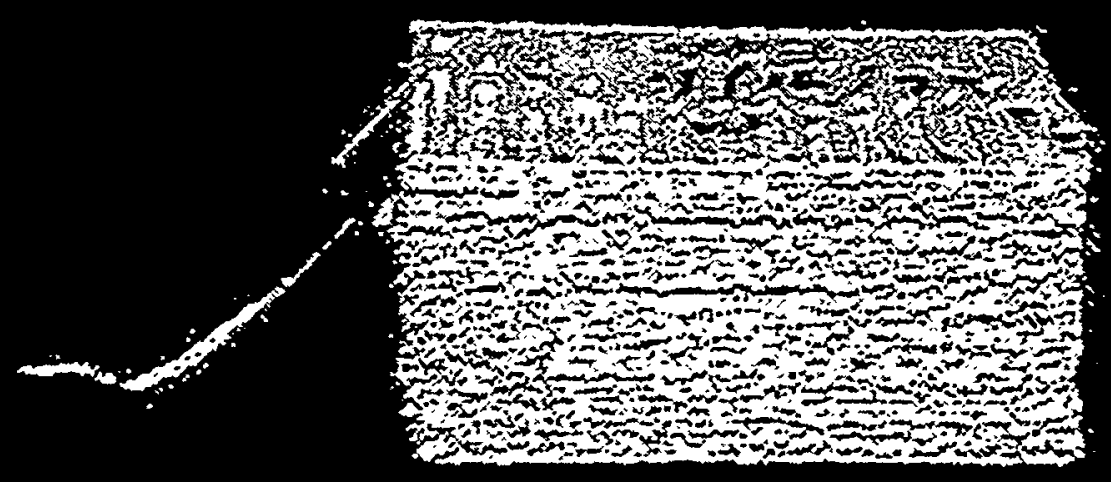




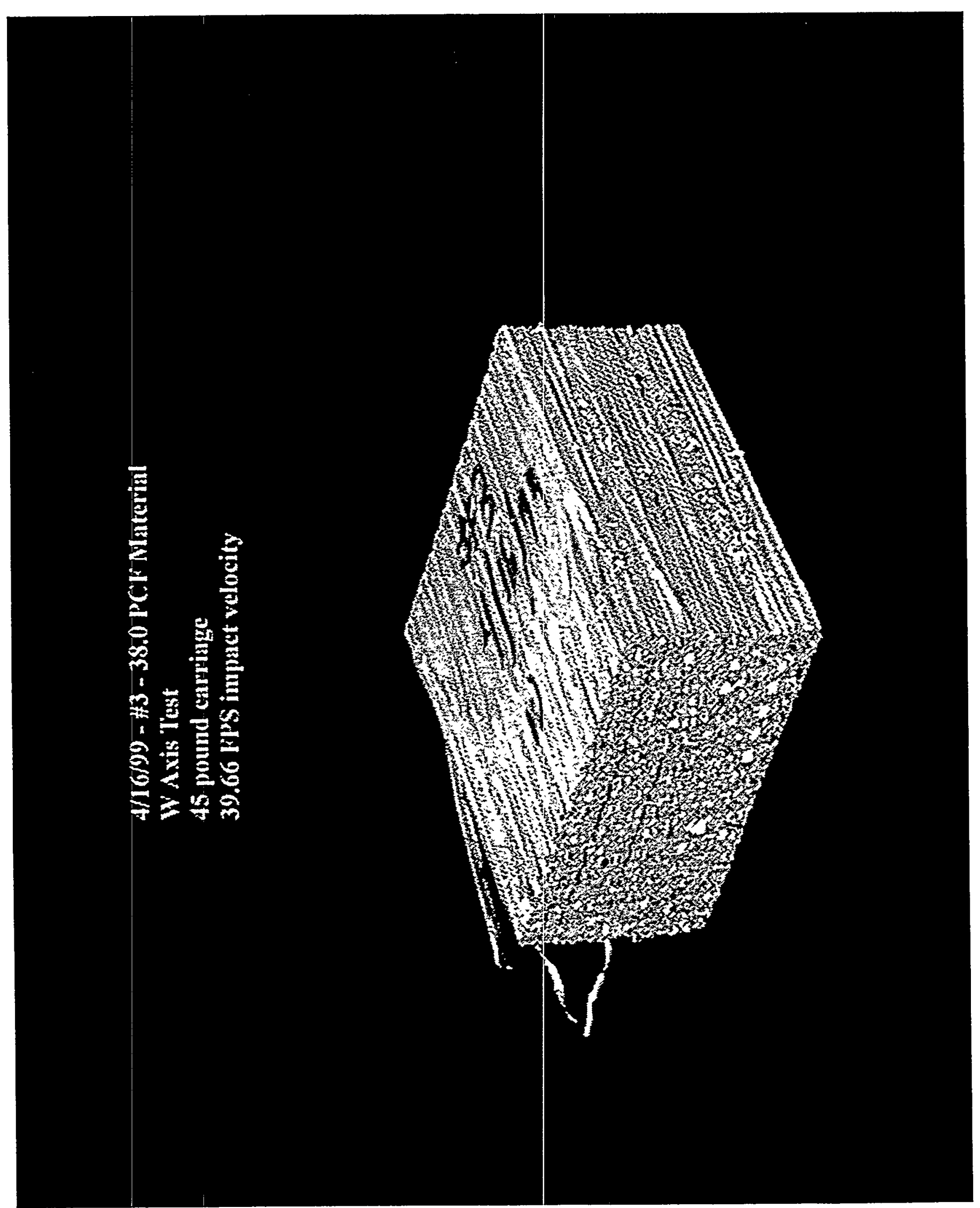



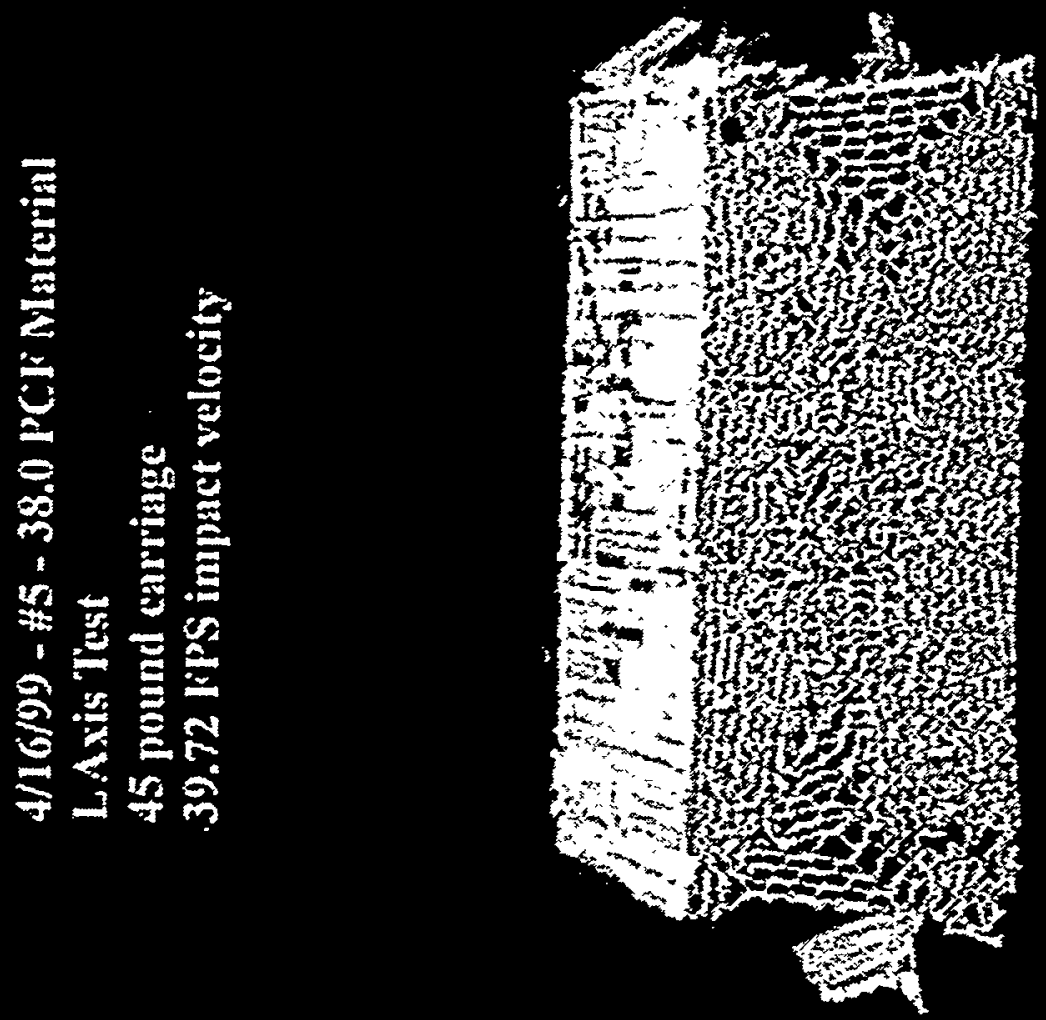


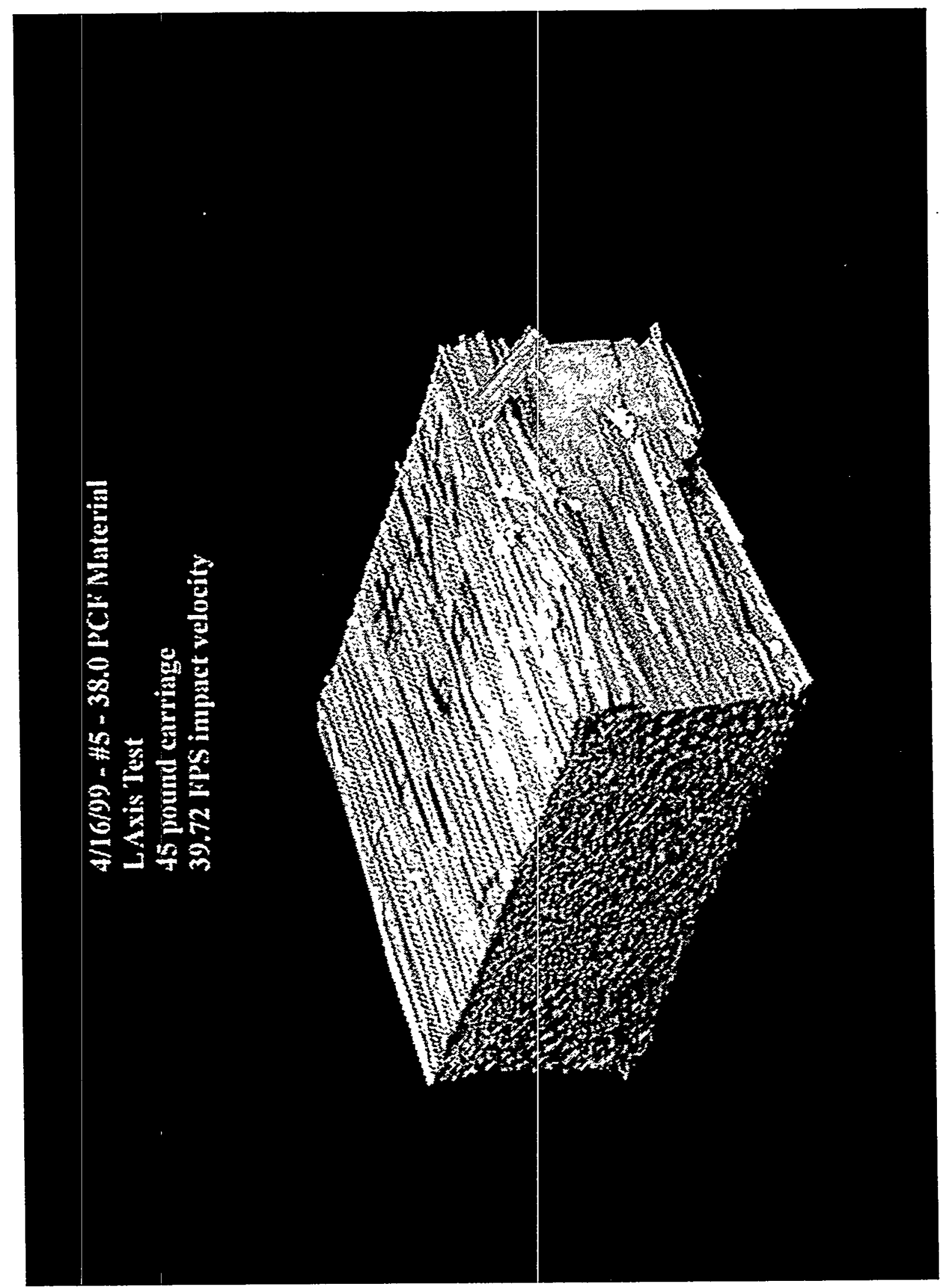



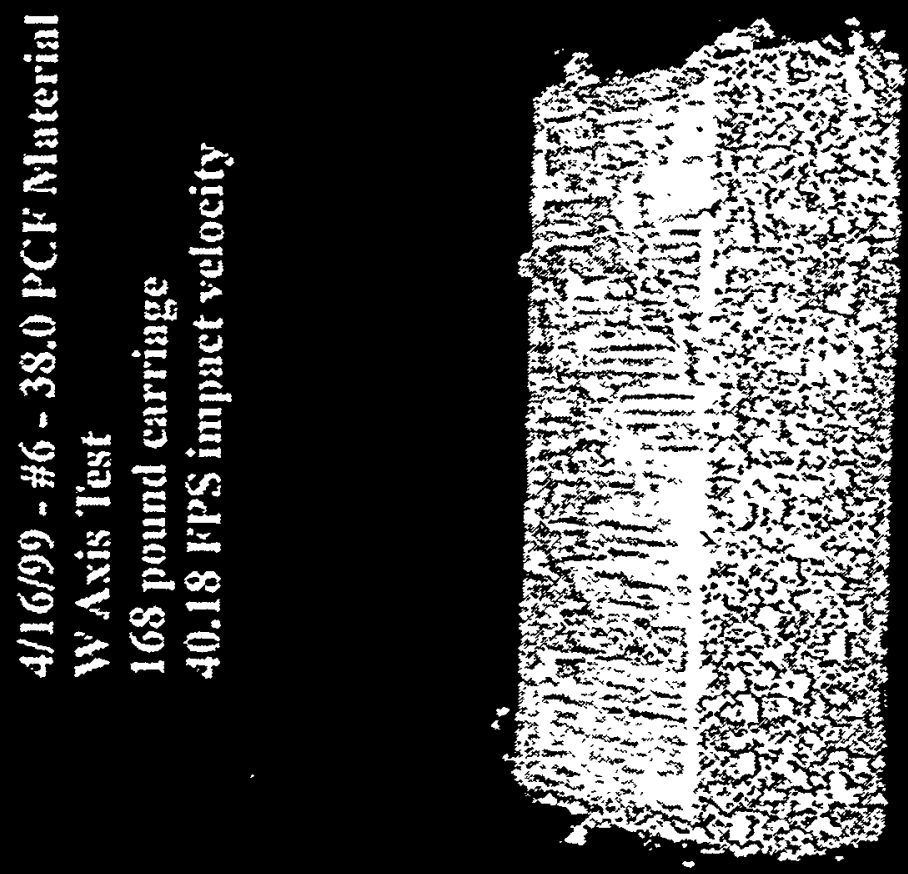

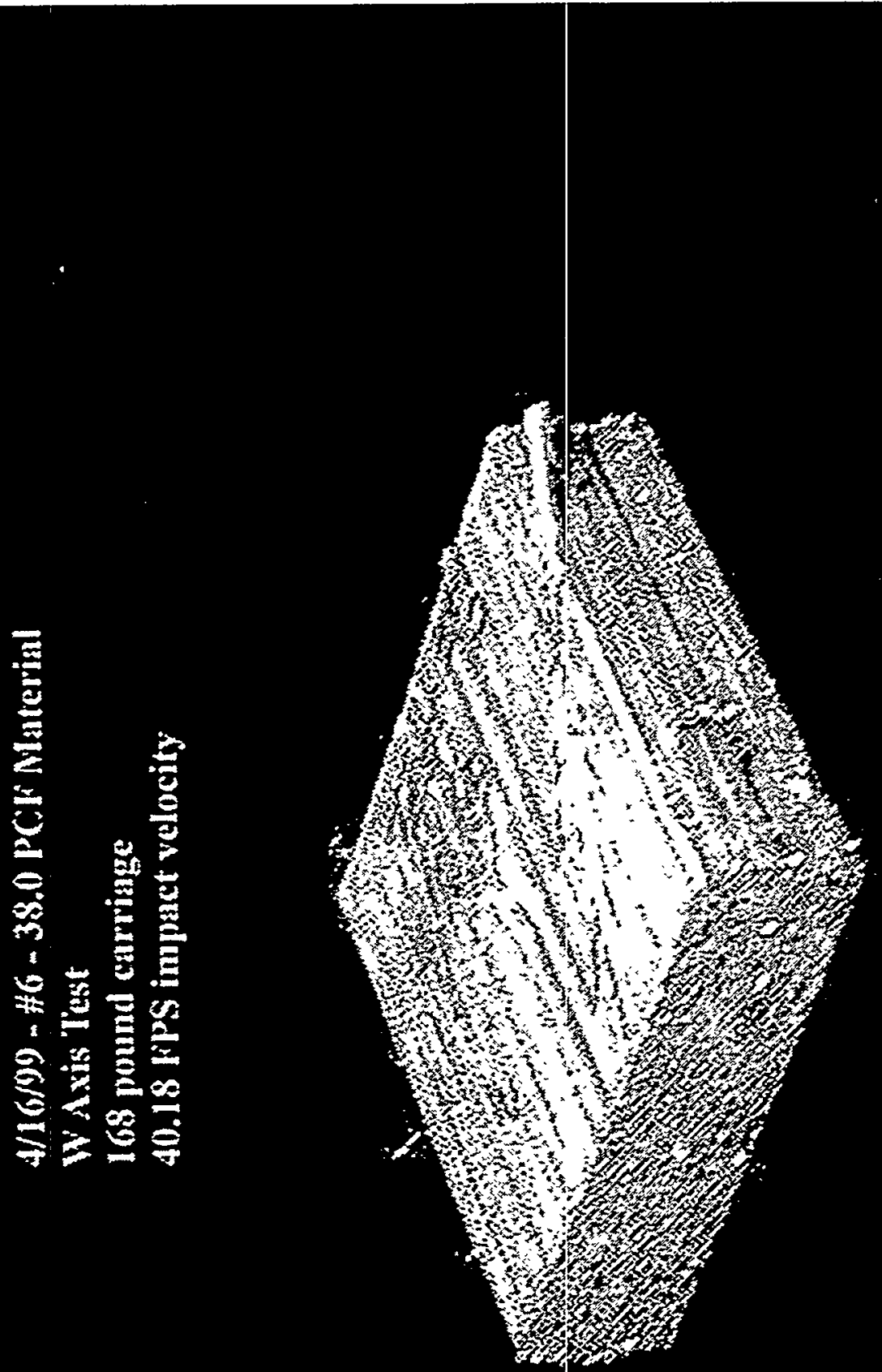

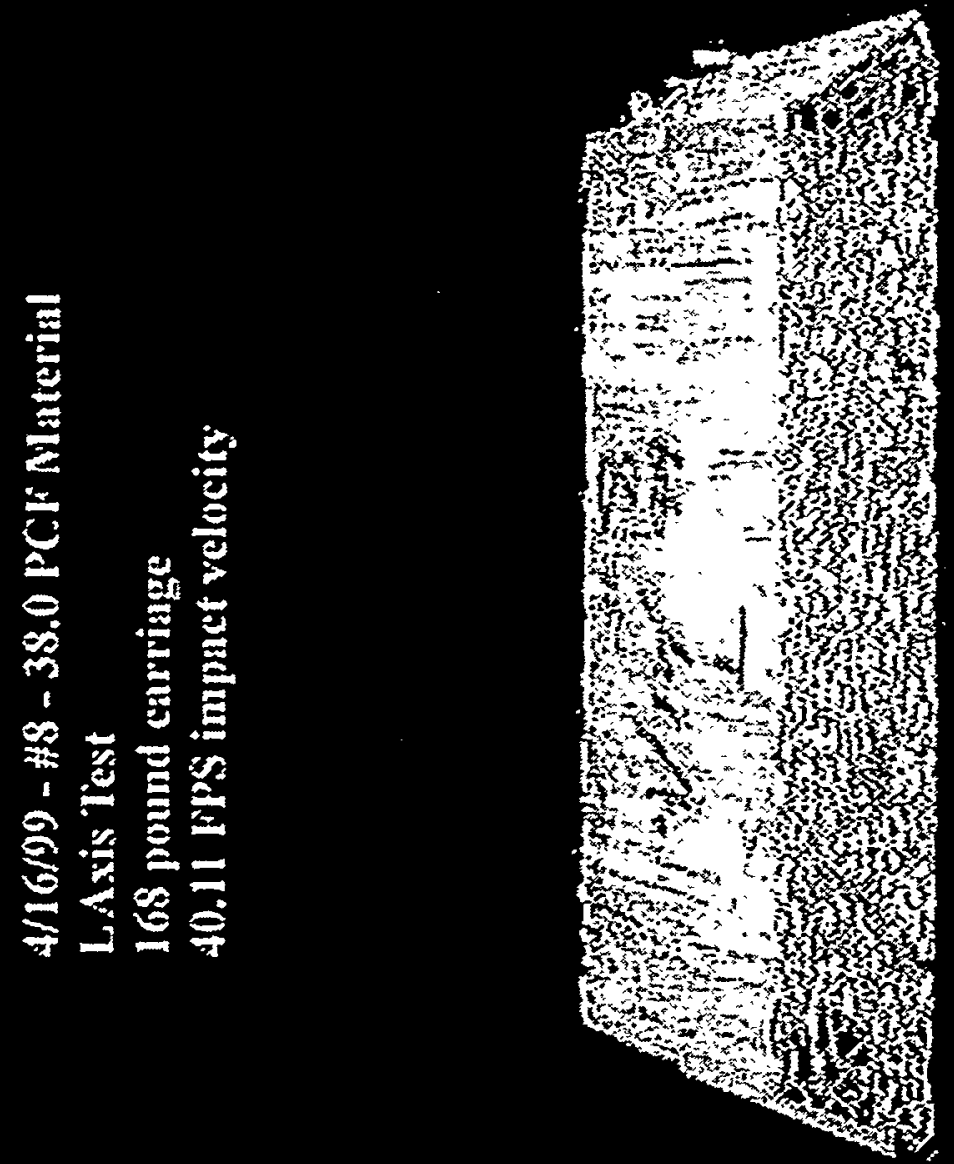


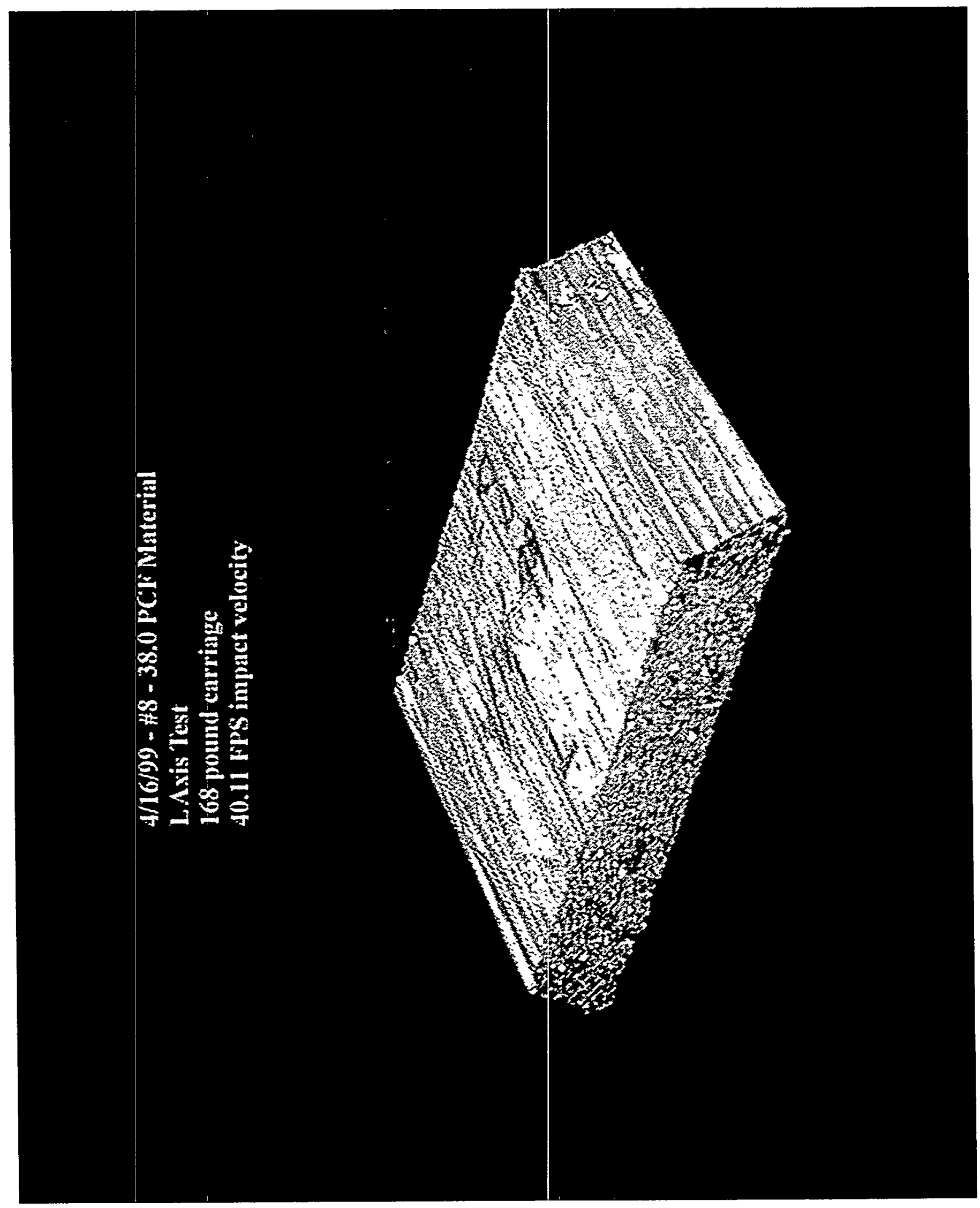




\section{Appendix E}

Raw Accelerometer Data Measured on the Drop Table Carriage and the Reaction Mass (1997-98) 


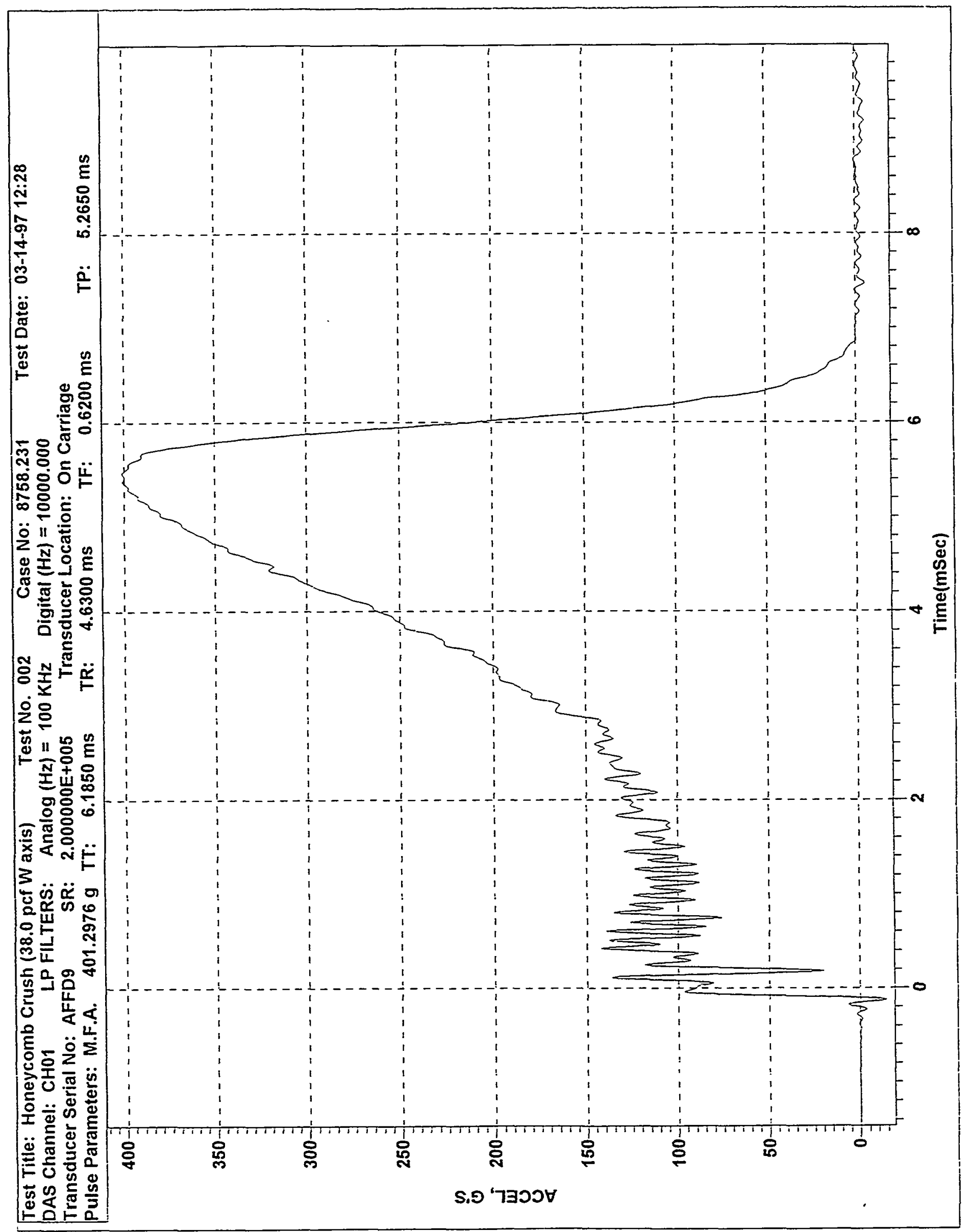




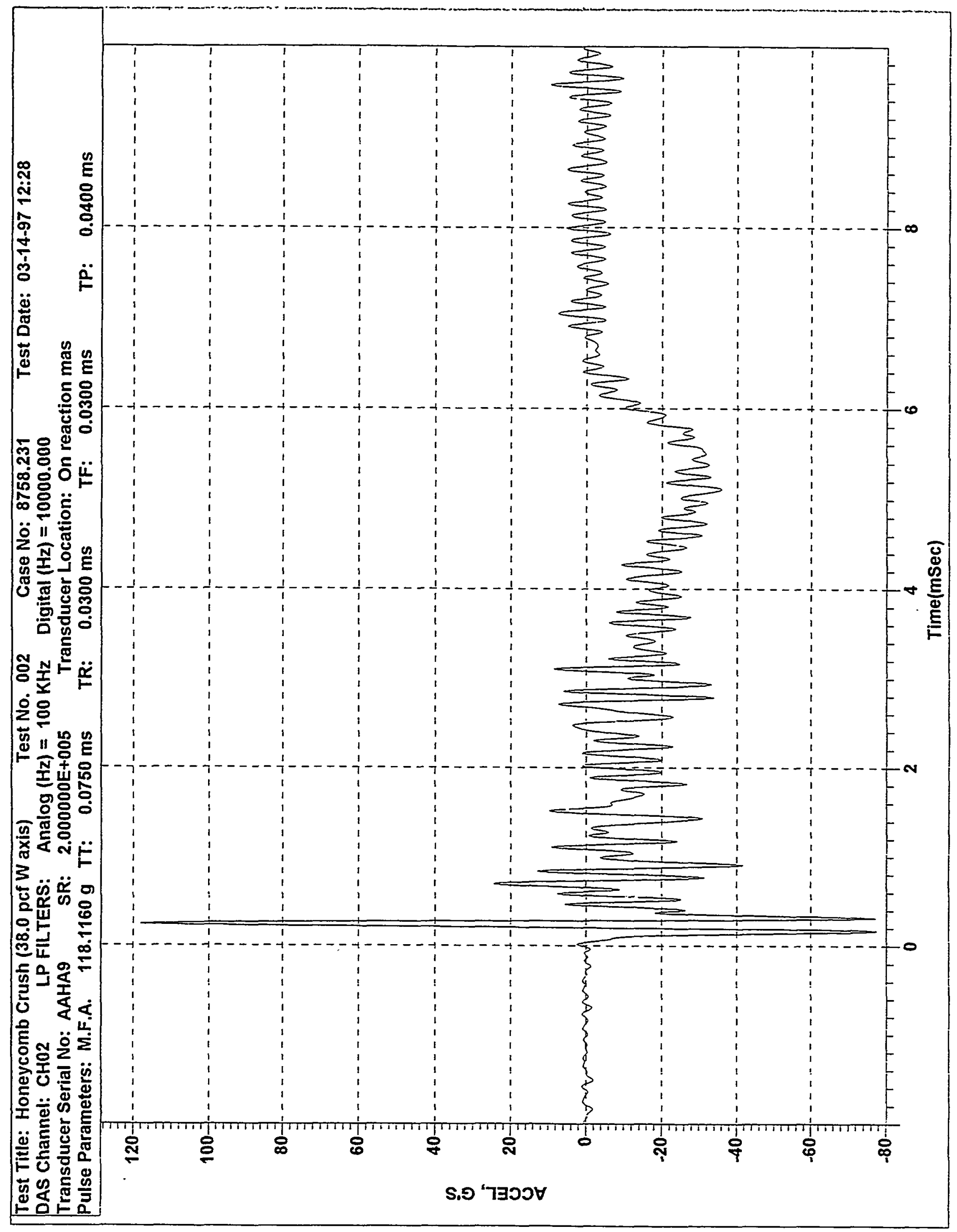




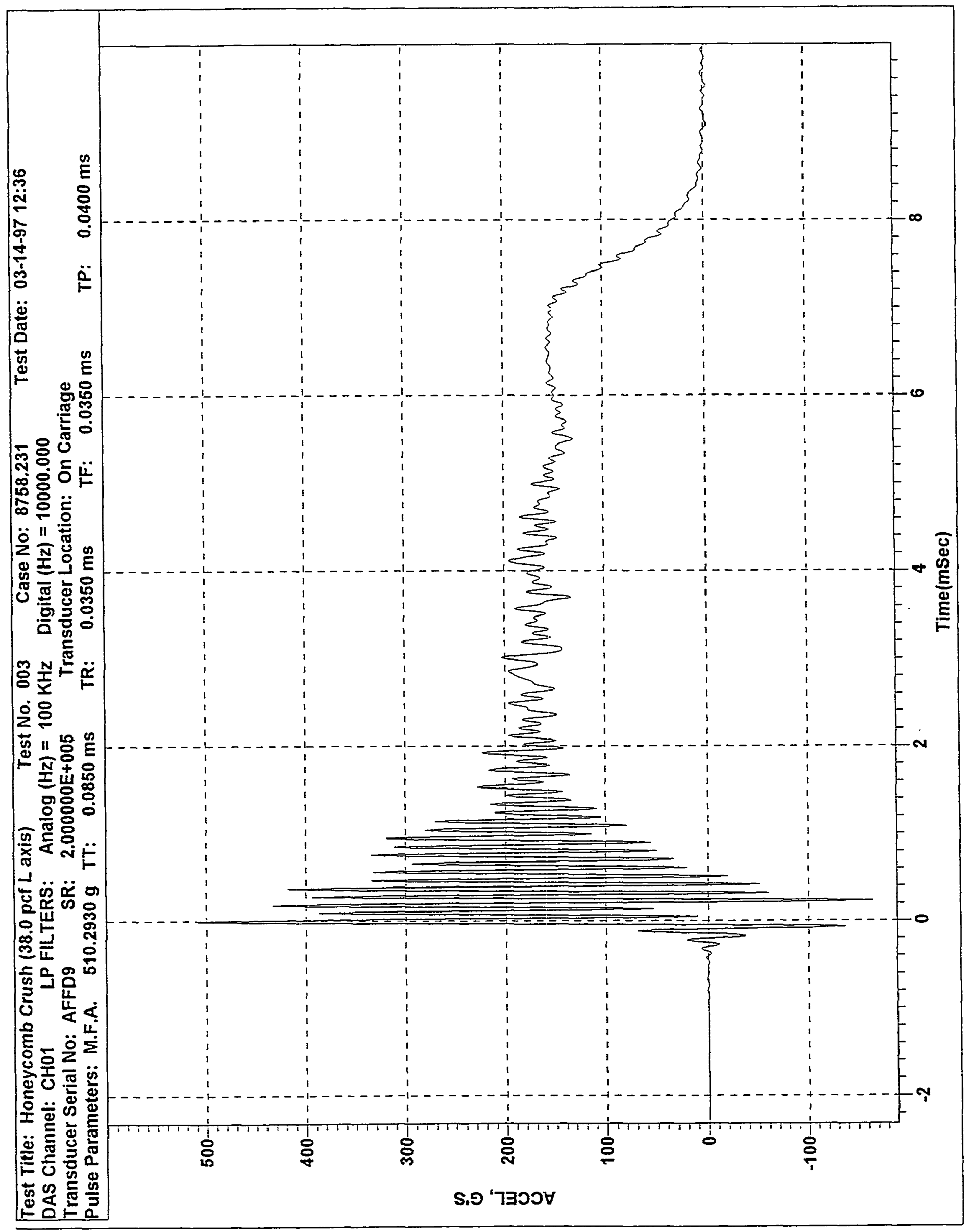




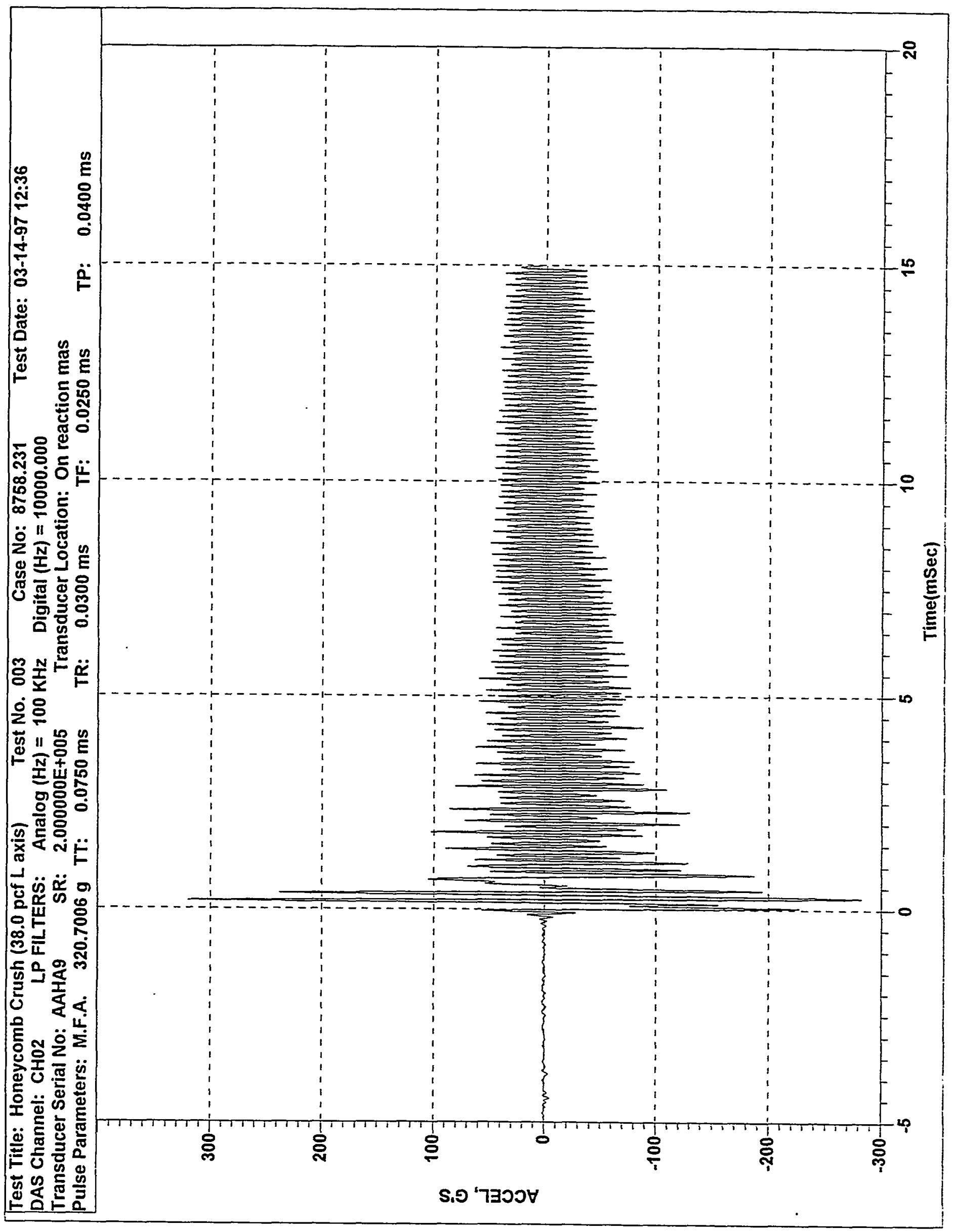




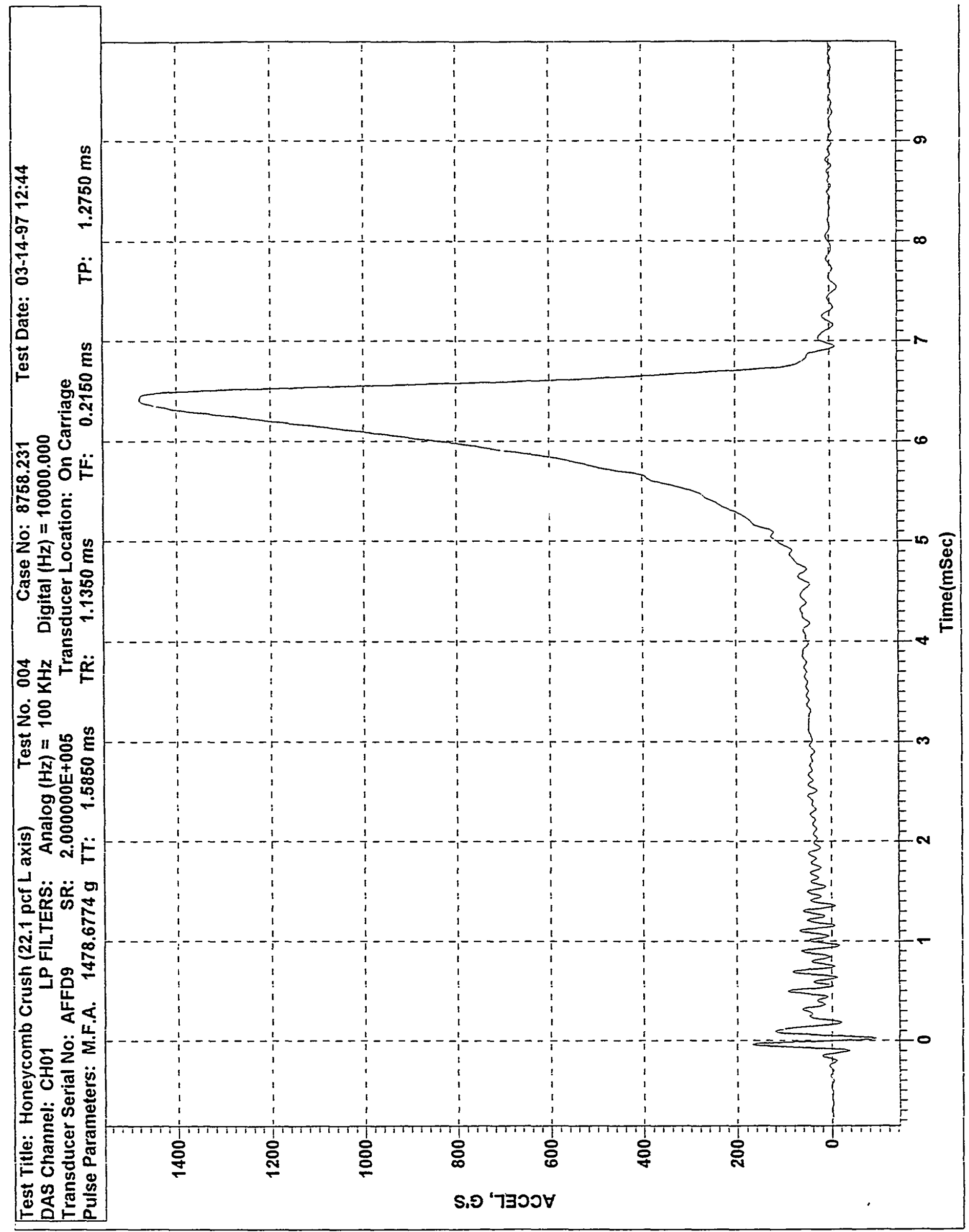




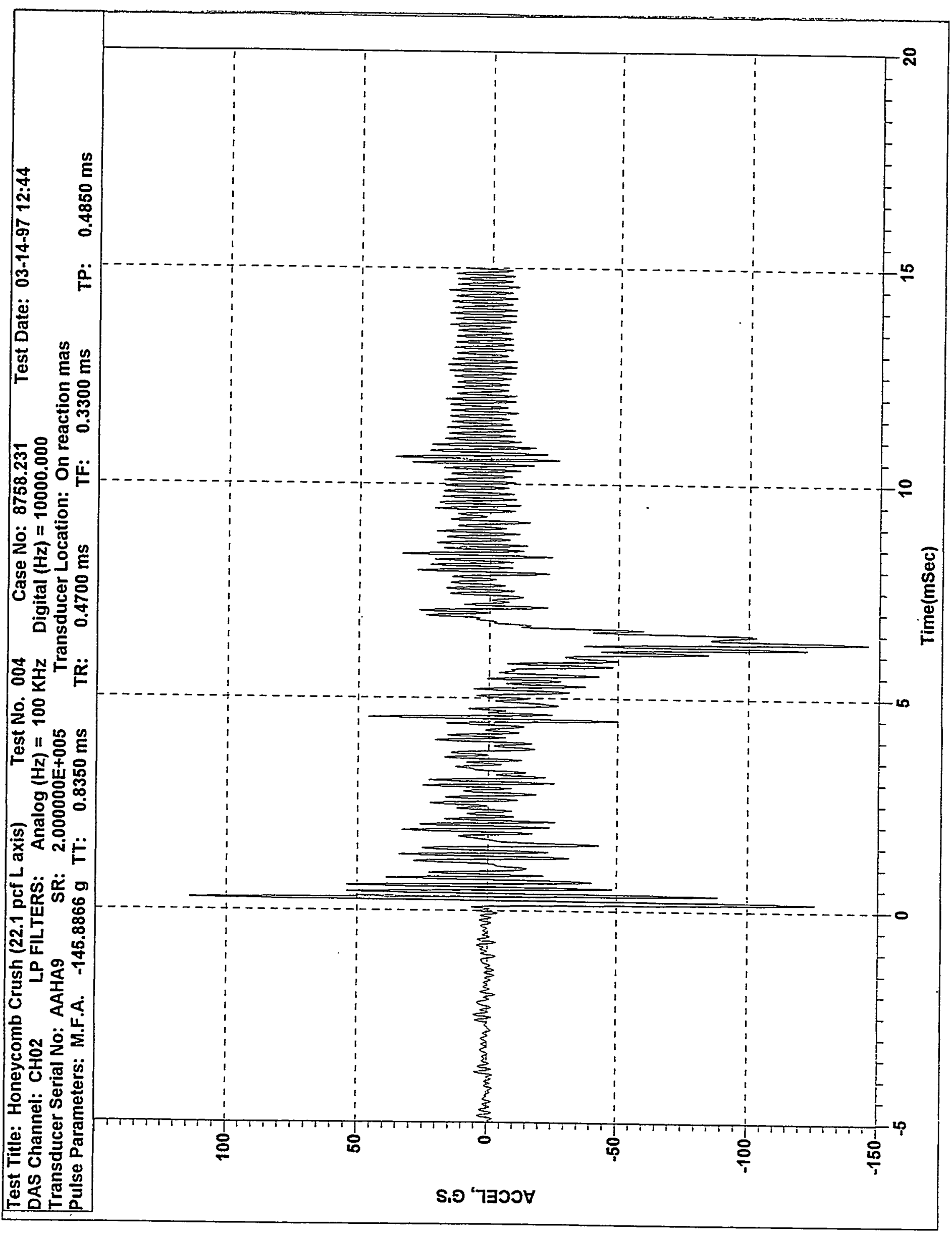




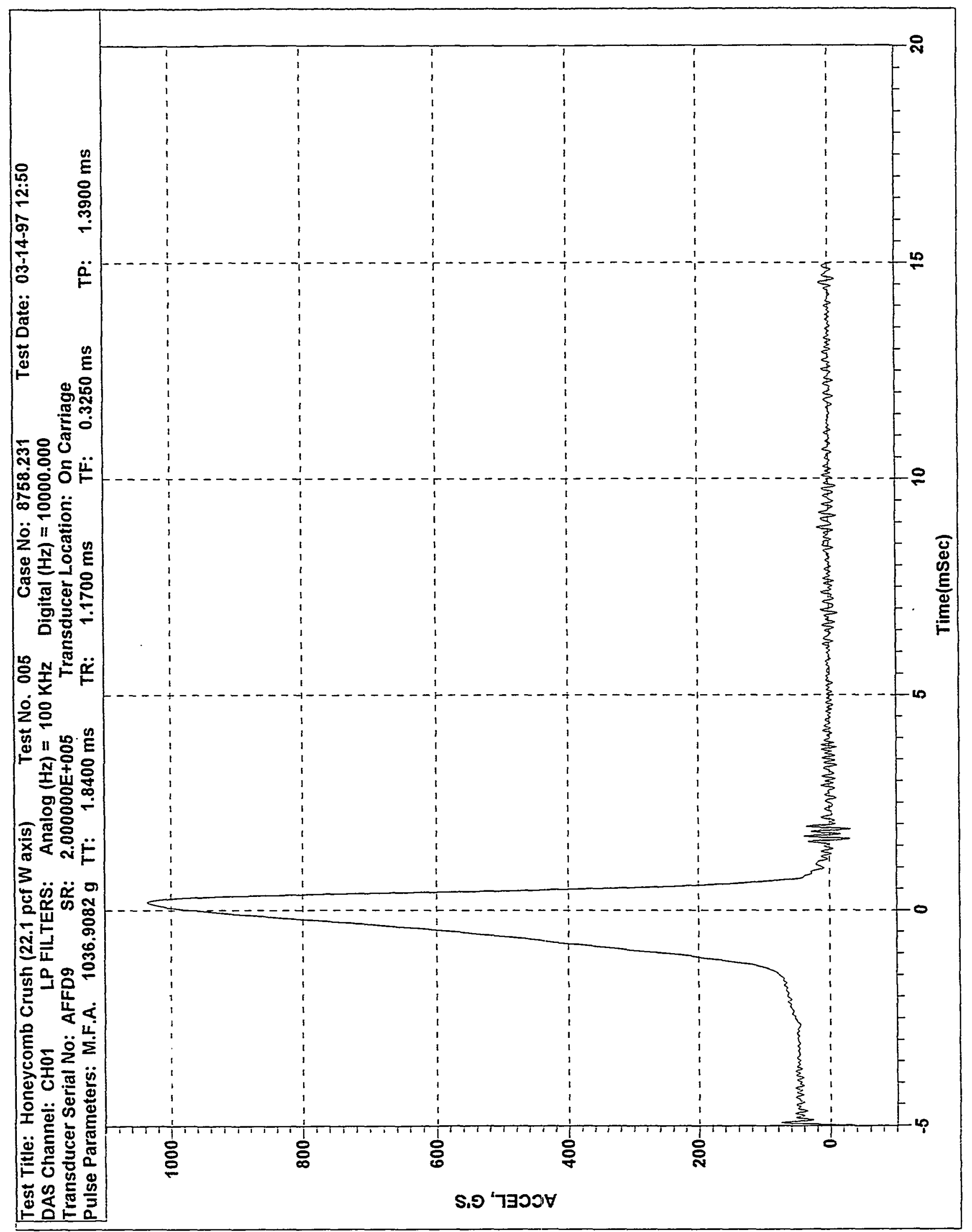




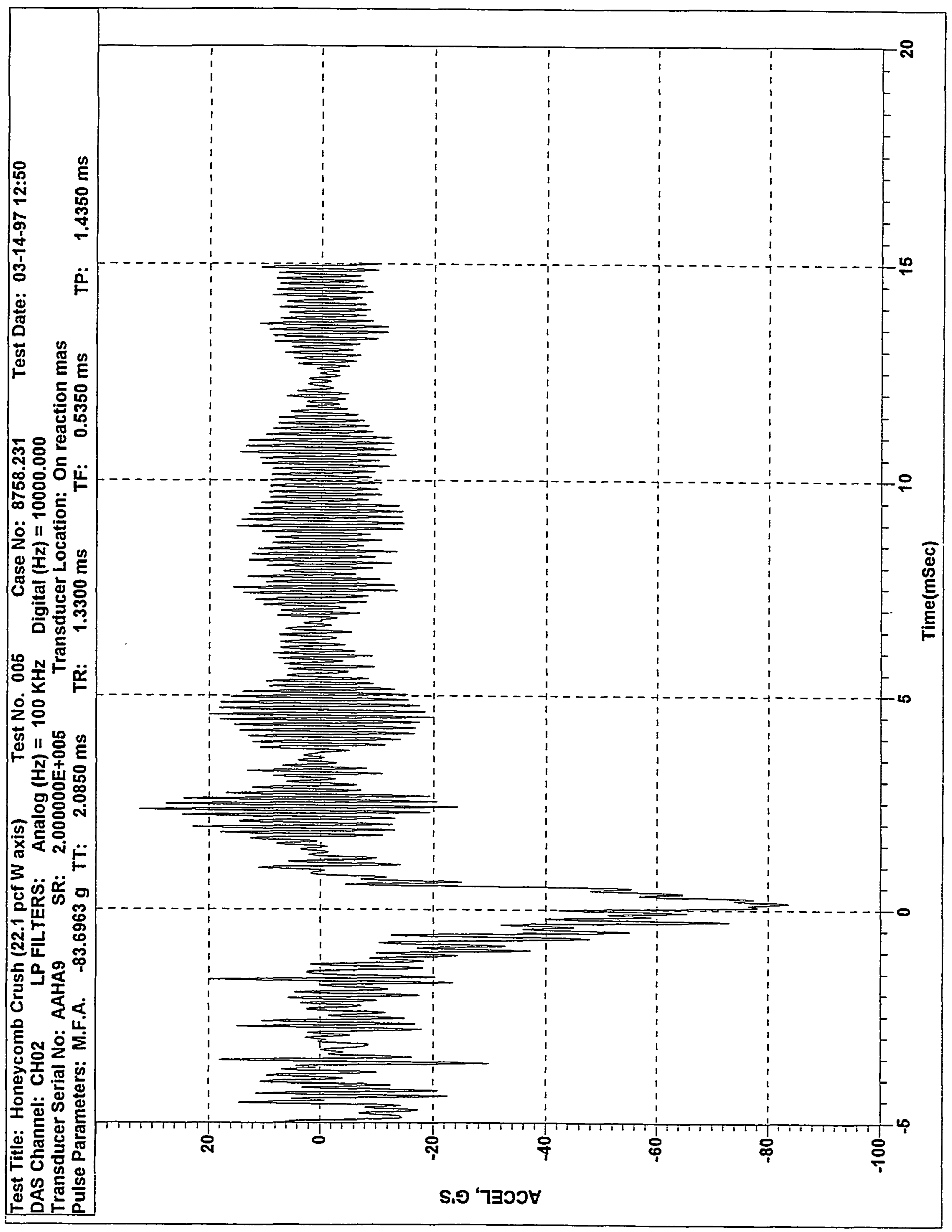




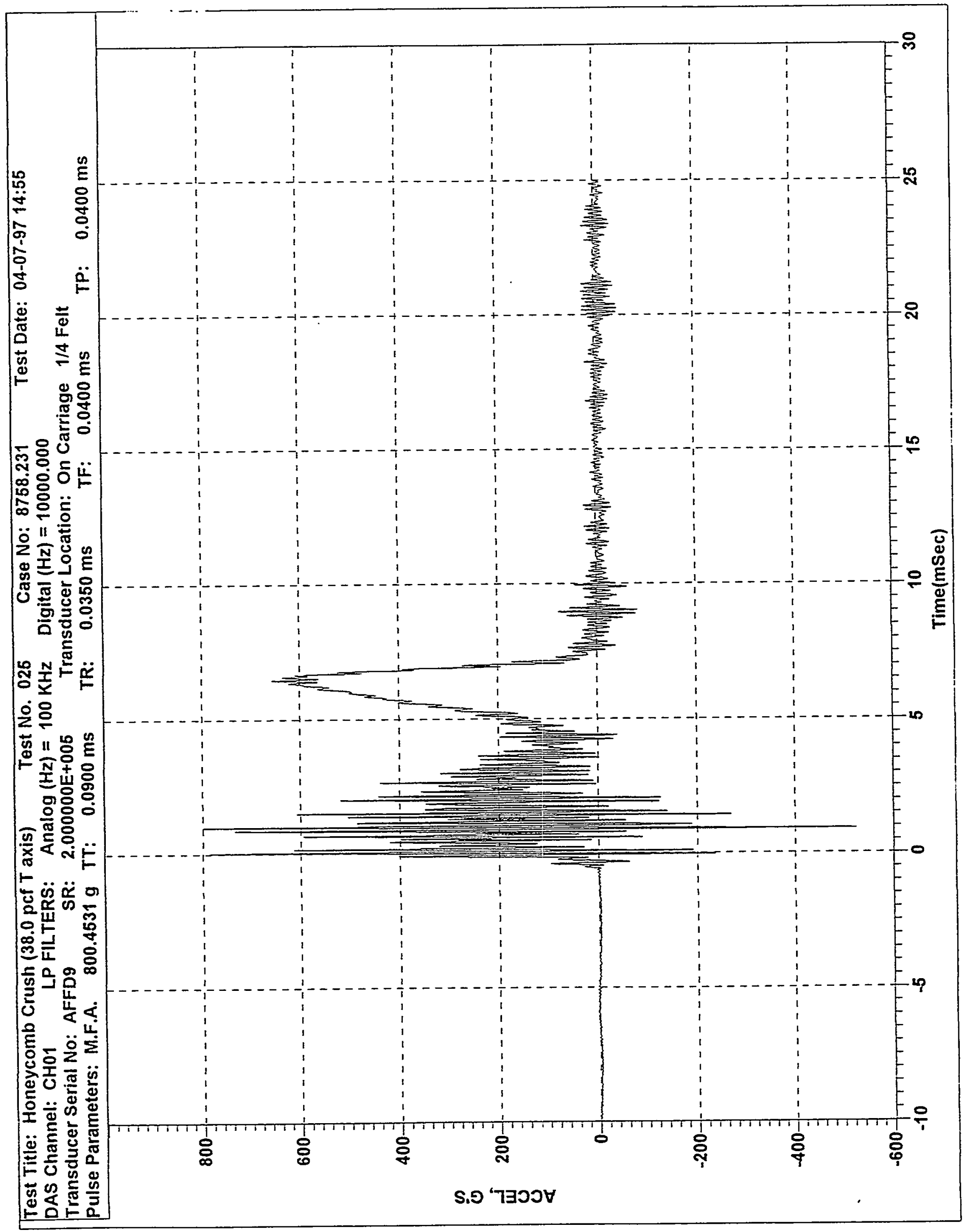




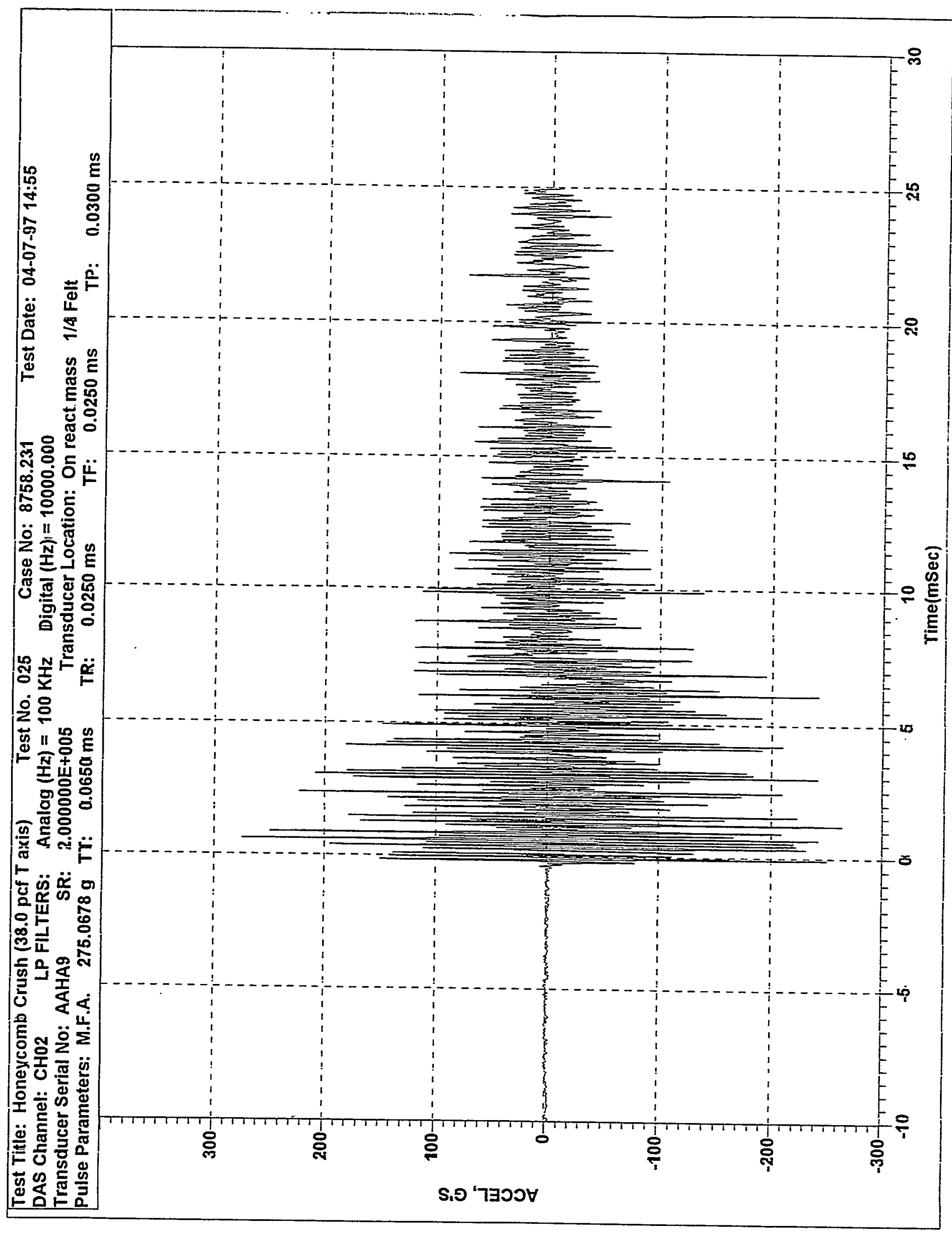




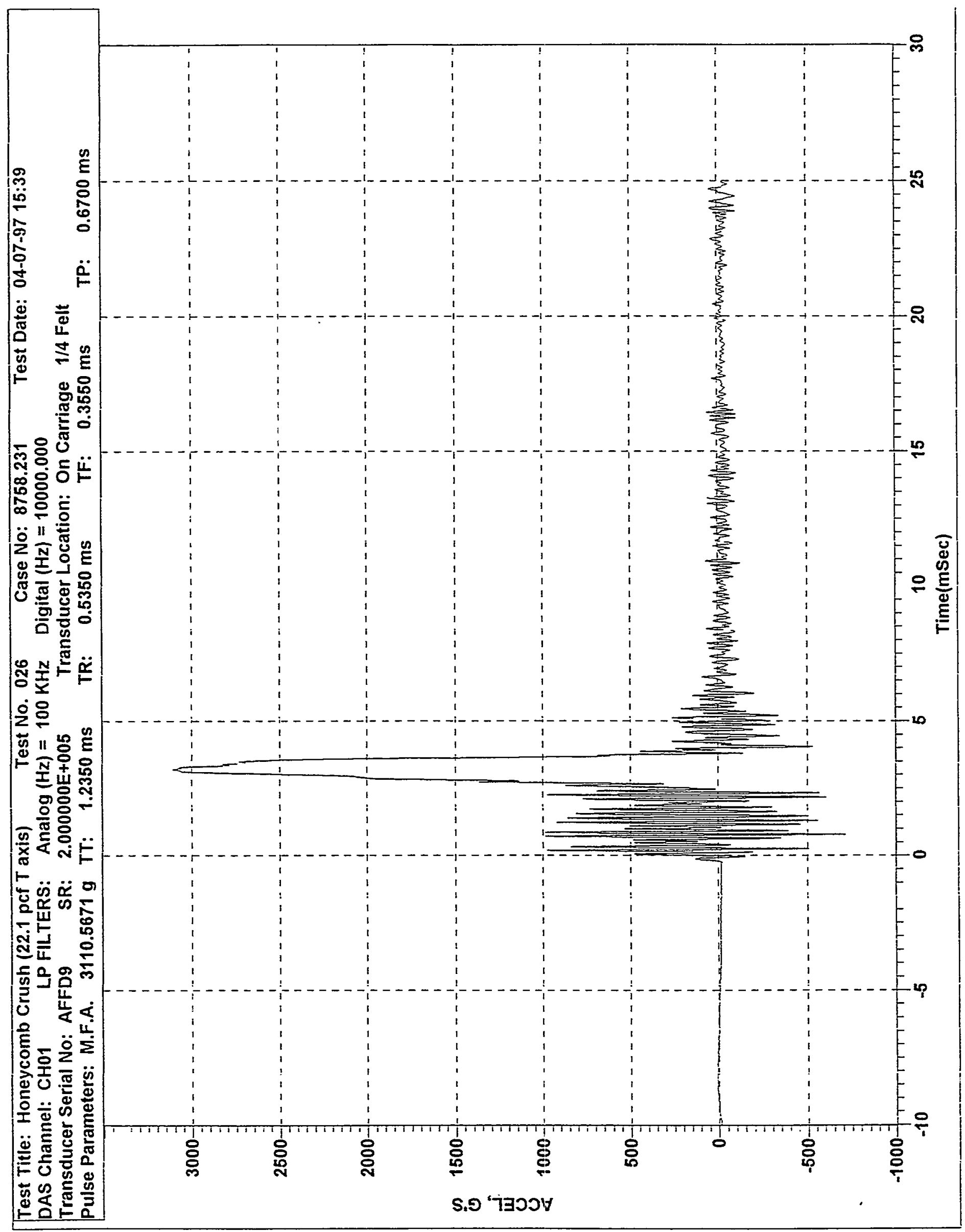




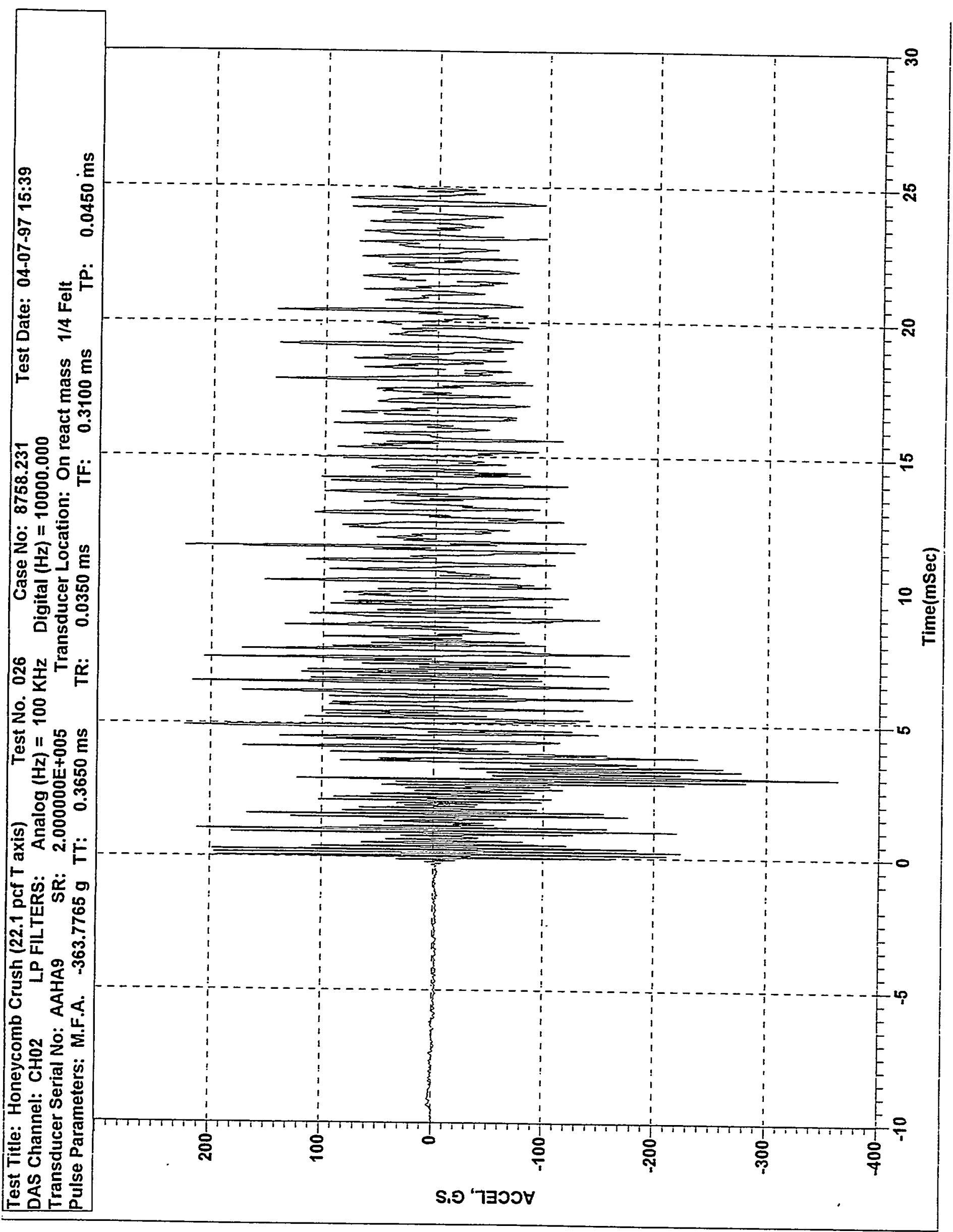




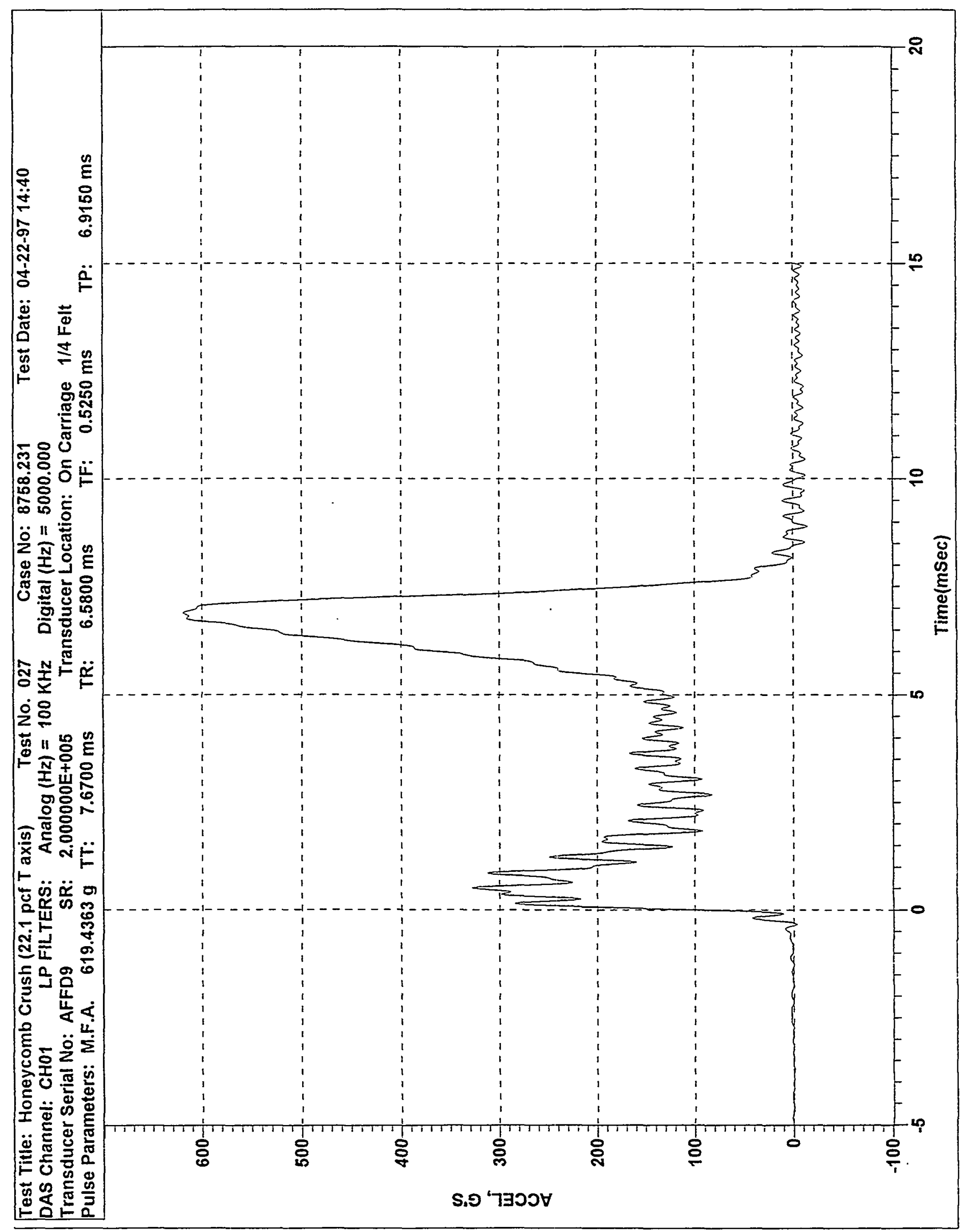




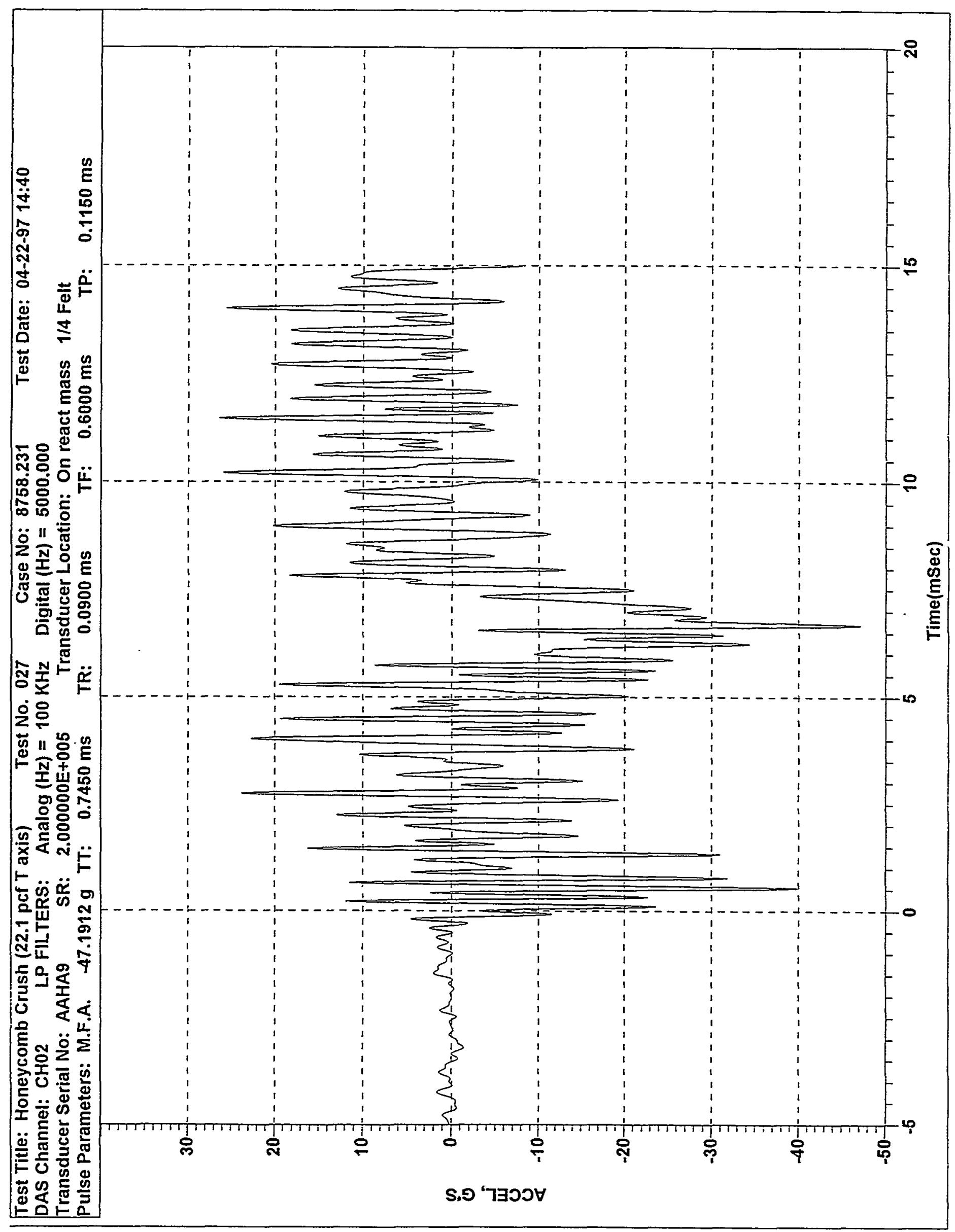




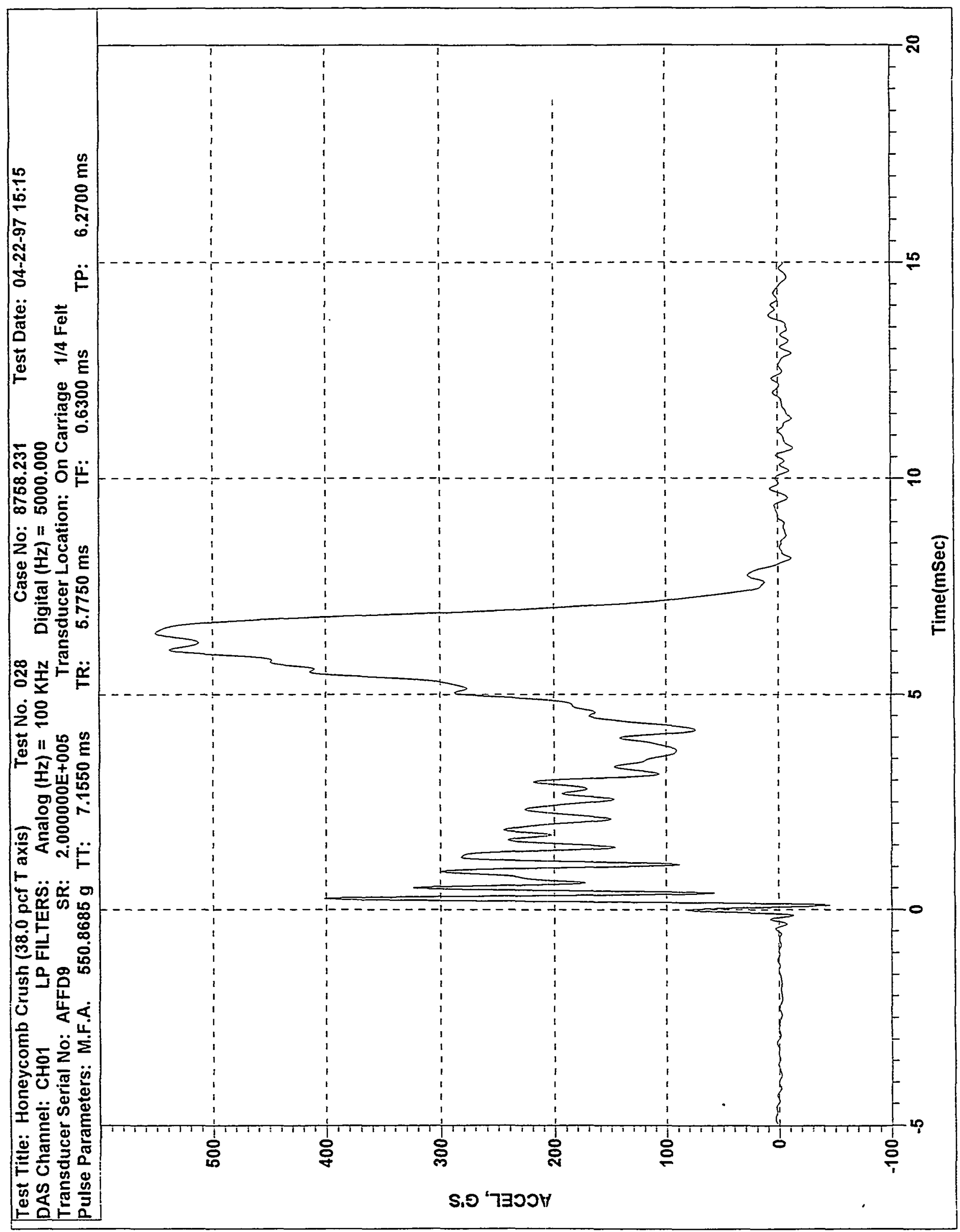




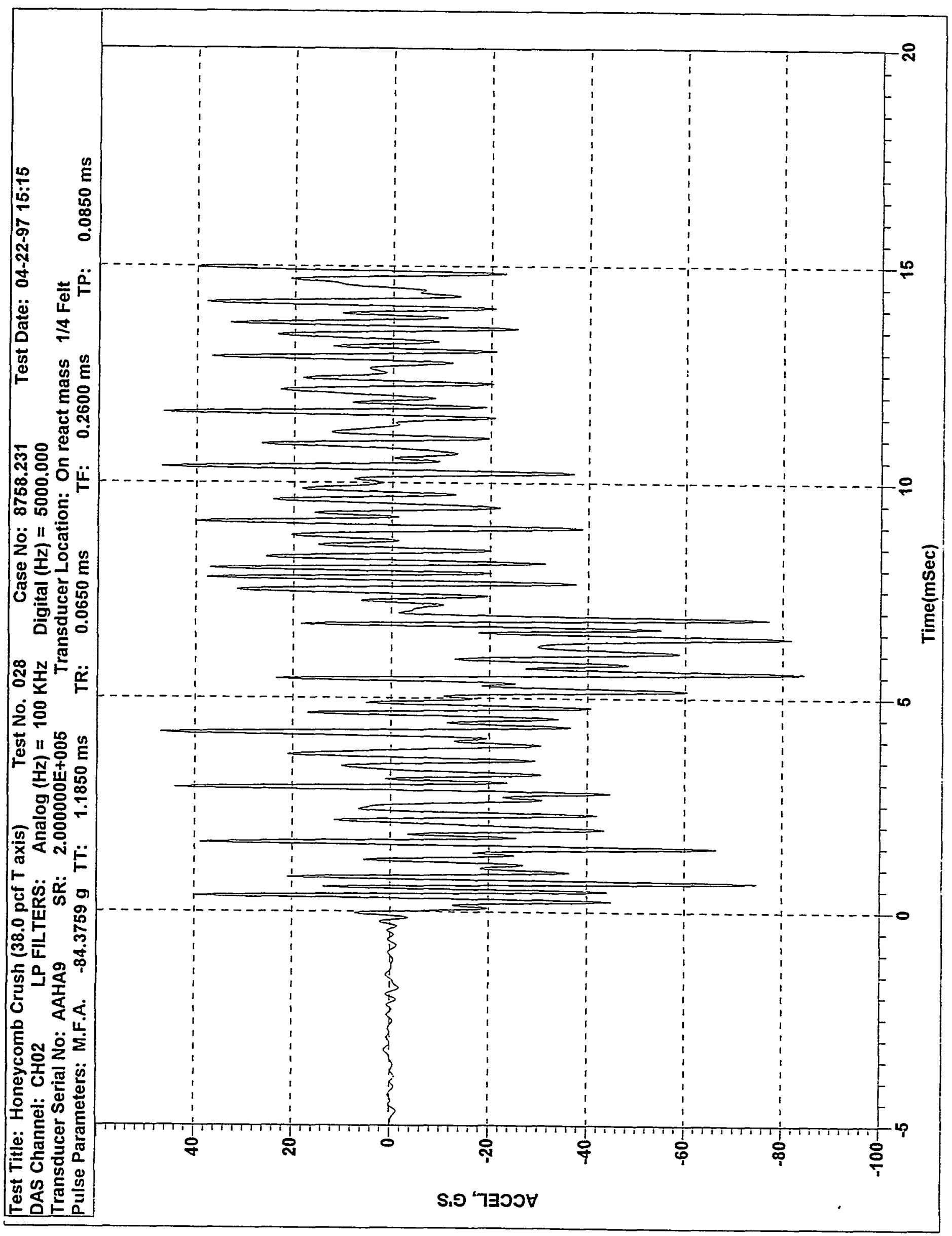




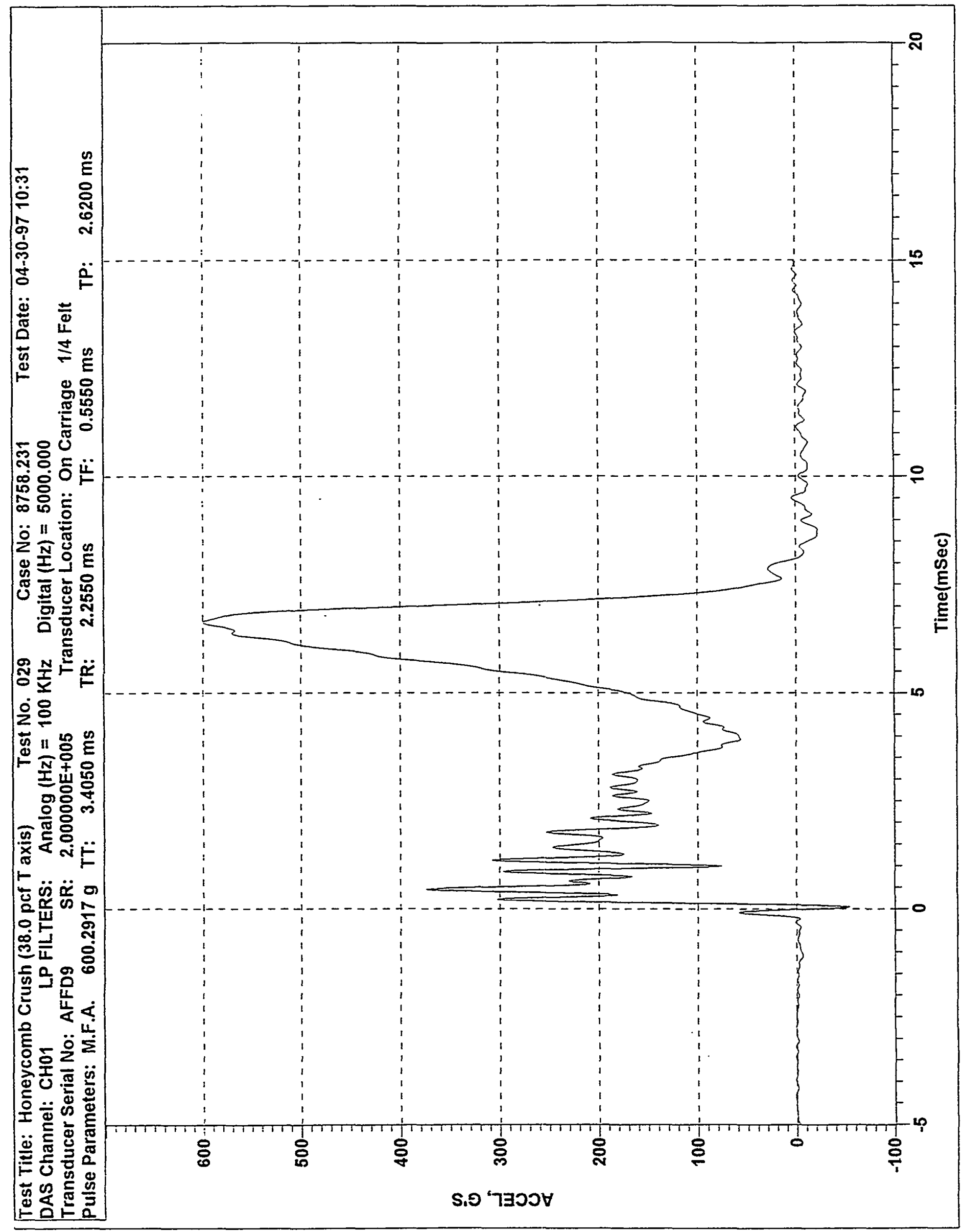




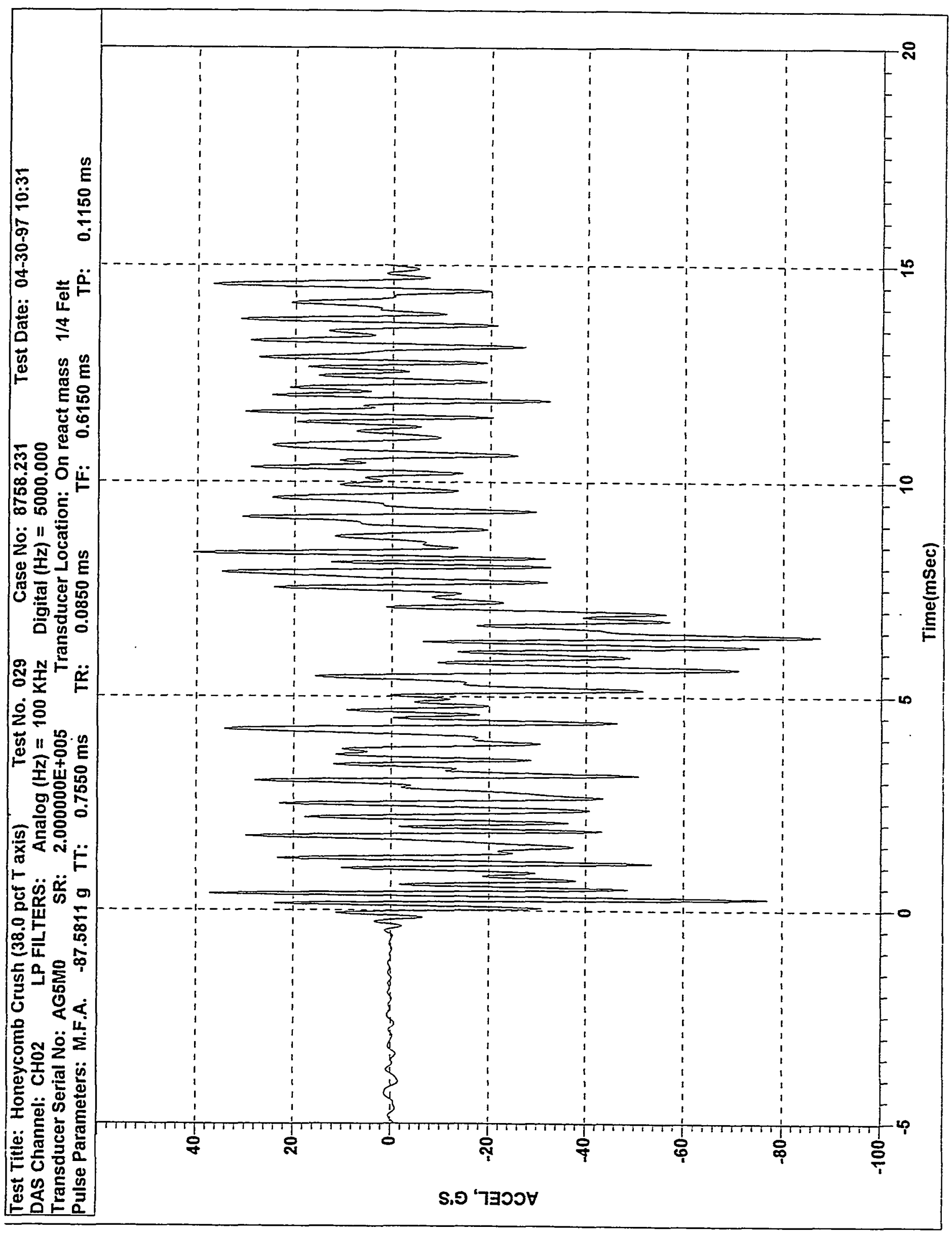




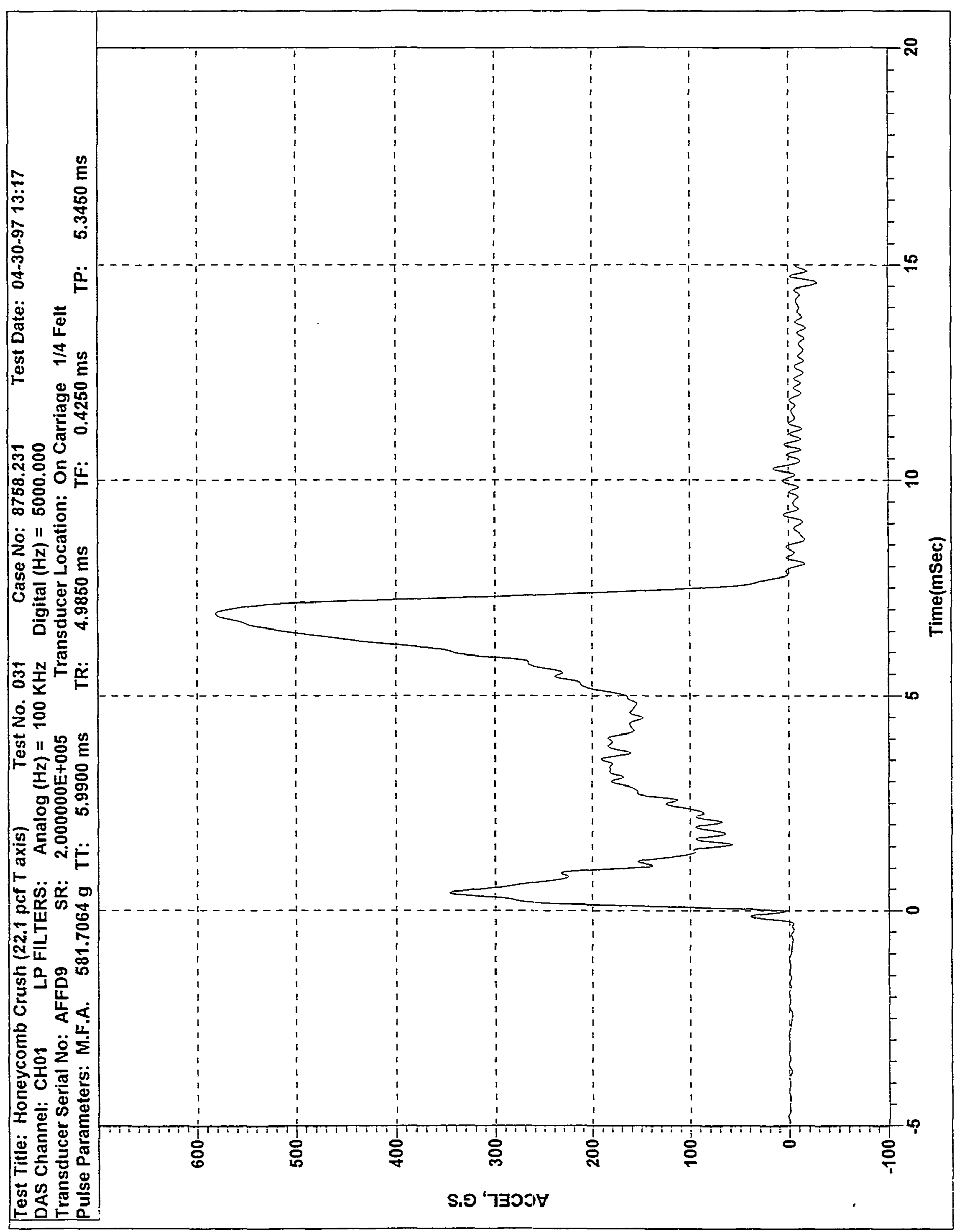




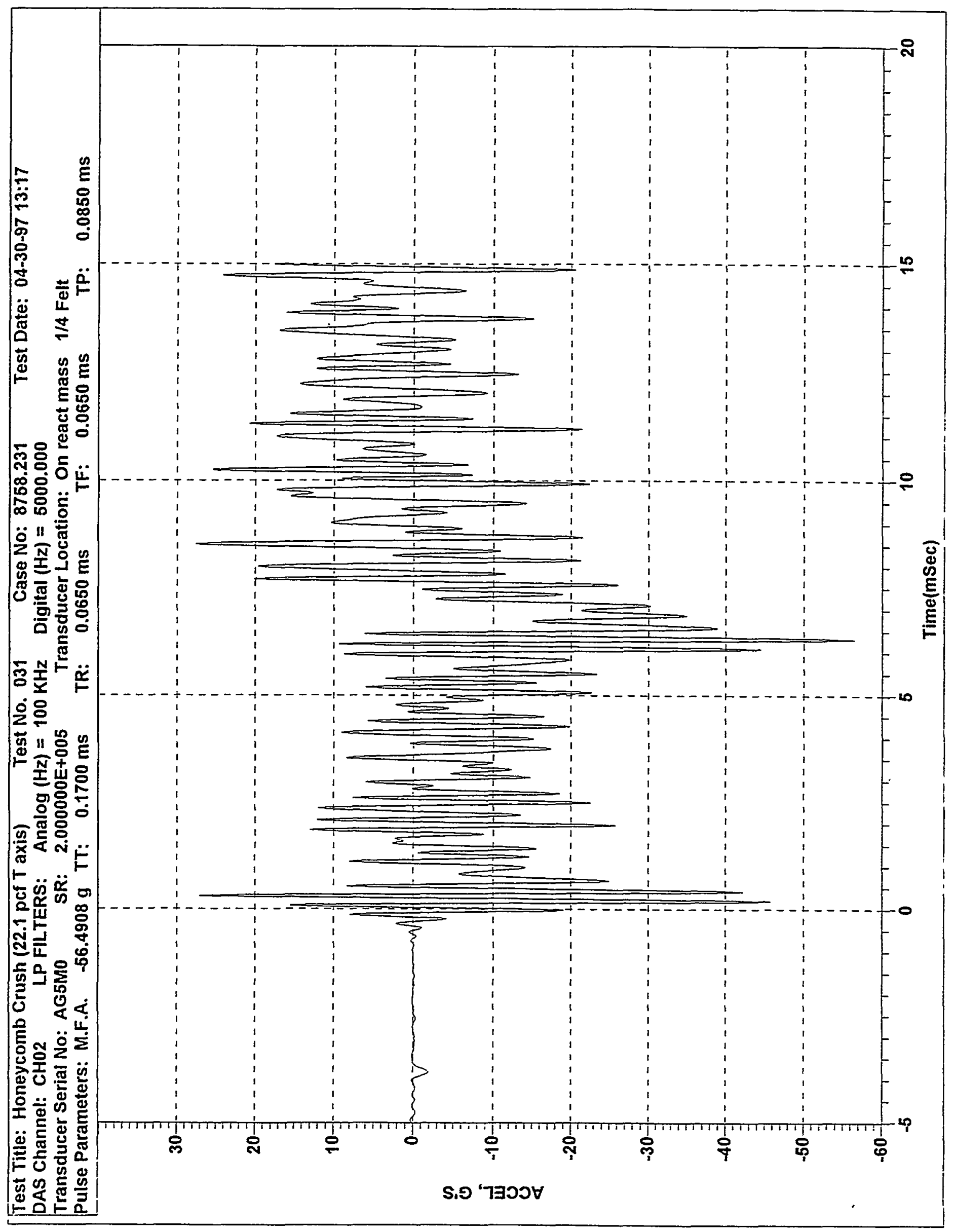




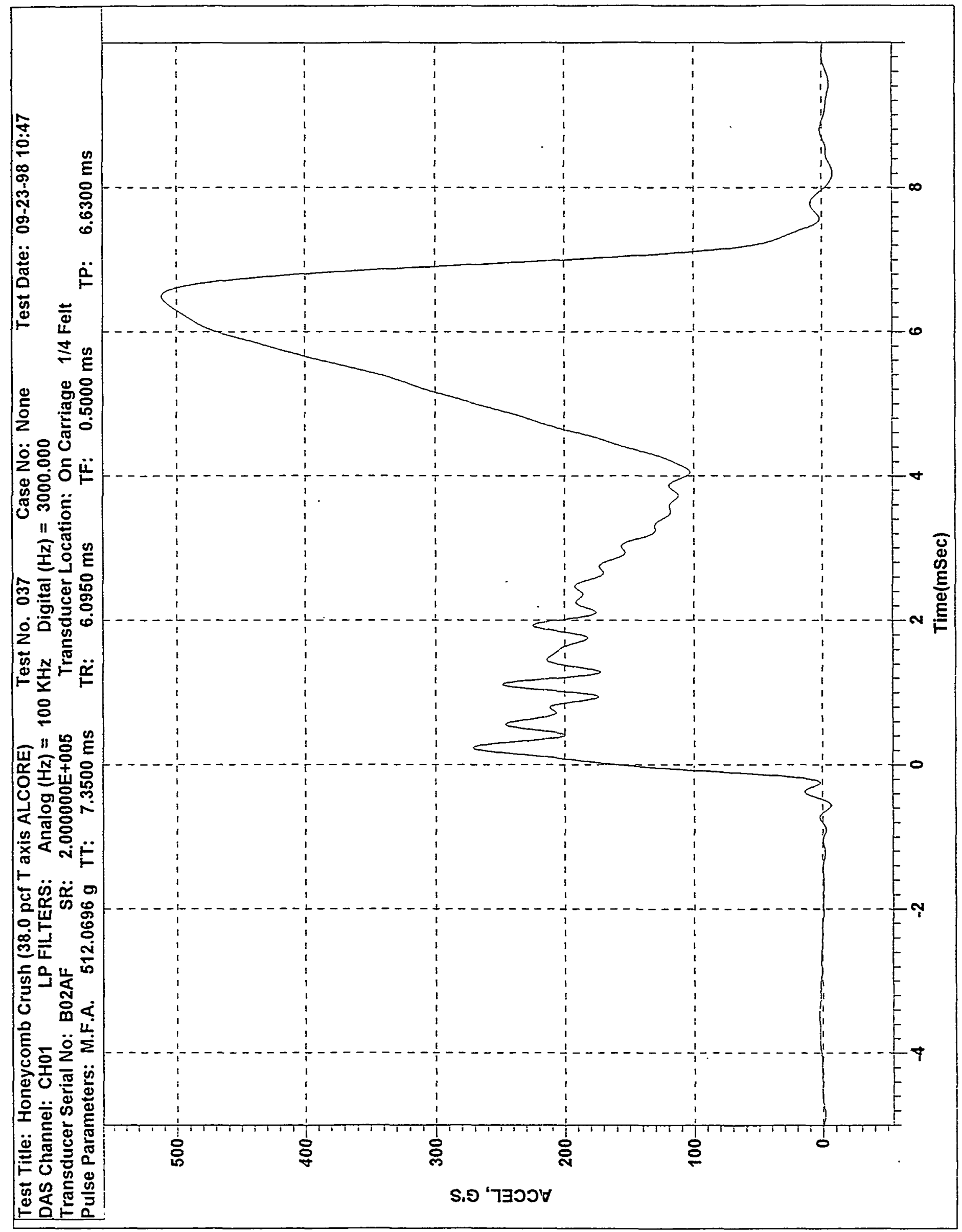




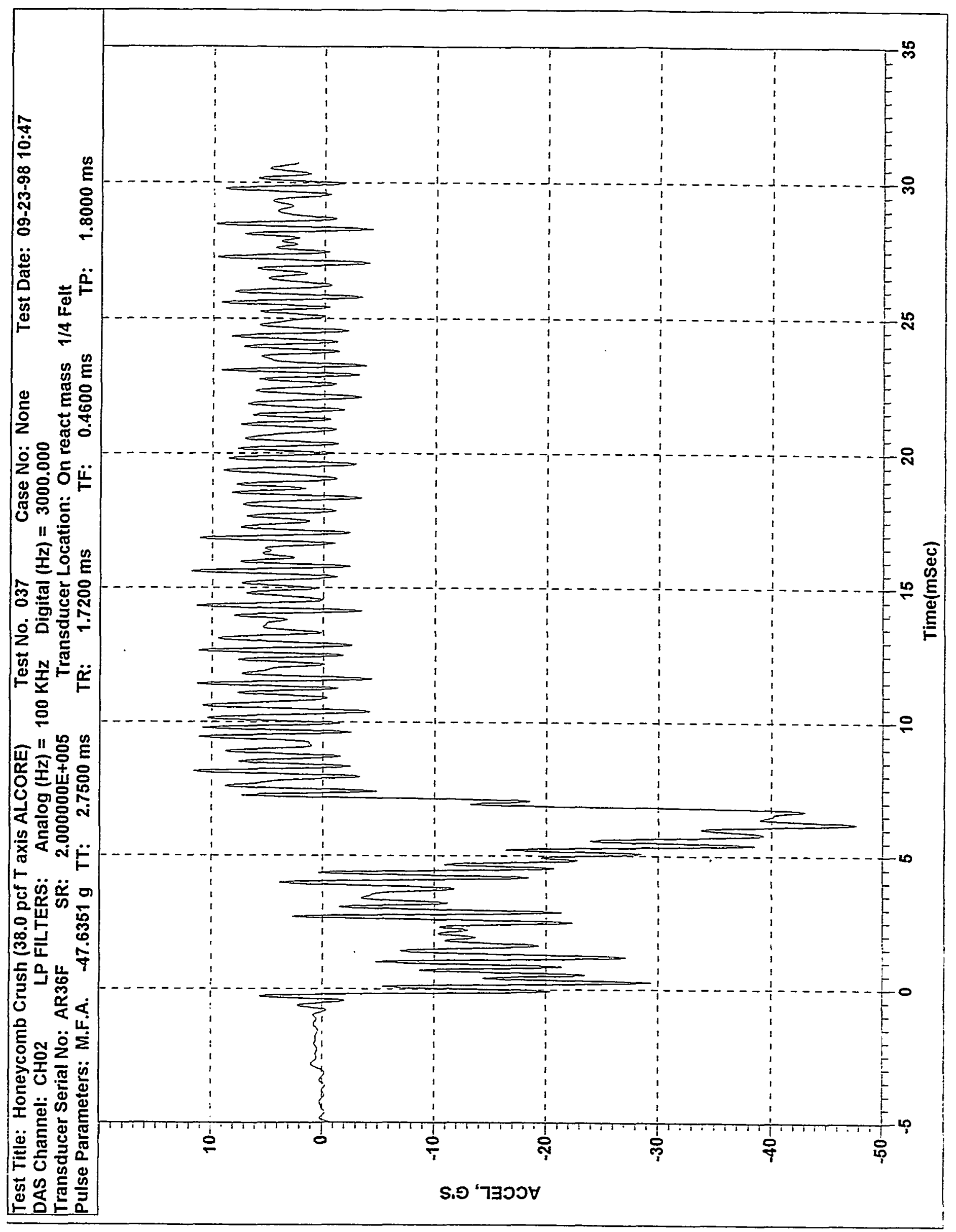




\section{Appendix $\mathbb{F}$}

Raw Accelerometer Data Measured on the Drop Table Carriage and the Reaction Mass (1999) 


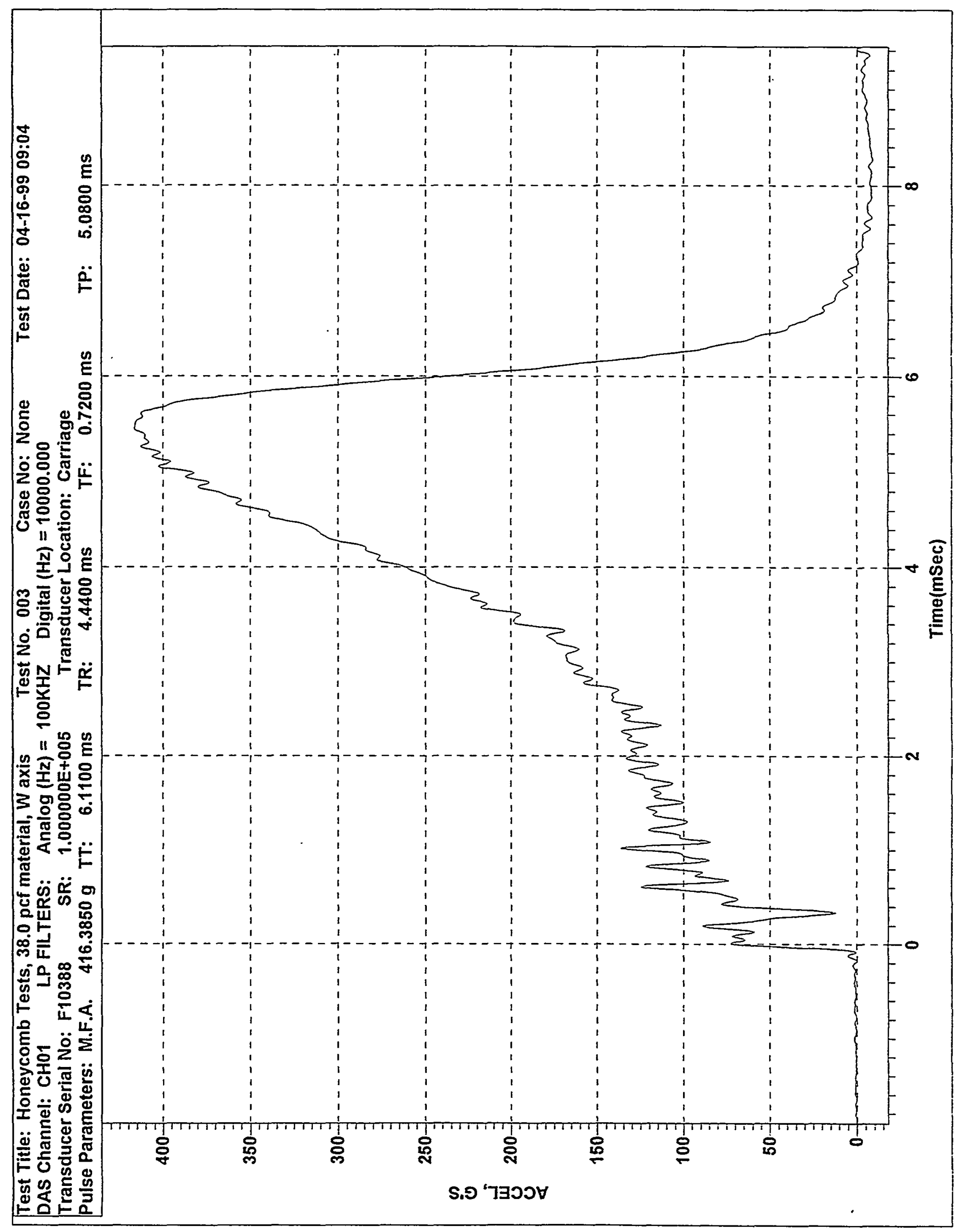




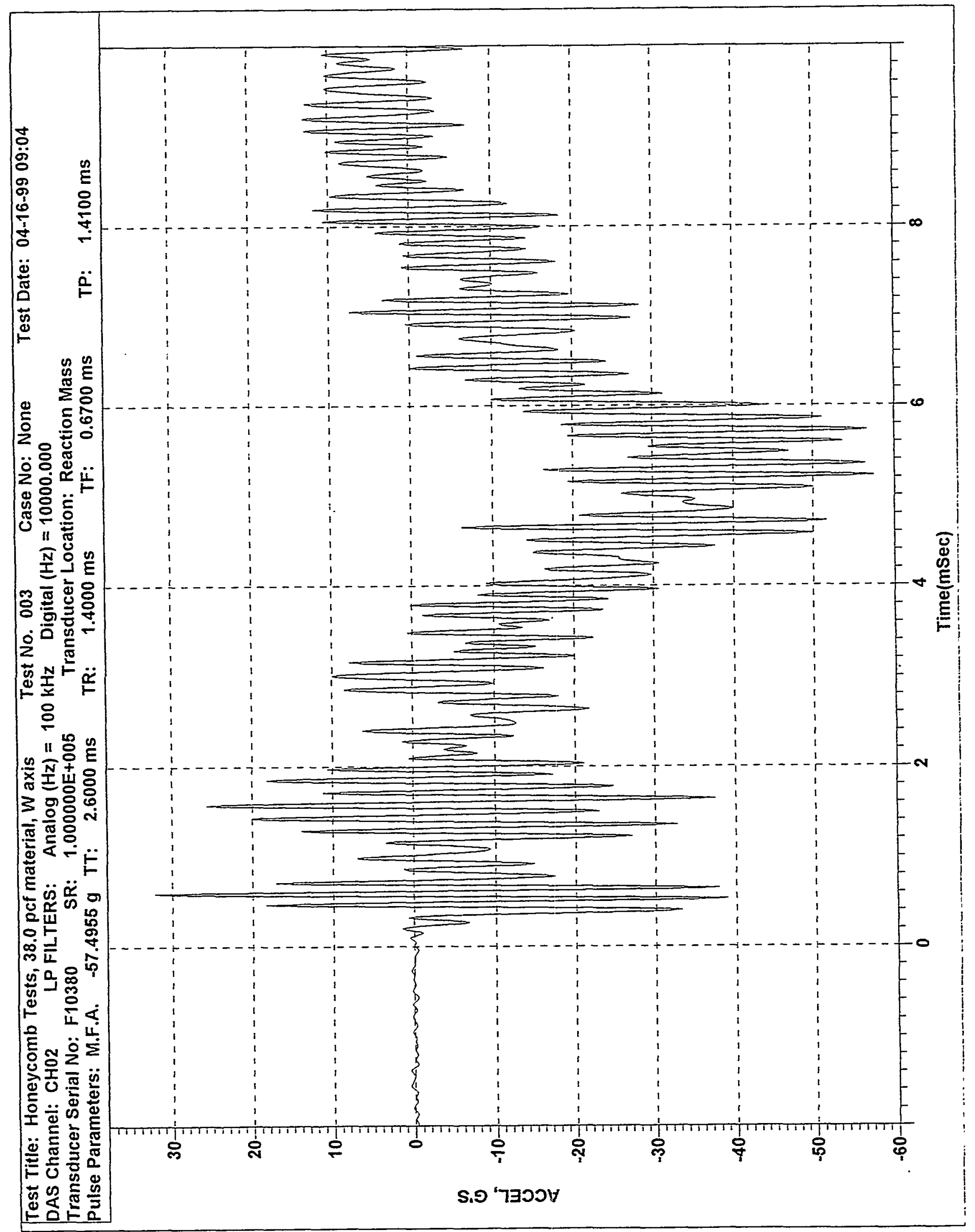




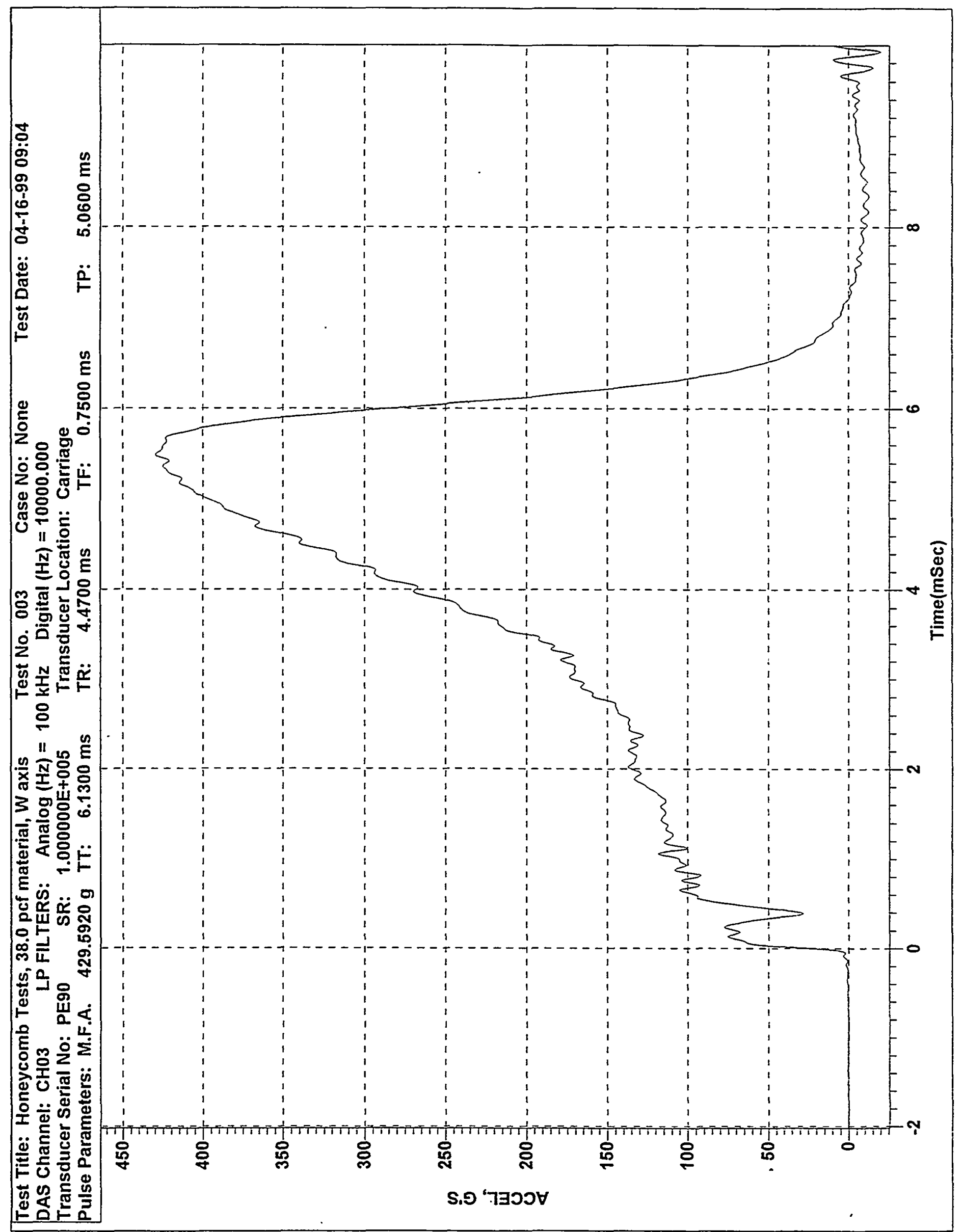




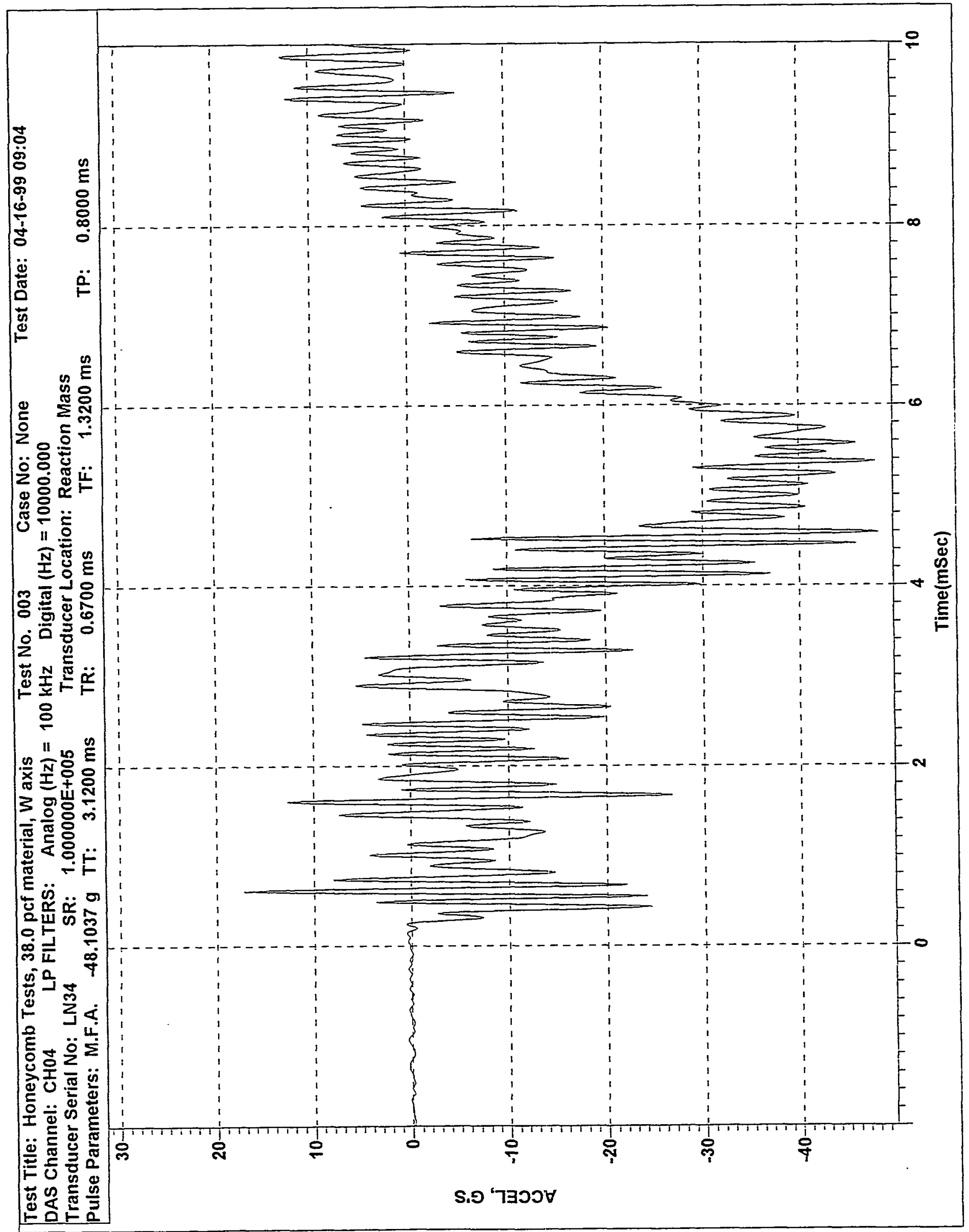




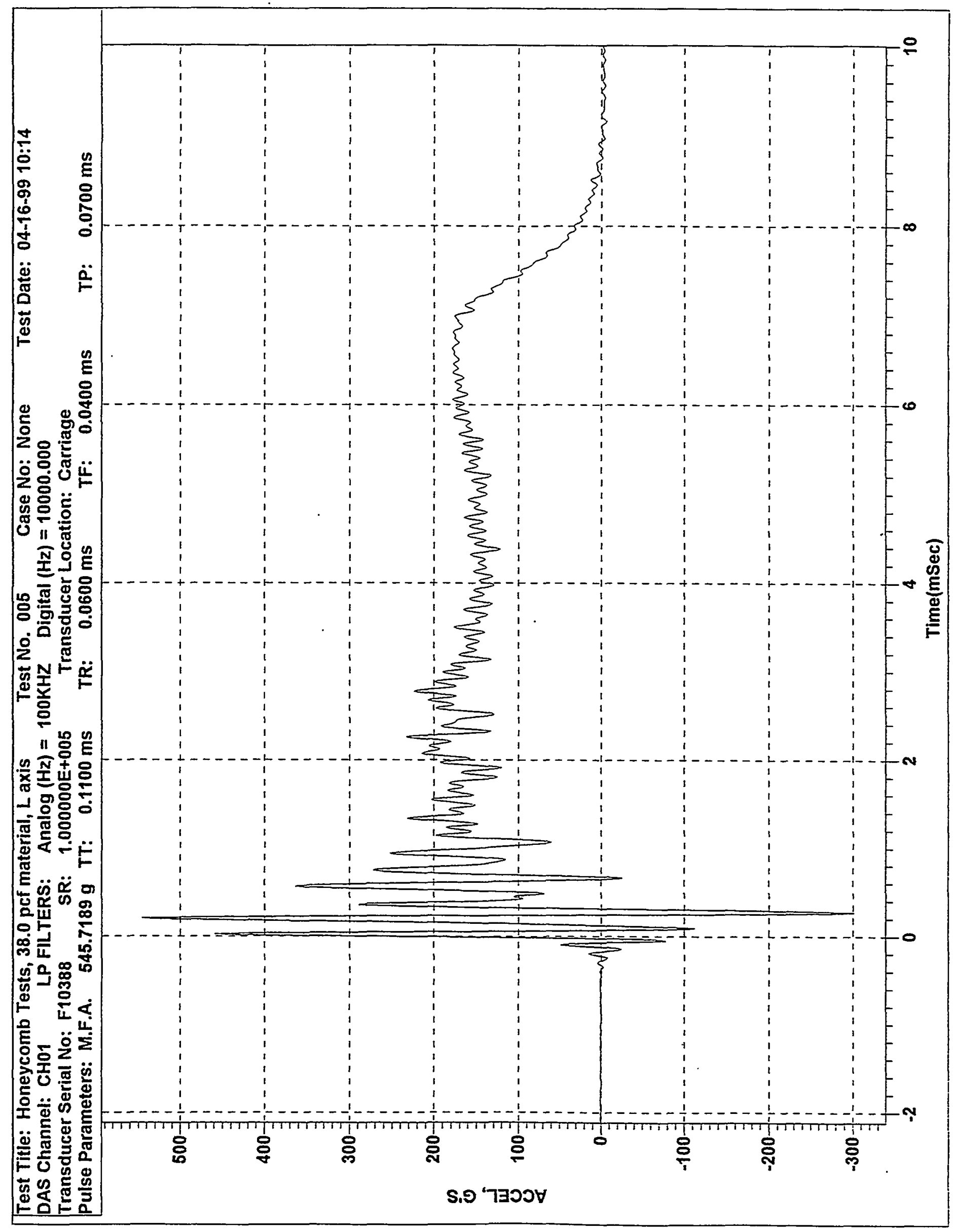




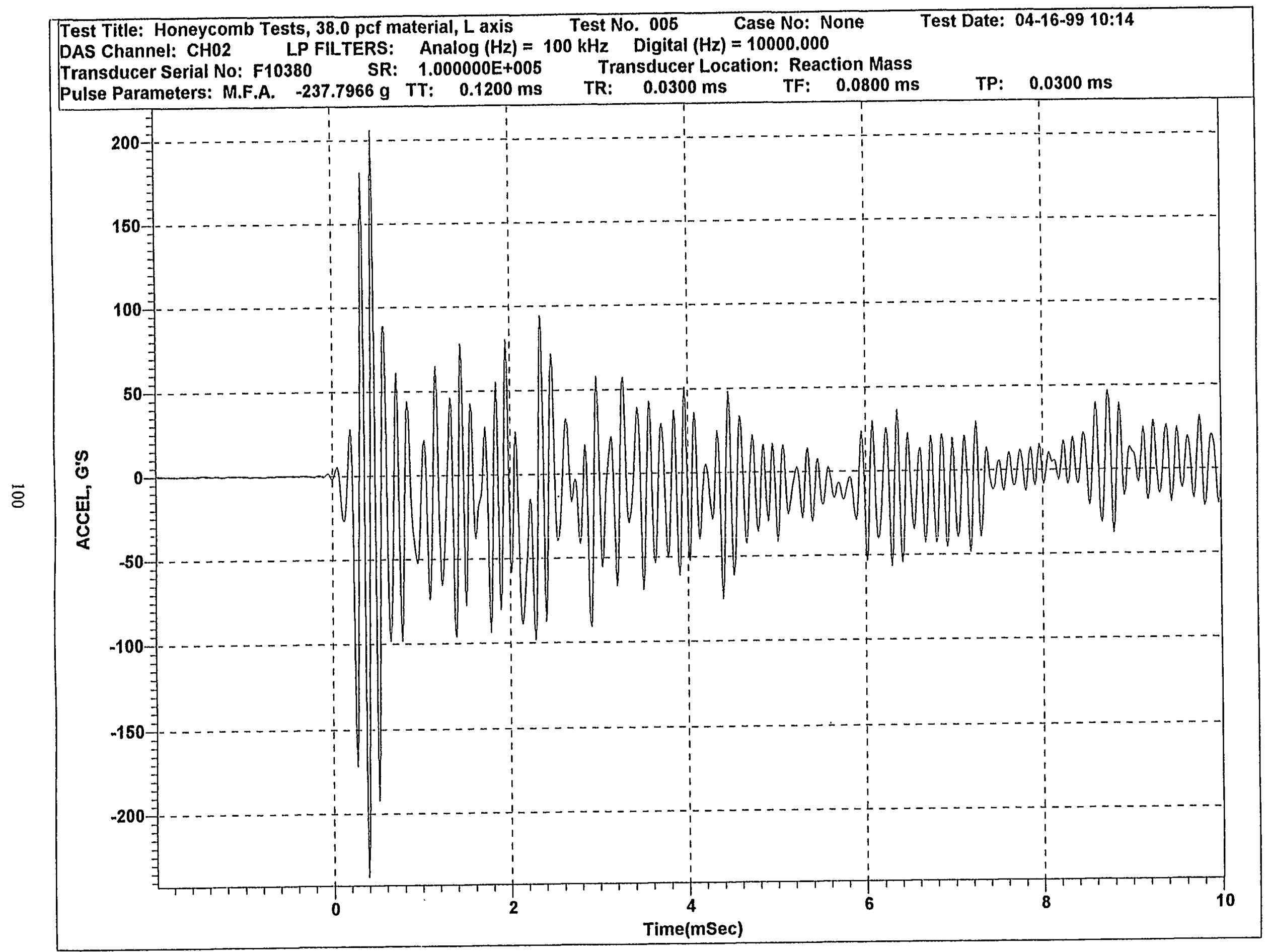




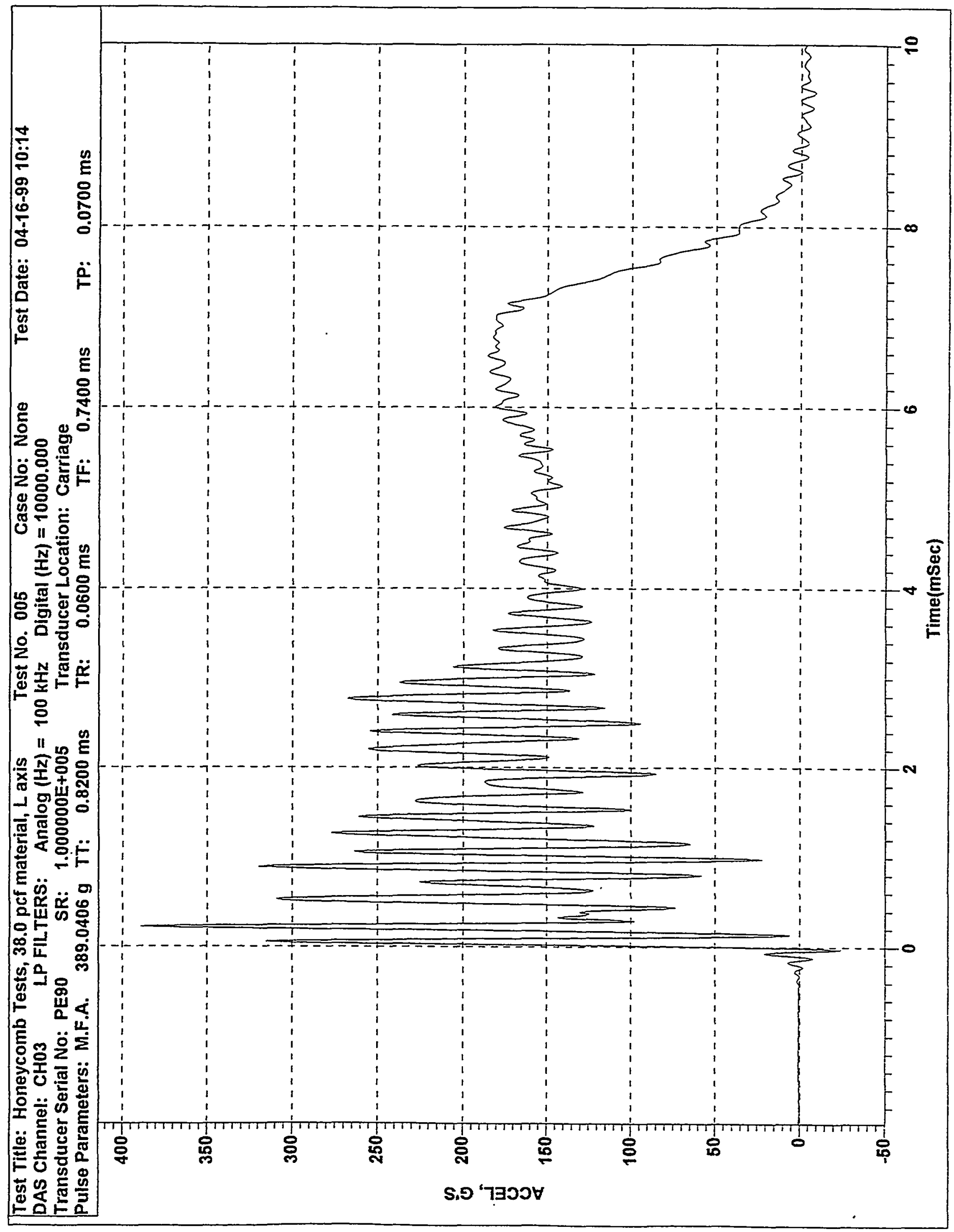




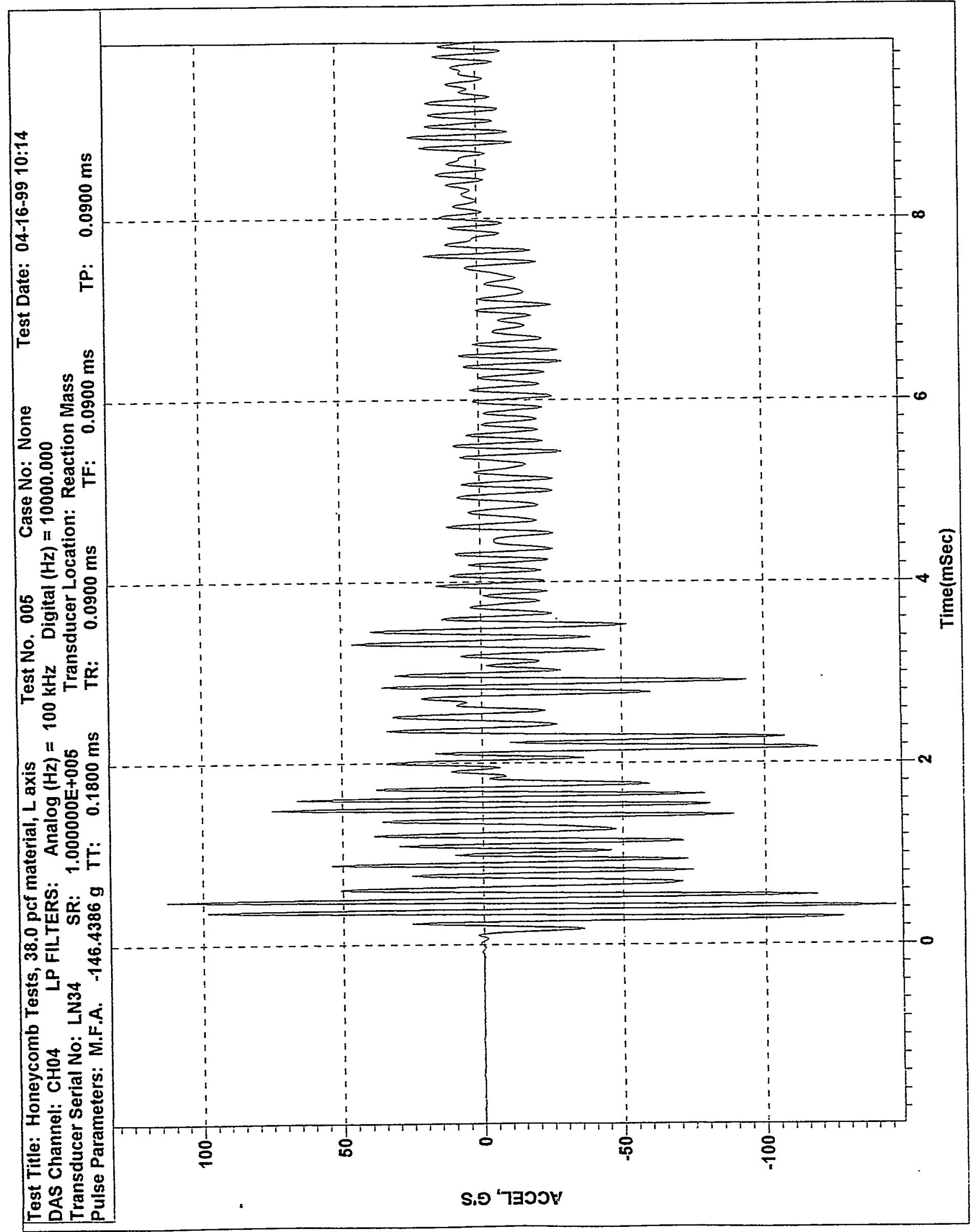




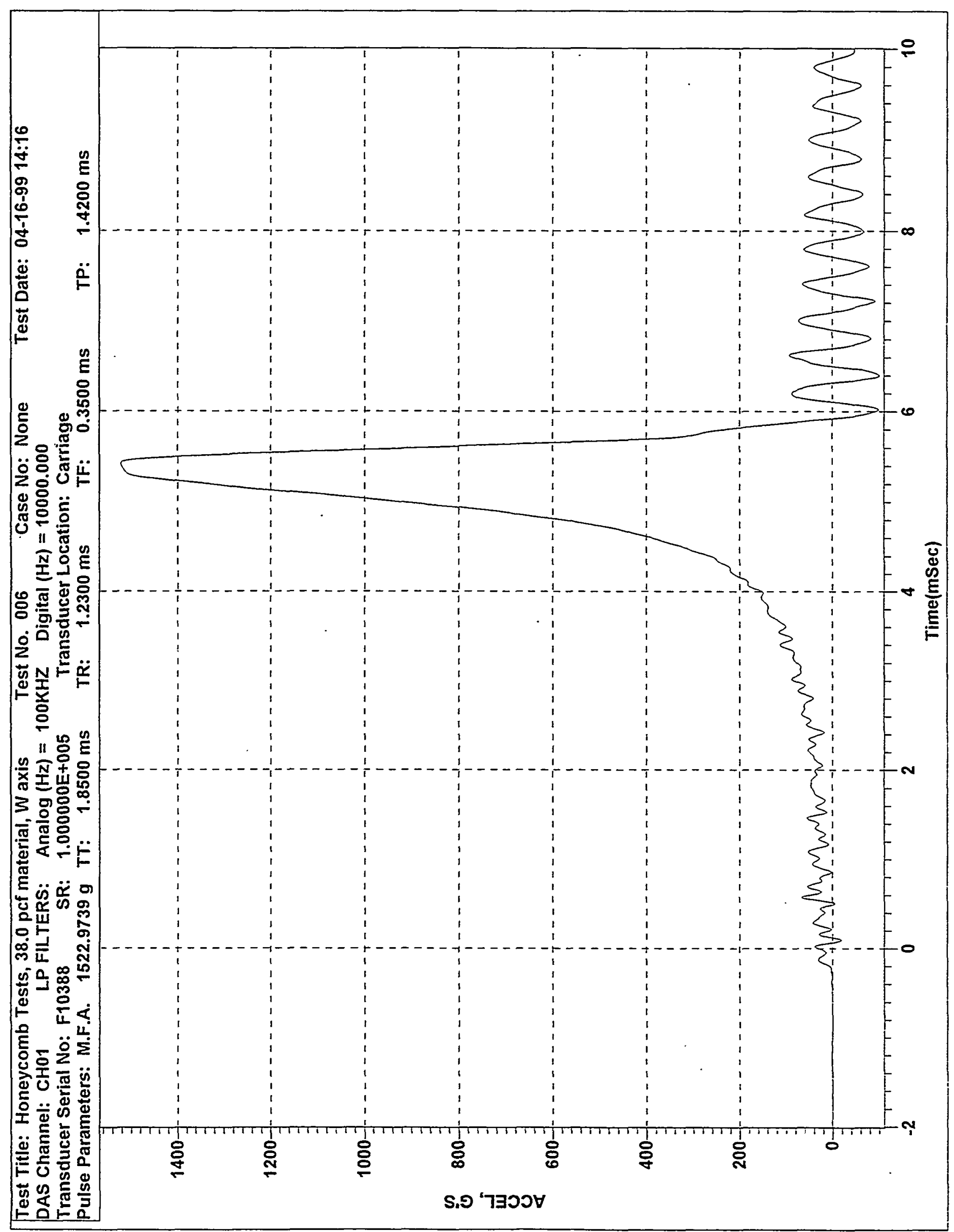




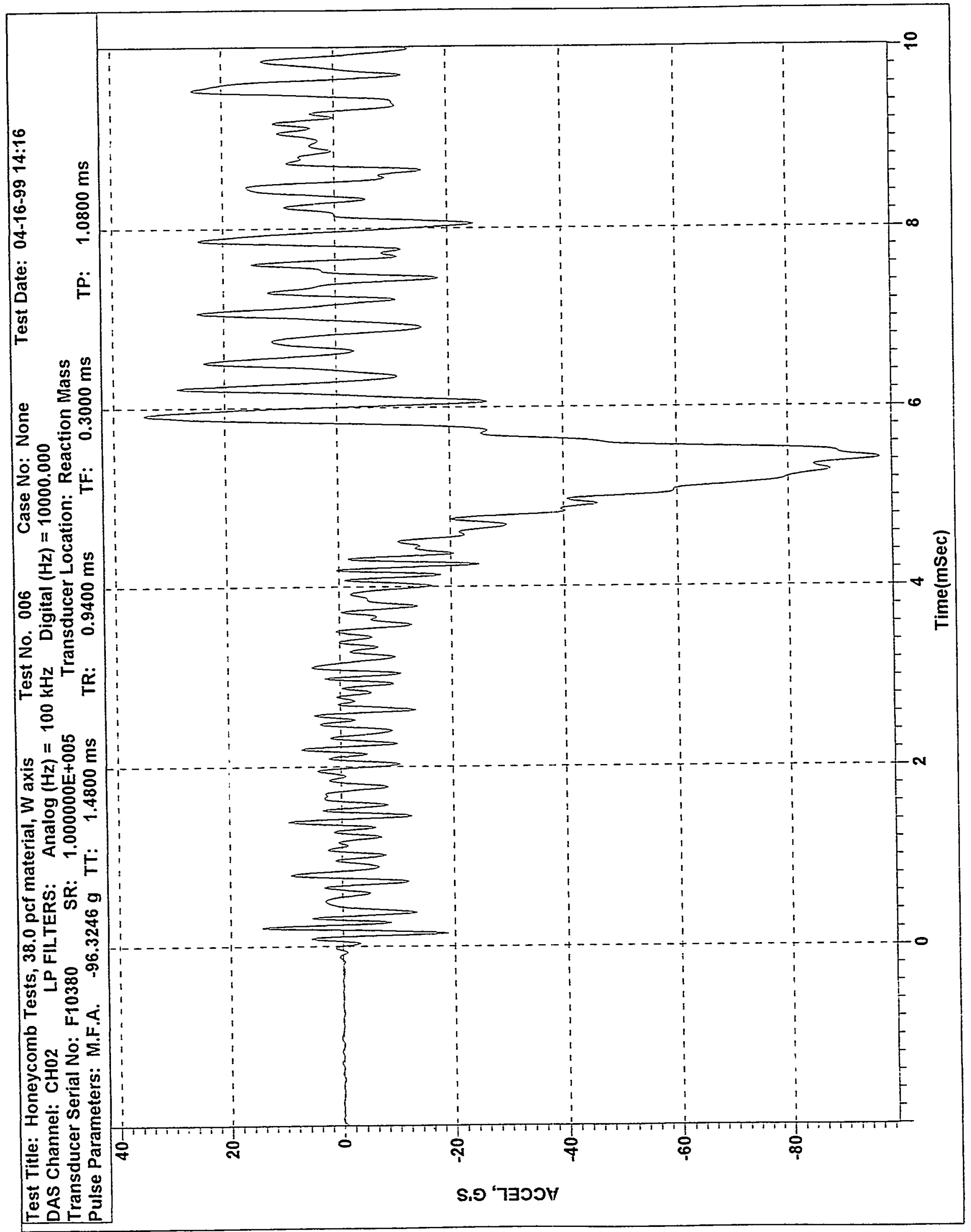




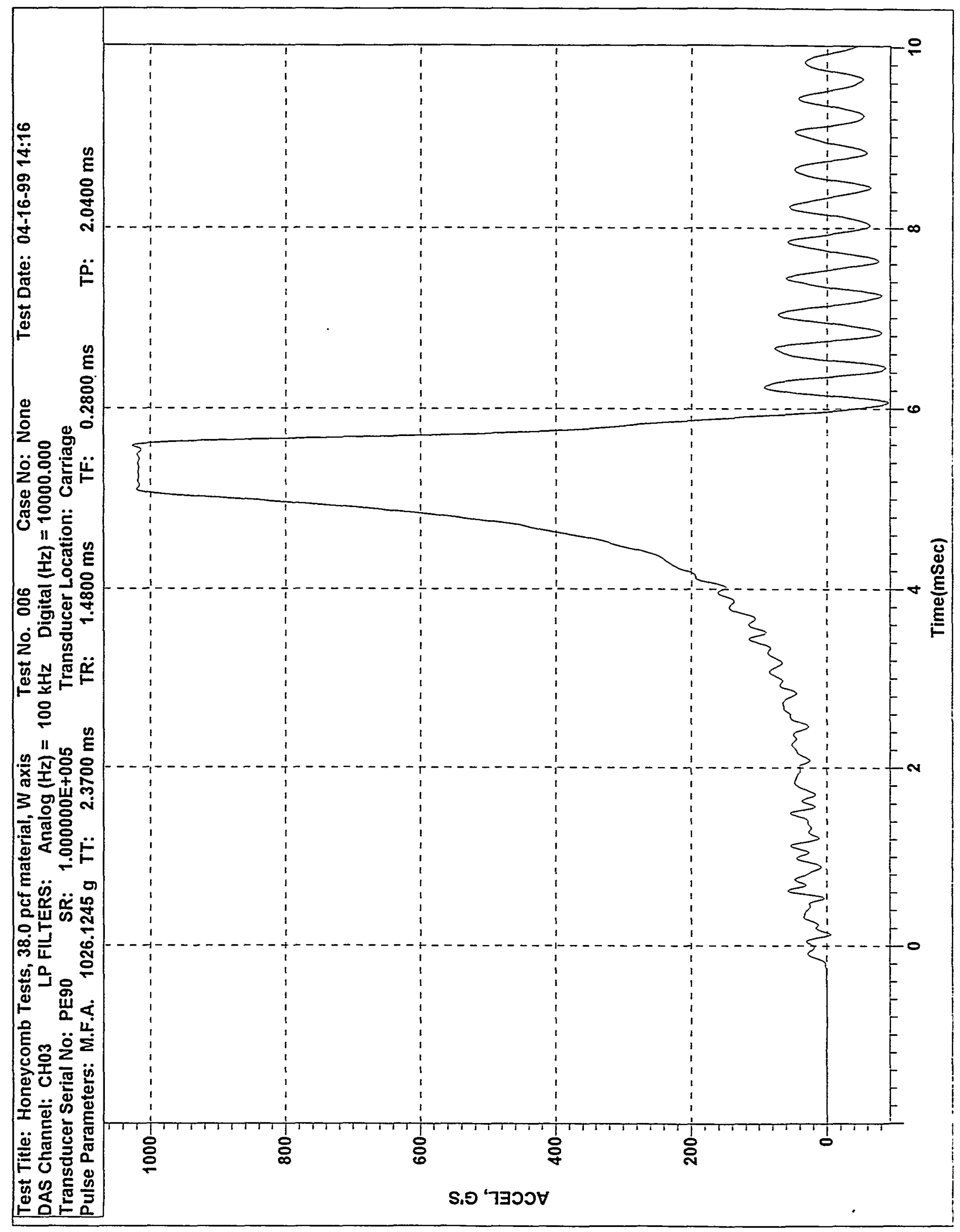




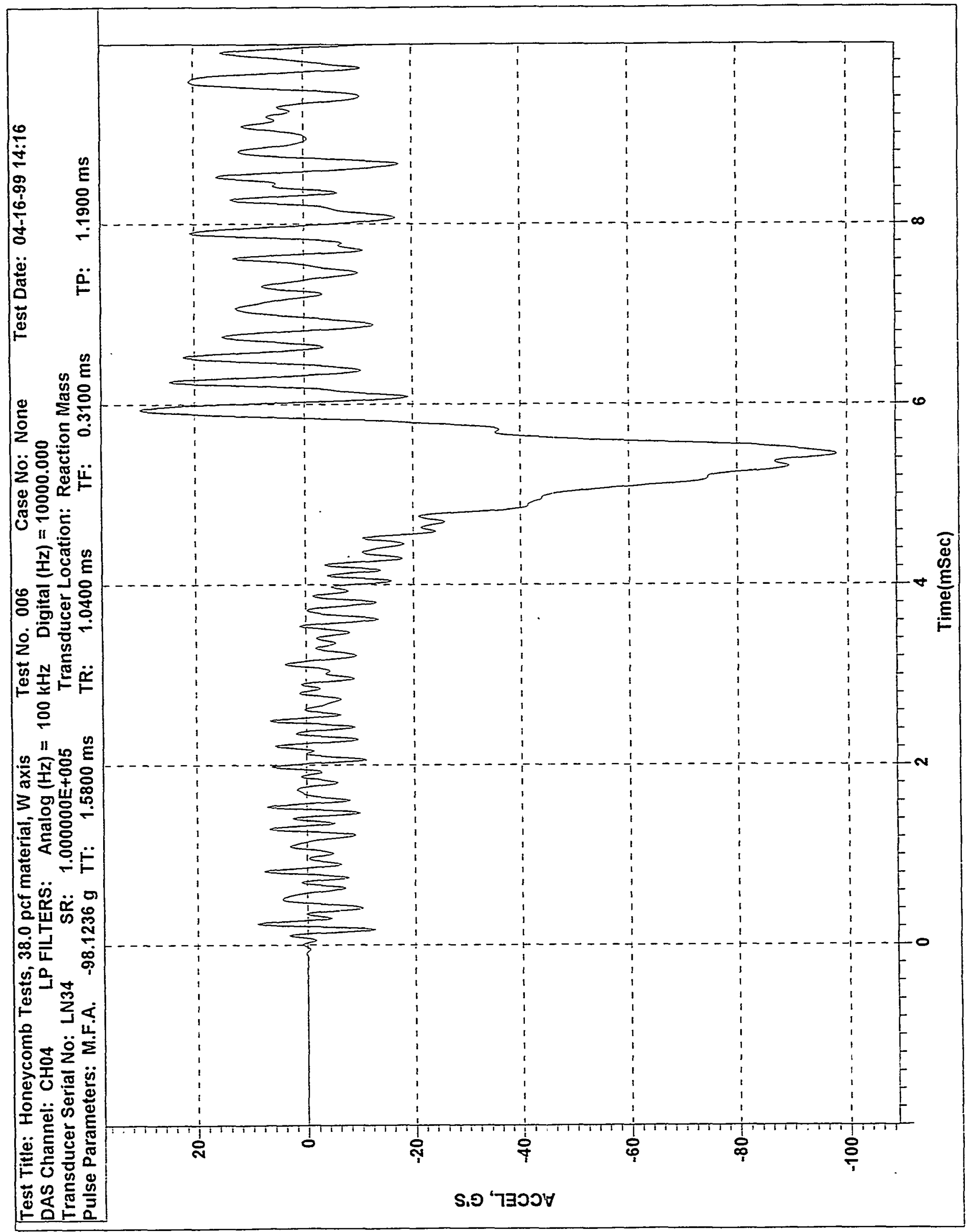




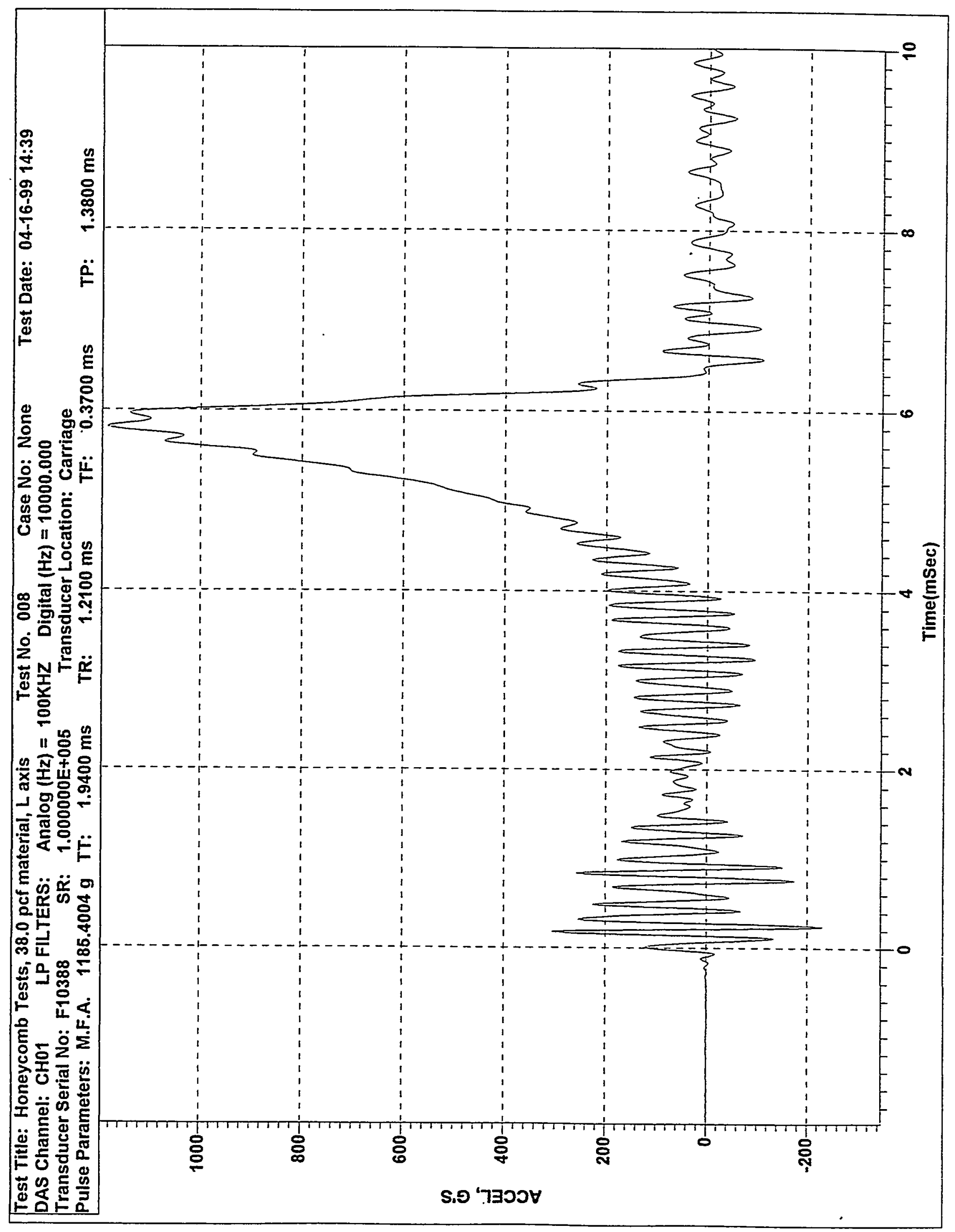




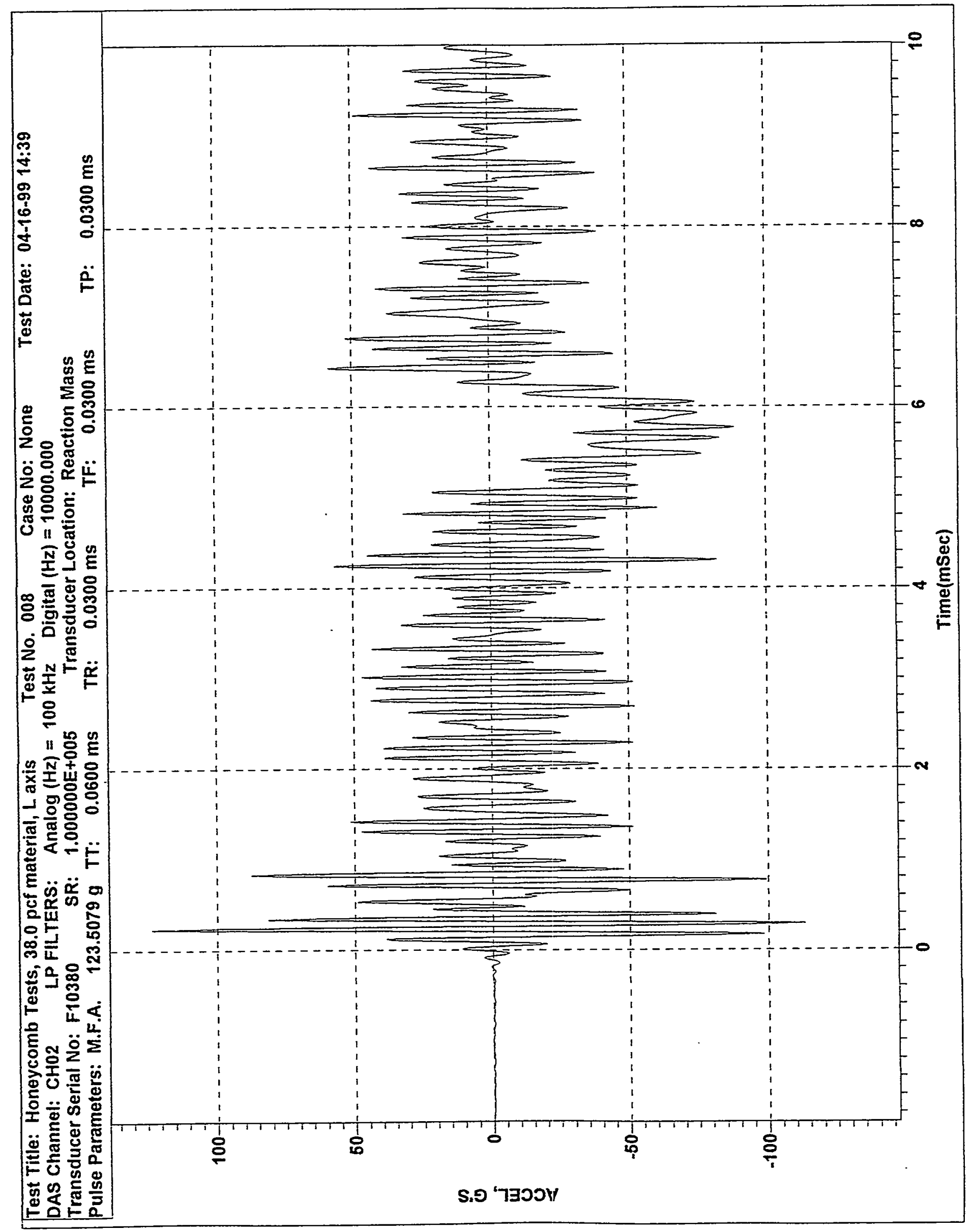




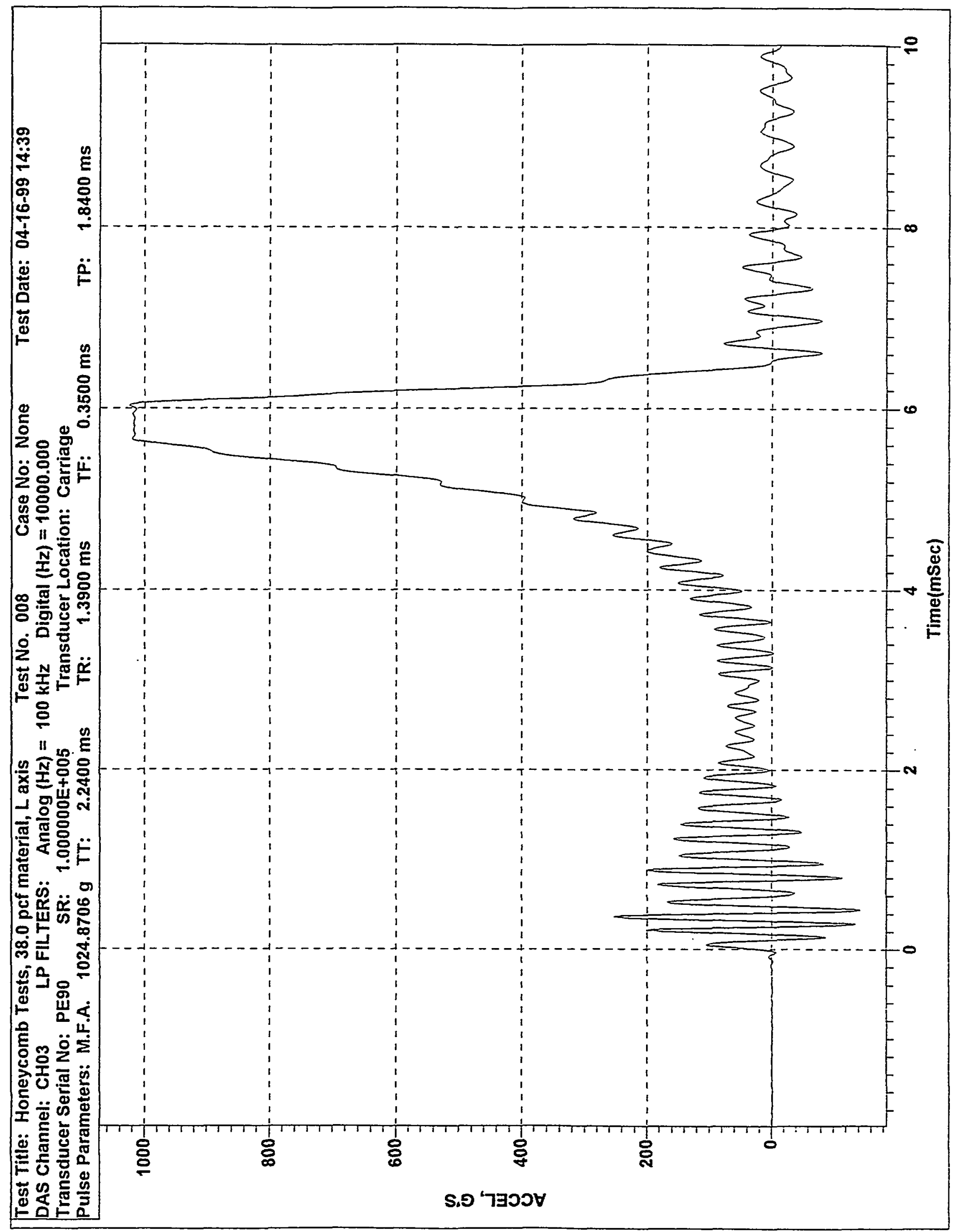




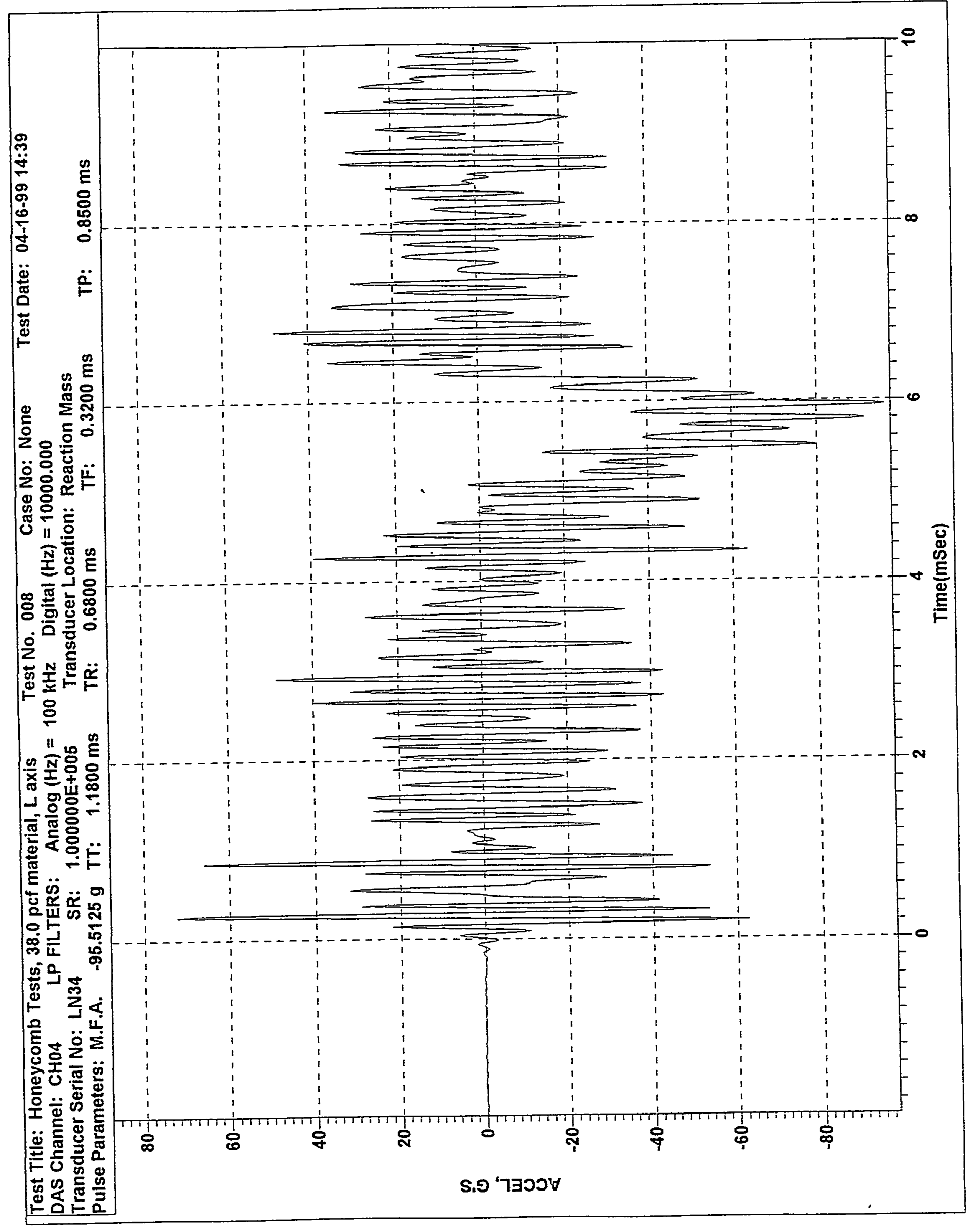




\section{Distribution - External:}

1 Randall D. Cope

NAWCWPNS

Code 478600D

China Lake, CA 93555

1 George N. Hennings

NAWCWPNS

Code 473330D

China Lake, CA 93555
1 Richard Mabry

101 West Eglin Blvd., Suite 219

WL/MNMF

Eglin AFB, FL 32542

1 Keith Thomas

AFRL/MNMI

101 West Eglin Blvd., Suite 246

Eglin AFB, FL 32542

1 Dr. Patrick L. Walter, Chairman

Texas Christian Univeristy

Department of Engineering

Box 298640

Fort Worth, TX 76129

\section{Distribution - Internal:}

\begin{tabular}{|c|c|}
\hline & \\
\hline & \\
\hline & \\
\hline & $\begin{array}{l}\text { MS0437 } \\
\text { MS0847 } \\
\text { MS0847 }\end{array}$ \\
\hline & MS0443 \\
\hline & \\
\hline & MS0443 \\
\hline & MS0443 \\
\hline & MS0447 \\
\hline & MS0453 \\
\hline & MS0453 \\
\hline & MS0481 \\
\hline & MS0481 \\
\hline & MS0481 \\
\hline & $\mathrm{MSO}$ \\
\hline & \\
\hline & \\
\hline
\end{tabular}

W. R. Reynolds (2103)

W. Scherzinger (9117)

D. R. Martinez (9234)

T. D. Hinnerichs (9234)

H. S. Morgan (9117)

K. W. Gwinn (9117)

J. A. Mitchell (9117)

M. K. Nielsen (9117)

J. Pott (9117)

D. L. McCoy (2104)

N. R. Hansen (2104)

M. A. Rosenthal (2167)

D. J. Giersch (2167)

D. A. Hoke (2167)

H. Montoya (2167)

V. O. Willan (2167)

M. S. Garrett (9133)

$\begin{array}{lll}4 & \text { MS0555 } & \text { V. I. Bateman (9133) } \\ 1 & \text { MS0555 } & \text { L. H. Swanson (9133) } \\ 1 & \text { MS0557 } & \text { T. J. Baca (9119) } \\ 1 & \text { MS0557 } & \text { B. D. Boughton (9119) } \\ 1 & \text { MS0557 } & \text { T. G. Carne (9119) } \\ 1 & \text { MS0828 } & \text { T. C. Bickel (9101) } \\ 1 & \text { MS0828 } & \text { J. L. Moya (9105) } \\ 1 & \text { MS0828 } & \text { J. R. Garcia (9106) } \\ 1 & \text { MS0834 } & \text { A. C. Ratzel (9112) } \\ 1 & \text { MS1181 } & \text { J. R. Asay (1611) } \\ 1 & \text { MS9042 } & \text { W. A. Kawahara (8746) } \\ 1 & \text { MS9042 } & \text { W. Y. Lu (8746) } \\ 1 & \text { MS9018 } & \text { Central Technical Files } \\ & & \text { Dept. 8940-2 } \\ 2 & \text { MS0899 } & \text { Technical Library (4916) } \\ 1 & \text { MS0619 } & \text { Review \& Approval Desk } \\ & & \text { Dept. 00111 } \\ & & \text { For DOE/OSTI }\end{array}$

